\title{
SPRAY COOLING WITH HFC-134A AND HFO-1234YF FOR THERMAL MANAGEMENT OF AUTOMOTIVE POWER ELECTRONICS
}

\author{
A Thesis report \\ Submitted in the partial fulfillment of the degree of Master of Science \\ by \\ SATVIK JANARDHAN YADDANAPUDI
}

December 2015

Thesis Committee

Dr. Huseyin Bostanci, Major Professor

Dr. Seifollah Nasrazadani, Member

Dr. Cheng Yu, Member

Department Of Engineering Technology

College of Engineering

University Of North Texas 
Yaddanapudi, Satvik Janardhan. Spray cooling with HFC-134a and HFO-1234yf for thermal management of automotive power electronics. Master of Science (Engineering SystemsMechanical Systems), December 2015, 63 pp., 3 tables, 35 figures, 43 numbered references.

This study aims to experimentally investigate the spray cooling characteristics for active two-phase cooling of automotive power electronics. Tests are conducted on a small-scale, closed loop spray cooling system featuring a pressure atomized spray nozzle. Two types of refrigerants, HFC-134a (R-134a) and HFO-1234yf, are selected as the working fluids. The test section (heater), made out of oxygen-free copper, has a $1-\mathrm{cm}^{2}$ plain, smooth surface prepared following a consistent procedure, and would serve as a baseline case. Matching size thick film resistors, attached onto the copper heaters, generate heat and simulate high heat flux power electronics devices. The tests are conducted by controlling the heat flux in increasing steps, and recording the corresponding steady-state temperatures to obtain cooling curves. The working fluid is kept at room temperature level $\left(22^{\circ} \mathrm{C}\right)$. Performance comparisons are made based on heat transfer coefficient (HTC) and critical heat flux (CHF) values. Effects of spray characteristics and liquid flow rates on the cooling performance are investigated with the selected coolants. Three types of commercially available nozzles that generate full-cone sprays with fine droplets are utilized in the tests. Effect of liquid flow rate is evaluated varying flow rates at 2, 3, $4 \mathrm{ml} / \mathrm{s}$. The experimental results obtained from this study provide a framework for spray cooling performance with the current and next-generation refrigerants aimed for advanced thermal management of automotive power electronics. 
Copy right

by

SATVIK. J. YADDANAPUDI 


\section{ACKNOWLEDGMENTS}

First and foremost, I would like to acknowledge the guidance and support of my major professor Dr. Huseyin Bostanci. Without his valuable suggestions throughout, this thesis would not have been possible. He always provided the freedom to work on my own and that helped me to hone my skills to work independently. Throughout this journey of my master's he is very patient and always encouraging. I am really thankful to him for his endless support and advice during the course of this research. Without his patience, understanding and help, I would not have been able to successfully complete this work.

I would like to thank Dr. S. Nasrazadani, committee member for his suggestions and his recommendations that have brought improvement to my thesis work. From the beginning he is very helpful in choosing the right courses for my development of master's degree and motivating me to take up the thesis.

I would also like to thank Dr. Cheng Yu for his assistance as a committee member and for providing useful suggestions.

I would also like to thank my lab mates Nihal Joshua for his assistance throughout my research and also my fellow graduate students. 


\section{Table of Contents}

LIST OF TABLES




\section{NOMENCLATURE}

\begin{tabular}{|c|c|}
\hline A & Area of heater surface, $\mathrm{cm}^{2}$ \\
\hline h & heat transfer coefficient, $\mathrm{W} / \mathrm{m}^{2{ }^{\circ} \mathrm{C}}$ \\
\hline I & Current, A \\
\hline K & thermal conductivity, $\mathrm{W} / \mathrm{m}^{\circ} \mathrm{C}$ \\
\hline$q^{\prime \prime}$ & heat flux, W/cm² \\
\hline $\mathrm{T}_{\text {avg }}$ & average temperature, ${ }^{\circ} \mathrm{C}$ \\
\hline $\mathrm{T}_{\text {sat }}$ & saturation temperature, ${ }^{\circ} \mathrm{C}$ \\
\hline$T_{\text {surf }}$ & surface temperature, ${ }^{\circ} \mathrm{C}$ \\
\hline $\mathrm{TC}$ & thermocouple \\
\hline V & voltage, $\mathrm{V}$ \\
\hline $\mathrm{X}$ & TC to spray surface distance in heater wall, $\mathrm{m}$ \\
\hline$\Delta \mathrm{T}_{\text {sat }}$ & surface superheat, ${ }^{\circ} \mathrm{C}$ \\
\hline$\Delta \mathrm{T}_{\text {sub }}$ & degree of subcooling $\left(T_{\text {sat }}-T_{\text {in }}\right)$ \\
\hline Q & total volumetric flow rate of spray \\
\hline $\boldsymbol{\rho}_{\mathrm{f}}$ & liquid density \\
\hline$C_{p}$ & Specific heat at constant pressure \\
\hline$h_{f g}$ & heat transfer coefficient of the refrigerant \\
\hline$\eta$ & Efficiency \\
\hline
\end{tabular}




\section{LIST OF TABLES}

Table1: Comparison for common cooling methods ....................................................................... 12

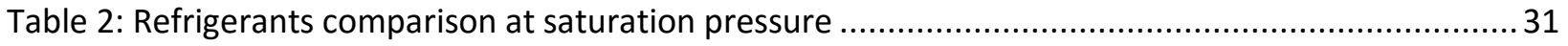

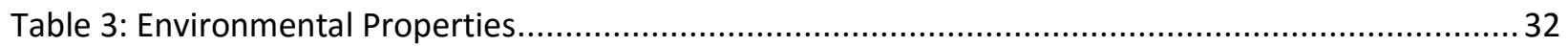




\section{LIST OF FIGURES}

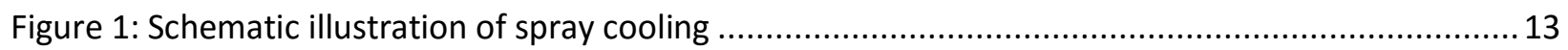

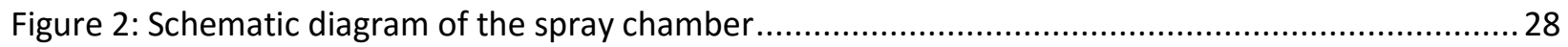

Figure 3: Schematic diagram of the experimental setup................................................................ 29

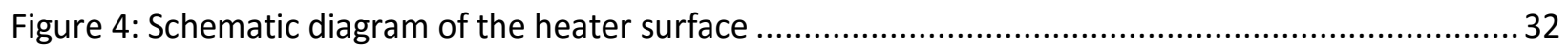

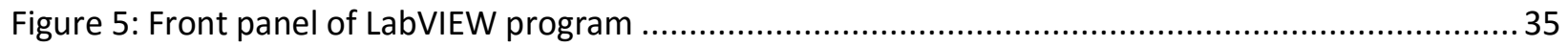

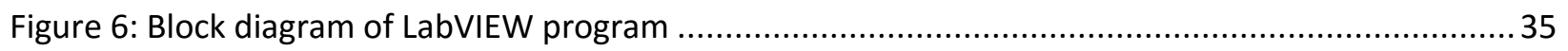

Figure 7: Heat transfer performance of HFC-134a with TG0.3 nozzle at flow rates of 2, $3 \mathrm{ml} / \mathrm{s} \ldots \ldots \ldots \ldots . . . .38$

Figure 8: Repeatability of HFC-134a with TG0.3 nozzle at flow rate of $2 \mathrm{ml} / \mathrm{s}$..................................... 39

Figure 9: Heat transfer performance of HFC-134a with TG0.5 nozzle at flow rates $2,3,4 \mathrm{ml} / \mathrm{s} \ldots \ldots \ldots \ldots . . . .40$

Figure 10: Repeatability of HFC-134a with TG0.5 nozzle at flow rate $2 \mathrm{ml} / \mathrm{s}$...................................... 41

Figure 11: Heat Transfer performance of HFC-134a with TG0.7 nozzle at flow rates 2, 3, $4 \mathrm{ml} / \mathrm{s} \ldots \ldots \ldots . . .42$

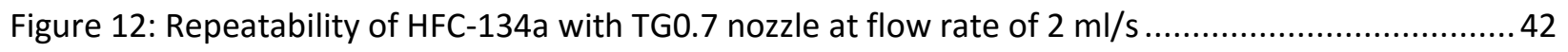

Figure 13: Heat Transfer performance of HFC-134a with nozzles TG0.3, 0.5, and 0.7 at flow rate of $2 \mathrm{ml}$

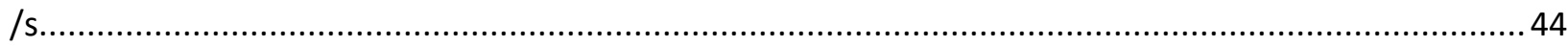

Figure 14: Heat transfer performance of HFC-134a with nozzles TG0.3, 0.5 and 0.7 at flow rate of $3 \mathrm{ml} / \mathrm{s}$

Figure 15: Heat transfer performance of HFC

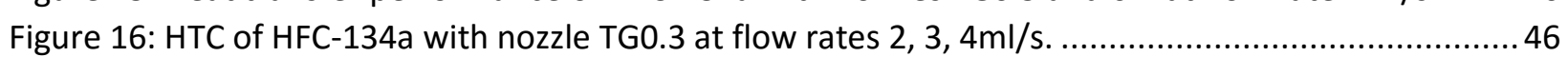

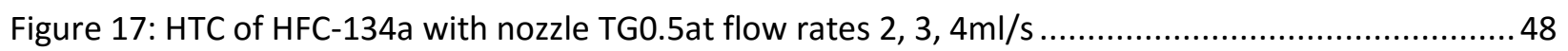

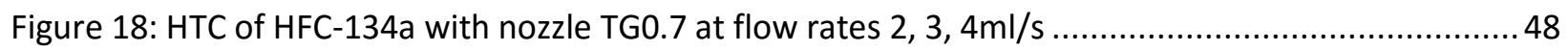

Figure 19: CHF values as a function of liquid flow rate of HFC-134a for nozzles TG0.3, 0.5 and $0.7 \ldots \ldots . . .49$

Figure 20: Heat transfer performance of HFO-1234yf with TG0.3 nozzle at flow rates of 2, $3 \mathrm{ml} / \mathrm{s} \ldots \ldots \ldots . . .50$

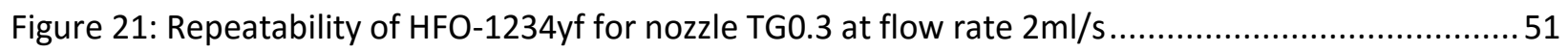

Figure 22: Heat Transfer performance of HFO-1234yf with TG0.5 nozzle at flow rates 2, 3, $4 \mathrm{ml} / \mathrm{s}$..........52

Figure 23: Repeatability of HFO-1234yf for TG0.5 nozzle at flow rate of $2 \mathrm{ml} / \mathrm{s}$.................................52

Figure 24: Repeatability of HFO-1234yf for nozzle TG0.5 at flow rate of $3 \mathrm{ml} / \mathrm{s}$................................. 53

Figure 25: Heat Transfer performance of HFO-1234yf with TG00.7 nozzle at flow rates of 2, 3, and $4 \mathrm{ml} / \mathrm{s}$

Figure 26: Heat transfer performance of HFO-1234yf for nozzle TG0.3, 0.5 , and 0.7 at flow rate of $2 \mathrm{ml} / \mathrm{s}$.

Figure 27: Heat transfer performance of HFO-1234yf for nozzle TG0.3, 0.5 , and 0.7 at flow rate of 3ml/s.

Figure 28: Heat transfer performance of HFO-1234yf for nozzle TG0.5 and 0.7 for flow rate of $4 \mathrm{ml} / \mathrm{s}$....57

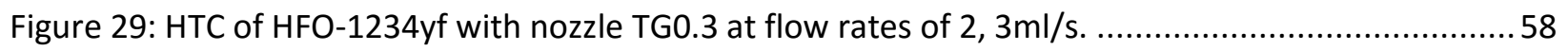

Figure 30: HTC of HFO-1234yf with nozzle TG0.5 at flow rates of 2, 3, and $4 \mathrm{ml} / \mathrm{s}$. .............................59

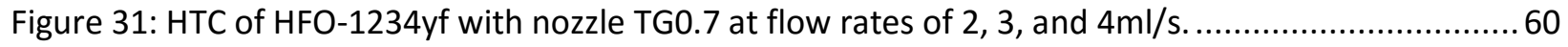

Figure 32: CHF values as a function of liquid flow rate of HFO-1234yf for nozzle type TG0.3, 0.5 and 0.7.

Figure 33: HTC of HFC-134a and HFO-1234yf with nozzles TG0.3, 0.5 , and 0.7 at flow rates of $3 \mathrm{ml} / \mathrm{s} . . .61$ Figure 34: CHF value as a function of liquid flow rate for nozzle types of TG0.3, 0.5, and 0.7 for HFC-134a and HFO-1234yf. 
Figure 35: Efficiency of spray heat transfer for HFC-134a and HFO-1234yf....................................... 63 


\section{CHAPTER I \\ INTRODUCTION}

Power electronics such as Insulated gate bipolar transistors (IGBT's) and Diodes dissipate large amount of heat due to increase of their clock speeds and reduction of size to obtain more power and compactness. These devices continue to evolve with less volume and more power as the technology advances. Gordon Moore, who was co-founder of the Intel stated that, "number of transistors on a chip will double approximately every 2 years". This was given as Moore's law and we can observe this statement in every power electronics technology. Because of their clock speeds and power dissipation, it is crucial to maintain these electronics at desired temperature range to eliminate stresses and to increase reliability of the device. Miniaturization of the electronic devices has created a space for thermal management to play a vital role in designing of the electronic equipment. In some areas, thermal management directly improve overall size, weight and cost of the system.

The present day technology has been revolutionized in such a way that gas powered vehicles are transitioning to electric drive vehicles. Power electronics in the hybrid vehicles function as an interface between the energy sources such as batteries and the traction drive motor, and therefore considered as the vital component of the vehicle. In order to ensure the efficient and reliable operation of the power electronics, thermal management plays a key role. The thermal management of the power electronics in the hybrid vehicles aims the removal of the high heat fluxes $\left(>200 \mathrm{~W} / \mathrm{cm}^{2}\right.$ ) from the electronics (IGBTs, diodes) and maintaining them in their allowable limits $\left(<150^{\circ} \mathrm{C}\right)$. In the meantime, the ideal thermal management solution should be 
low-cost, compact, lightweight and energy efficient. In a broader sense, improving the thermal management of power electronics would also help the penetration of hybrid and electric vehicles into the market. Thermal management technologies are mainly classified into Passive and Active thermal management methodology.

- Passive Thermal Management - Passive cooling thermal solutions takes the leverage of using thermodynamic properties such as conduction, convection and radiation to transfer the heat to ambient air. These technology don't consume any energy and hence are cheapest and easiest thermal solutions. Some examples of passive thermal management are Heat sinks, Thermal interface materials (TIM's), Heat spreaders, Heat pipes.

- Active Thermal Management - In this active thermal solution external energy will be introduced to attain the heat transfer process. In fact they are most complex and expensive systems with better performance. Some of the active thermal management techniques are forced air (use of external fans), thermoelectric coolers, and spray cooling. 
Table1: Comparison for common cooling methods

\begin{tabular}{|c|c|c|c|c|}
\hline Natural Convection & Forced Convection & $\begin{array}{l}\text { Liquid Cooling } \\
\text { (water) }\end{array}$ & $\begin{array}{l}\text { Immersion } \\
\text { Cooling }\end{array}$ & Spray Cooling \\
\hline $\mathrm{h}=5-30 \mathrm{~W} / \mathrm{m}^{2} \mathrm{~K}$ & $h=20-400 \mathrm{~W} / \mathrm{m}^{2} \mathrm{~K}$ & $\begin{array}{r}h=100-1600 \\
W / m^{2} K\end{array}$ & $\begin{array}{l}h=800-10000 \\
W / m^{2} K\end{array}$ & $\begin{array}{l}\mathrm{h}=200000- \\
400000 \\
\mathrm{~W} / \mathrm{m}^{2} \mathrm{~K}\end{array}$ \\
\hline $\begin{array}{l}\text { CHF up to } 15 \\
W / \mathrm{cm}^{2}\end{array}$ & $\begin{array}{l}\text { CHF up to } 35 \\
W / \mathrm{cm}^{2}\end{array}$ & $\begin{array}{l}\text { CHF up to } 90 \\
W / \mathrm{cm}^{2}\end{array}$ & $\begin{array}{l}\text { CHF up to } 150 \\
\qquad \mathrm{~W} / \mathrm{cm}^{2}\end{array}$ & $\begin{array}{r}\text { CHF up to } 1200 \\
\mathrm{~W} / \mathrm{cm}^{2}\end{array}$ \\
\hline Free Convection & Forced Convection & Forced Convection & Free Convection & Forced Convection \\
\hline
\end{tabular}

In general, there are several cooling techniques in order to remove heat from the required element and maintain them under sustained conditions. The very first method of cooling technique is by air cooling and is used for conventional purposes. These air cooling methods are confined to some limited applications. However, for demanding applications, advanced liquid cooling methods, involving phase change mechanisms, are evolved based on extensive research.

The very first method of the liquid cooling technique was immersion cooling, in this process the heating element is placed in the pool of the working fluid or dielectric in order to remove the heat from the heating element by changing the phase of the liquid from liquid to vapor. But the immersion cooling technique cannot be served in the areas where larger amount of the heat fluxes to be removed.

In order to remove the high heat fluxes, an advanced cooling technique, known as spray cooling has been developed. In this technique liquid is forced through a small orifice of the nozzle at which the liquid stream is atomized into fine droplets and is sprayed on to the heating element 
in order to remove the high heat fluxes and to maintain the device temperature at the required temperature. These atomized droplets involve in phase change immediately after contacting the heated surface. With the time being, bubbles nucleate on the heated surface inside the thin liquid film. The droplets that are continually sprayed interact with the growing bubbles with in the film, results in high heat removal through conduction, convection and phase change. The spray cooling process is schematically shown below in the Figure1.

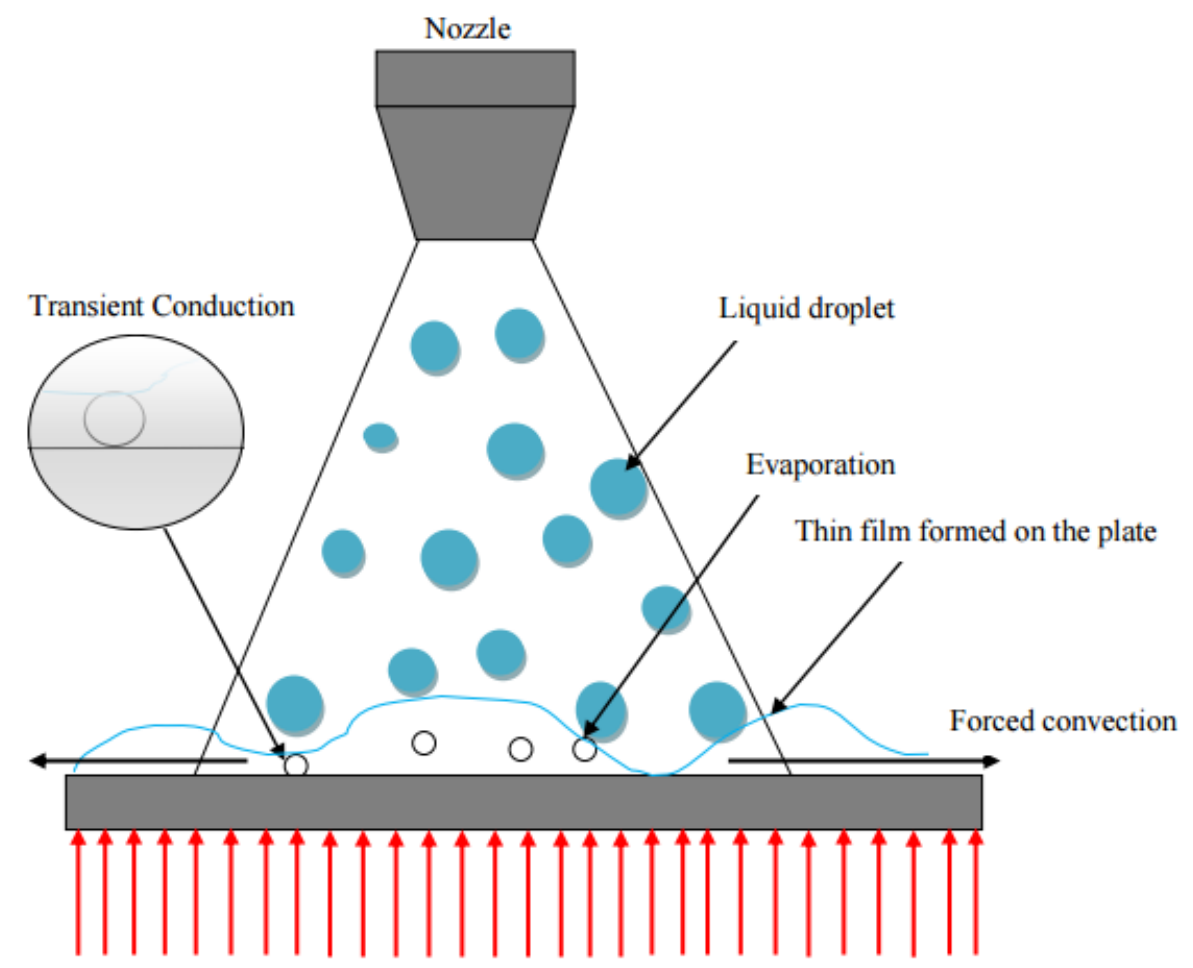

Figure 1: Schematic illustration of spray cooling

By this spray cooling technique a large surface area-to-volume ratio can be achieved. Some of the advantages of the spray cooling technique are [1]

1) Removes large amount of thermal energy due to latent heat of vaporization 
2) It helps in creating uniform temperature and reduce magnetic field fluctuations

3) It can reduce electrical noise

4) Ability to scale-up for large surfaces

5) Low droplet impact velocity and no temperature overshoot

The main task lies in the selection of appropriate coolant for the spray cooling method for the particular application. Many spray cooling tests were conducted with different dielectric liquids, such as Ammonia, HFE-7100, HFE-7200 and HFC-134a has been used. For the cooling of the automotive power electronics many studies has selected the coolant HFC-134a which belongs to the family of the hydrofluorocarbons. . HFC-134a is the present generation refrigerant presently using in all the automotive air conditioning systems. This liquid is used because of its zero ozone depletion and less global warming effects. HFC-134a are introduced in the place of Hydrofluorocarbons (HCFC's) such as R123, R124 and R141b. As the technology advances the U.S and European governments are requiring the use of a refrigerant with a global warming potential (GWP) of less than 150. In the replacement for the present generation refrigerant because of its carbon emissions, a new refrigerant has been developed and is known as HFO-1234yf which is also called as Tetrafluoropropene. When compared the GWP of HFO-1234yf is much less than HFC-134a and is 4.

This study aims to experimentally investigate the spray cooling characteristics of HFC-134a and HFO-1234yf refrigerants. The results are expected to provide an initial performance comparison with the current (HFC-134a) and next-generation (HFO-1234yf) mobile air conditioning refrigerants that would be implemented for active two-phase cooling of 
automotive power electronics found in hybrid and electric drive vehicles. Experimental parameters involve three types of commercial pressure-atomizing nozzles and varying flow rates for each refrigerant to determine their heat transfer performance in terms of heat transfer coefficient (HTC) and critical heat flux (CHF). 


\section{CHAPTER II \\ Literature Review}

The need for high heat flux cooling techniques is driven very much by the microelectronics and semiconductor industry. With the continuing technology, the semiconductor industry allow the device feature size to shrink and the transistor density and switching speed to double every one and half to two years. Correspondingly, the heat dissipation from the chip increase in proportion if there is no change in the semiconductor technology. The operating efficiency and the stability of these power electronics depends on how effectively the heat generated can be removed from the system. During the decades there are several types of the cooling techniques have been developed and the heat removal rate for those techniques are discussed in the table above.

The choice of an appropriate cooling technique is however depend on the specific application and the critical system factors which must be satisfied, such as maximum permissible heat flux, total heat load, tight temperature tolerances, reliability considerations or overall power consumption. Studies show that not only the cooling requirements of the chip have to be met but also their junction temperature needs to be maintained at certain range. Excessive temperatures could melt joints, cause oxidation, induce stress and also cause failure frequency. Thus perfect cooling technique is to be preferred in order to sustain the chip with more reliability. As shown in the above table, for heat fluxes up to $15 \mathrm{~W} / \mathrm{cm}^{2}$ forced cooling is adequate. But the amount of the heat fluxes that are to be removed from the hybrid vehicle electronics is $>200$ 
$\mathrm{W} / \mathrm{cm}^{2}$. Therefore, in order to remove these large amount of heat flux spray cooling technique is much more adequate.

The main technical challenge for the thermal management of the hybrid vehicle electronics is to develop an efficient method for removing several kilowatts of heat in a confined space under harsh ambient conditions and to maintain the chip temperature below $<150^{\circ} \mathrm{C}$. There are many previous studies had conducted on the spray cooling technology. A study conducted by Toda (1972) [2], had stated that subcooling of the liquid does not affect much on the single phase and nucleate boiling heat transfer and shows some dominant effect on the CHF. A comparison between the spray cooling and pool boiling by Monde (1980) [3] explained that, in the terms of nucleate boiling gradient spray cooling values are nearly half when compared to the pool boiling. He also concluded that by increasing the spray volume flux, cooling performance can be increased. A study by Mudawar et al. [4] in the year 1989, found that spray volume flux had the most effect on the critical heat flux when compared to other hydrodynamic properties of spray.

In the year 2004, many researchers have misrepresented the term spray cooling by "spray evaporative cooling". It was pointed out by Pautsch [5], and he explained that many system design that uses spray cooling does not undergoes evaporative state of liquid for heat removal. He then also proposed a name called "spray cooling with phase change" for the system that utilizes spray cooling that has phase change. He also suggested that the values of CHF are much higher for the system that has phase change than designs with lower CHF values. 
The main parameters for the spray are spray nozzle, volume flux, subcooling and properties of the liquid. These are studied by Mudawar et al [6]. in the year 1996 to understand the concept of nucleate boiling and critical heat flux for the full cone nozzle sprays. They suggested that $\mathrm{CHF}$ is mainly increased by the increase of the flow rate and also because of the subcooling of the liquid. They also suggested that surface tension mainly plays a vital role in to achieve greater CHF (small droplets with greater surface tension achieves greater CHF). They also explained that, for a full cone spray nozzle the droplet diameter which in term is defined as Sauter mean diameter $\left(d_{32}\right)$ is very important parameter to understand the spray characteristics. The Sauter mean diameter is defined as droplet diameter that has the same area of the volume surface as the entire spray. They also suggested that the Sauter diameter is dependent on the nozzle parameters such as orifice diameter, orifice flow conditions with calculated weber and Reynolds number before the breakup of the liquid into droplets.

The very first experiment with the subcooled liquid for the spray cooling was investigated by Chen et al. [7] in the year 2002 to study the effect of the spray characteristics. Form their research they suggested three spray parameters which are independent and are mean droplet velocity $(V)$, Sauter mean droplet diameter $\left(d_{32}\right)$ and mean spray droplet flux $(N)$. They suggested that critical heat flux varies with proportional to $\mathrm{V}^{1 / 4}$ and $\mathrm{N}^{1 / 6}$ and it is dependent on $\mathrm{d}_{32}$. The heat transfer coefficient and the critical heat flux increases with increase in V. CHF and Heat transfer coefficient also increases with increase in $\mathrm{N}$, while the other spray parameters were kept within the close ranges. Their results showed that dilute spray with large droplet velocity is more effective than a dense spray with low velocity to increase the CHF for a given $\mathrm{N}$ value. 
For the spray cooling, the very first liquid using to spray was water by Toda [8] in the year 1972. He found that there was an increase in the CHF approximately by $50 \%$ when he increased the mean droplet diameter from 88 to 120 microns. Pais et al [9]. in the year 1992 suggested that $\mathrm{CHF}$ can be achieved greatly by decreasing the droplet diameter. Another research by Sehmbey et al. [10] suggested that because of the smaller flow rates the CHF attained was very low and with the larger flow rate there are great values of CHF. Bostanci et al. [11] in the year 2010 has stated that increase of the flow rate beyond certain level will have lesser impact on the attaining the greater $\mathrm{CHF}$.

A research by Peterson [12] in the year 1970 has found that a heat flux of $15 \mathrm{MW} \backslash \mathrm{m}^{2}$ can be removed using spray cooling technique. Bonacina et al [13] (1979) studied that, by the spray cooling the surface temperature of $130^{\circ} \mathrm{C}$ can be maintained in order to remove $2.2 \mathrm{MW} / \mathrm{m}^{2}$ of the heat from the surface. Again in the year 1975, Bonacina et al. [14] also found that the highly wetted surface can help to achieve in the high heat transfer. This was also explained by Kim et al. [15] in the year 1997 that the large film thickness helps to produce lower heat transfer rates.

A research conducted by Yang et al. [16] in the year 2006 observed that, heat fluxes of $10 \mathrm{MW} / \mathrm{m}^{2}$ can be achieved through the gas assisted spray cooling with water having the phase change from a low wall surface heat. Mudawar et al [17] in the year 1996 experimented with FC72 as working fluid which is a dielectric liquid and found that it can remove heat flux nearly of 1 $\mathrm{MW} / \mathrm{m} 2$.

Pautsch et al [18] in the year 2006 found one of the parameter that effect the spray cooling performance was thickness of the liquid film layer that exits on the heater surface. In 
general, this thickness will be the size of 0 to 90 microns. They also explained the concept that once the droplet leaves the nozzle and hit the heated surface, they continuously swept of by the subsequent droplets in that continuous flow and as a result the surface was continually wetted hence helps in the formation of a thin film layer on the heated surface. The main mechanism explained in this theory was bubble nucleation, gas bubbles, conduction and convection. They also concluded that the explained mechanisms help in the heat removal process and also helps in the formation of the thin layer on the surface.

This thin film concept was mainly developed by a group of researchers Pais et al [19] in the year 1992. They found that this thin film layer on the heated surface helps in the conduction of heat and also explained that high heat transfers can be achieved by the thinner film and also due to the thermal gradient across this thin film.

In the spray cooling process, the liquid that leaves the nozzle is divided in to fine droplets and these droplets are forced to hit the heater surface and results in the formation of the thin film because of their wittedness. The next coming droplets which poses some momentum helps in the film to moves and evolve along the surface. These new droplets have much less temperature than the temperature of the film at the heater surface. These droplets helps in the continuous formation of the thin film on the heater surface and helps in the removal of heat transfer. This entire process was explained by Toda in the year 1972.

A professor named Kim [20] in the year 2007, made an extensive research in the area of spray cooling and found that heat transfer mechanism by the spray cooling are not properly understood because they are relied on the parameters such as unique droplet size distribution, 
droplet number density and droplet velocity. He also reported other unique parameters which effect the heat transfer process by spray cooling such as roughness of the surface, angle of impact, content of gas in the system, thickness of the film formed, type of the nozzle used and the orientation of the heated surface. In this report he also explained that because of the droplet impingement they spread on the heater surface to form a liquid film which helps in the removal of large amounts of heat or energy. He also stated that with the increase of the flow rate there will be increase in the heat transfer process because of the velocity of the liquid on the heated surface and the thickness of the thermal boundary layer. He specified that that the mechanisms which results in the occurrence of the critical heat flux during the spray cooling are currently unknown. He also suggested two mechanisms and they are homogenous nucleation within the film and other one was removal of the thing liquid film because of the nucleation with in the film. He also concluded that in order to know more about the spray cooling process many applications and new experimental techniques have to be developed in this area.

In the year 2006, Pautsch et al. [21] experimented the liquid film using the low flowrate for the single nozzle and also for high liquid flow rate using the multiple nozzles (four nozzles). The working fluid used by them was a refrigerant known as FC-72. The thickness of the film from these experiments were measured by the basics of the geometric optics. They arranged a small glass which in return projects a light rings on to the heated surface and then these rings were photographed. These rings are used for the measurement of the radius and from its radius the thickness of the film was calculated. The results showed that liquid film formed by the multiple nozzles was thick and shows the poorest heat transfer. It also observed that the thickness of the liquid film for the single nozzle has been changed because of the heat load. 
Previous, before the contribution to the measurement of the liquid film thickness by the single and multiple nozzle sprays. Pautsch et al. [22] in the year 2005 they also proposed that spray cooling with single nozzle helps two phase heat transfer process to increase $20-35 \%$ than using the multiple nozzle, where it only helps in attainment of $15-25 \%$. Their further studies indicate that the heat transfer process is much efficient in the two phase than compared to the single phase.

Many studies have been developed to explain the liquid film thickness by the spray cooling and there was no particular theoretical method was proposed until the year 2007. Kalantari [23] conducted extreme research on the liquid film thickness formed with interaction of the heated surface during the spray and introduced a theoretical model based on the predictions such as average film thickness, flux density, Reynolds number, average drop diameter and the impacting droplets.

Secondary nucleation, which is one of the main mechanism involved in the heat transfer process was initially explained by Tang et al [24] in the year 1996 and the research was further elaborated by Rini et al [25] in the year 2002.

The importance of the spray cooling over the jet impingement was professionally explained by Oliphant et al [26] in the year 1998. They mainly investigated in the areas of spray cooling and jet impingement cooling at the non-boiling regime. They showed that the heat transfer mainly depends on the droplet velocity and the spray mass flux. Their experiments showed that the surface temperature on impingement cooling is maintained below the saturation temperature of the spray liquid. In the non-boiling regime their experiments showed 
that because of the combination of the both evaporative cooling and unsteady thermal boundary layer resulted in the increase of the heat transfer for spray cooling when compared to the jet impingement cooling. They explained that spray cooling can use the minimal fluid than the jet impingement fluid and can provide same amount of heat transfer. They concluded that because of the large area covered by spray cooling because of the droplets atomized by the spray nozzle can helps in greater heat transfer in a much promising way.

In general, spray cooling was mainly used to remove high heat fluxes from the electronic devices, in the year 2006, Rybicki et al. [27] simulated a square heater for the high heat flux generating device to study the spray parameters. The working fluid used for this experiment was PF-5052. They tested the cooling performance by using three full cone nozzles with orientation facing upward and also for the different subcooling temperatures. From their experiments, it was demonstrated that to study the performance of the spray cooling the main hydrodynamic parameters are Sauter mean diameter and the volume flux. They also concluded that the orientation of the nozzle doesn't play much role in increasing the performance of heat transfer.

A research performed by Karwa et al. [28] in the year 2007 by spray cooling with the low wall superheats reported that the heat transfer takes place mainly using the single phase convection mechanism. When the saturation temperature of the fluid is equal to the heated surface temperature then there will be higher evaporation rates and there will be a formation of the thin film on the surface of the heating element. They also concluded that impingement of the droplets on the thick film provides enhanced mixing and also increases the film turbulence which results in the increase rate of heat transfer. Lin et al. [29] in the year 2003, conducted an experiment to observe the spray cooling performance in a closed loop system and concluded 
when the mass flux is higher, it results in the reduction of the evaporation rate because of the formation of the thicker liquid film.

For the any spray cooling to observe the performance of the system, the distance between the surface (heating element) and the nozzle play an important role. This was clearly explained by Zhao et al. [30] in the year 2010. The conditions used for this research was isothermal surface and used only a single nozzle with water as the working fluid. He ran some set experiments with spacing between the heater and the nozzle having the distance of 3 to $7 \mathrm{~mm}$ and they kept the heater surface limited to $100^{\circ} \mathrm{C}$. Their experiments showed that with an increase in the distance between the nozzle and the surface the temperature decreases first and then increases beyond certain position. They also explained that as increasing in the spray height there was increase in the average surface temperatures. They also suggested that system heat transfer performance is also a function of the distance between the nozzle and spray. The reason for the increase in the surface temperature when the nozzle is away from the surface because there will be non-uniform distribution of the spray on to the heated surface and formation of the thin film which helps in heat transfer and this was explained by Hseih et al. [31] in the year 2004.

Another study by Campbell et al. [32] and Ayers et al. [33] showed that thermal management of power electronics is vital to the operation of hybrid electronic vehicles. They also suggested that R134a has no damaging effect on the normal operation of the submerged IGBT. The results proved that flow boiling of R134a can give the adequate cooling capacity and keep junction temperature below $150^{\circ} \mathrm{C}$. 
The increasing interest in this field has brought up another research conducted by Mudawar et al. [34]. Their results with HFE-7100 spray cooling showed adequate performance level, and viability of this method in meeting thermal management requirements for hybrid vehicle electronics. Mudawar et al. [35] also considered R134a as an alternative coolant, and provided some predictive performance metrics.

In year 2012, Bostanci et al. [36] investigated spray cooling using high temperature antifreeze coolant, and indicated that thermal management of power inverter modules with spray cooling technology was an attractive option for hybrid and electric cars towards developing a cost competitive electric drive system. Augusto et al. [37] in 2013 conducted a research for evaluation of spray cooling of R134a on a plain and enhanced surfaces and concluded that critical heat flux for the plain surfaces are much more higher than the enhanced surfaces due to decrease in the film velocity and an increase in the film thickness. 


\section{CHAPTER III \\ Experimental Setup and Procedure}

This chapter explains the experimental setup and the steps of procedure used in the current research. This section discuss in more detail about the test setup, working fluid, heater fabrication and test conditions and procedures. This chapter concludes with the uncertainty analysis of the measurements.

\subsection{Experimental Setup}

The major components of the test equipment includes a spray chamber, a reservoir chamber for the storage of the refrigerant, test section, a condenser, temperature and pressure sensors, a DC power supply, and a computer controlled data acquisition system (DAQ). The reservoir chamber is designed to withstand a pressure of 300psi with material stainless steel 316 to provide greater strength and reliability. The wall thickness of the reservoir was $6.35 \mathrm{~mm}$ where it has the outer diameter as $82.55 \mathrm{~mm}$ and the having the internal diameter as $76.2 \mathrm{~mm}$ with height of $163 \mathrm{~mm}$. This shell was tightly enclosed by the top and bottom peek lids which are tightly held closely by 6 sets of stainless steel bolts of $6.35 \mathrm{~mm}$, nuts and washers. Two O-rings of the respective size are placed in between the lids and the shell in order to eliminate any leaks of the liquid or vapor through the reservoir during the storage and also while operating the system. The bottom lid of the reservoir section consist of the two installed cartridge heaters, which are used 
to heat the liquid pool to simulate the desired test conditions using a temperature controller if necessary. The bottom lid also accommodates an outlet tubing which is in turn connected to gear pump for the circulation of the liquid. The top lid consists of an installed thermocouples, to continually monitor the temperature of the pool and the installed cartridges in the reservoir. The top lid also accommodates a pressure transducer which is used to monitor the pressure of the reservoir during the test conditions and also when the system is at ideal stage. The refrigerant that was used to cool the heated surface is then collected back into the reservoir through the condenser from the top lid of the reservoir. The reservoir section is illustrated in the following Figure. The liquid refrigerant is circulated through the system using a small gear pump which has the potential of up to taking 12 volts. It helps in increasing in the pressure of the liquid based on the nozzle and flow rate to obtain fine atomization of the liquid. A filter with was arranged next to the pump contains a filter of 80 micron size to remove any particles or dust that enters the spray chamber and effect the performance of the system. Then there was a flowmeter which was helps in maintaining certain flow rate based on the density of type of the refrigerant. Then the liquid enters from flowmeter to spray chamber. The spray chamber is detailed as follows.

In general, the spray chamber consists of different sections such as Liquid Inlet, Exhaust Outlet, spacer, Strainer and Nozzle.

Liquid Inlet: The subcooled liquid which was circulated by the pump enters the liquid manifold. This liquid manifold consists of a strainer which is used to purify the refrigerant that enters the nozzle. The refrigeration pressure and temperature in this inlet manifold are monitored continuously. 
Exhaust Outlet: After leaving the inlet manifold, the liquid enters the exhaust manifold. This exhaust manifold contains a specific type of nozzle supplied by spray system co. these nozzle types are TG0.3, TG0.5, TG0.7 having the diameter of the orifices as $0.51 \mathrm{~mm}, 0.61 \mathrm{~mm}$ and $0.76 \mathrm{~mm}$. These nozzles provide the full cone spray on the heated surface. The refrigerant will be in the two-phase in the exhaust manifold and the pressure, temperatures in the exhaust manifold are also monitored continuously with the help of the fully developed LabVIEW software.

Spacer: The spacer is used to separate the heater from the exhaust manifold. The spacer consists of a four holes to which the heater will be attached using the $2 / 56$ screws. The nozzle and the heater were separated by a distance of $10 \mathrm{~mm}$. The detailed Figure of the spray chamber can be observed from the below diagram.

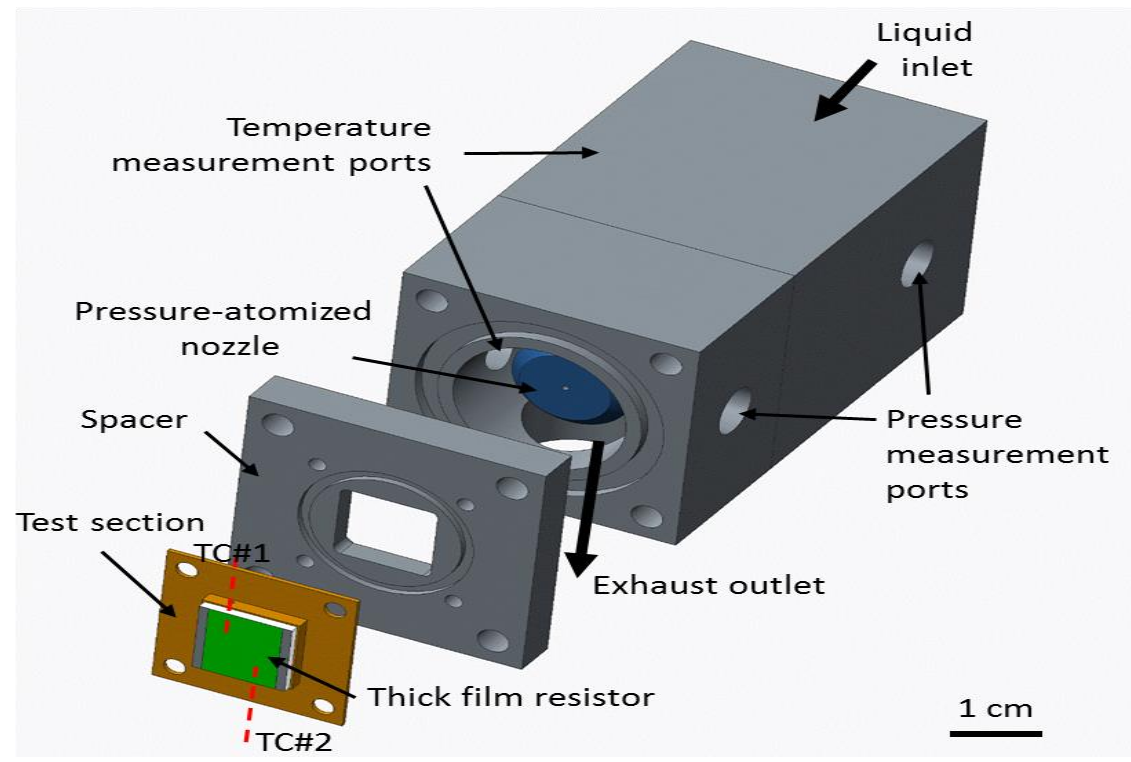

Figure 2: Schematic diagram of the spray chamber

The liquid or the vapor that exists from the exhaust outlet of the spray chamber enters the plate heat exchanger in which the heat was rejected to the ambient air with help of the chiller. The chiller temperature was maintained at a level that the liquid enters the reservoir should be at 
room temperature. The antifreeze used in the chiller was the mixture of ethylene glycol and water with the ratio of 1000: $400 \mathrm{ml}$. In the plate heat exchanger the vapor was condensed and the liquid was directed into the reservoir to again circulate in the system. The entire schematic sketch of the setup is showed as below.

Figure 3: Schematic diagram of the experimental setup

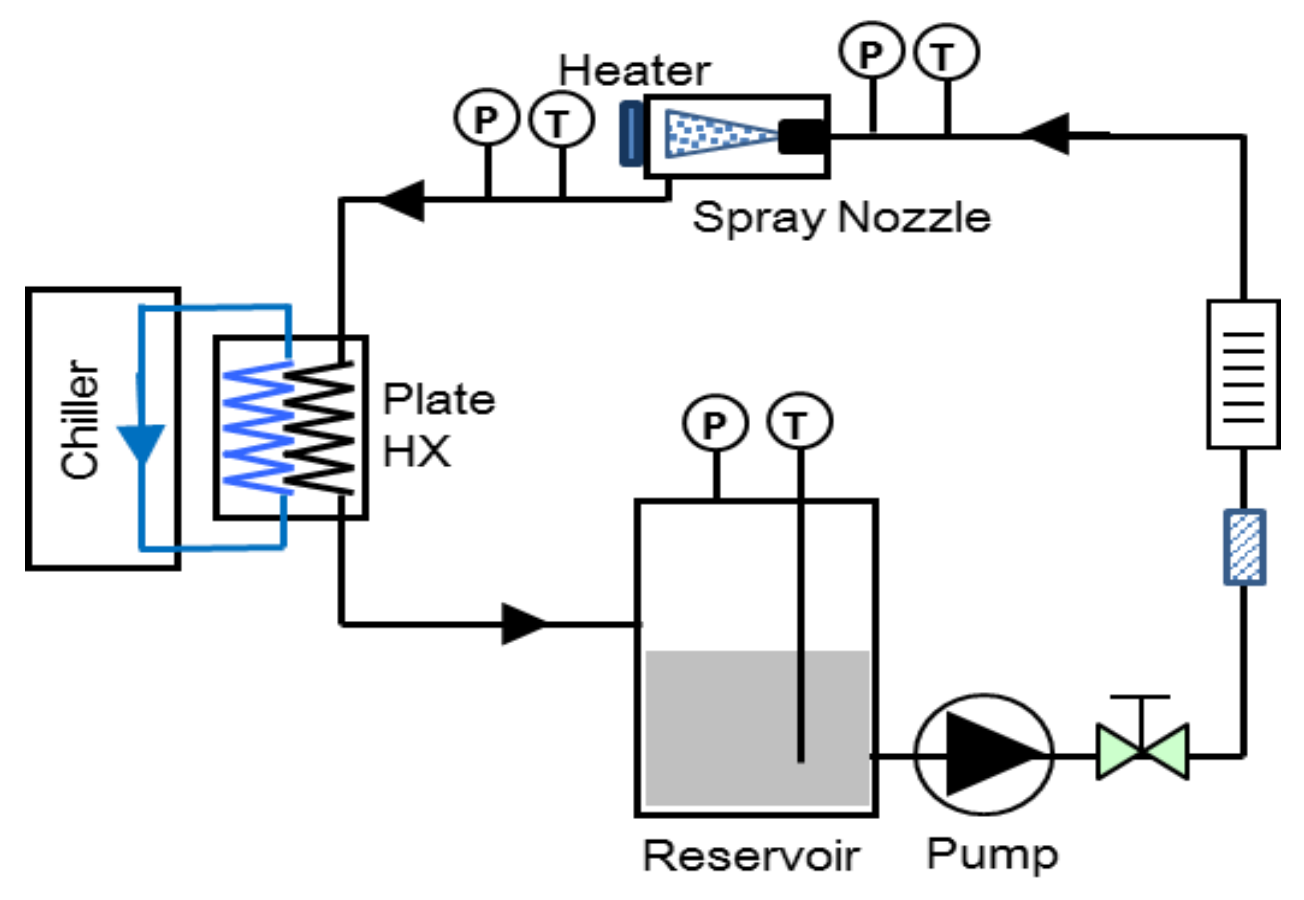




\subsection{Working Fluid}

Spray cooling is an attractive option because of its ability to remove large amounts of heat. Since, the fluid would be in the direct contact with the electronics it must be di-electric, stable, and non-toxic and have a low boiling point. Thermal requirements helps to represent only one aspect of the task in selecting an appropriate coolant. The other crucial requirements are inertness, material compatibility and environmental concerns. In general, there are two types of coolants such as liquid coolant and refrigerants. Liquid fluids (HFE-7100) can be describes as the fluids that maintain the liquid state even at the atmospheric pressure and the refrigerants (HFC134a) possess vapor state even at atmospheric pressure.

Numerous studies investigated different liquids, refrigerants and addressed its heat transfer performance, CHF limits, and enhanced methods with different heating surfaces for various applications [38-40]. HFC-134a is the present generation refrigerant presently using in all the automotive air conditioning systems. This refrigerant is used because of its zero ozone depletion and less global warming effects. HFC-134a is introduced in the place of Hydrofluorocarbons (HCFC's) such as R-123, R-124 and R-141b. As the technology advances the U.S and European governments are requiring the use of a refrigerant with a global warming potential (GWP) of less than 150. In the replacement for the present generation refrigerant because of its carbon emissions, a new refrigerant has been developed and is known as HFO$1234 \mathrm{yf}$ which is also called as Tetrafluoropropene. When compared the GWP of HFO-1234yf is much less than HFC-134a and is 4. 
Two types of refrigerants, HFC-134a and HFO-1234yf, are used as working fluids in this study. HFC-134a is the currently used refrigerant in the Mobile Air Conditioning (MAC) systems worldwide, and HFO-1234yf is the next generation refrigerant that is considered to be the most suitable alternative in addressing the new regulations for MAC systems. When compared to HFC134a, HFO-1234yf possesses different thermophysical properties as outlined in Table 2, and offers a much less environmental impact (Table 3), specifically marked by a $99.7 \%$ reduction in Global Warming Potential (GWP) which is 1430 (HFC-134a) to 4 (HFO-1234yf) [41-42\}.

Table 2: Refrigerants comparison at saturation pressure

\begin{tabular}{|c|c|c|}
\hline Property & HFC-134a & HFO-1234yf \\
\hline Boiling Point & $-26.1^{\circ} \mathrm{C}$ & $-29.45^{\circ} \mathrm{C}$ \\
\hline Freeze Point & -142 & $-150^{\circ} \mathrm{C}$ \\
\hline Molecular Weight $(\mathrm{g} / \mathrm{mol})$ & 102.03 & 114.04 \\
\hline Liquid Density $(\mathrm{Kg} / \mathrm{m} 3)$ & 1206.7 & 1092 \\
\hline $\begin{array}{c}\text { Vapor Density }(\mathrm{Kg} / \mathrm{m} 3) \\
\text { Liquid Viscosity } 25^{\circ} \mathrm{C} \\
(\mu \mathrm{Pa} \cdot \mathrm{sec})\end{array}$ & 5.28 & 155.4 \\
\hline $\begin{array}{c}\text { Liquid Specific heat } 25^{\circ} \mathrm{C} \\
\left(\mathrm{kJ} / \mathrm{kg} \cdot{ }^{\circ} \mathrm{K}\right)\end{array}$ & 202.0 & 1.392 \\
\hline $\begin{array}{c}\text { Latent Heat of Vaporization } \\
(\mathrm{KJ} / \mathrm{KG})\end{array}$ & 1 & 180.1 \\
\hline \begin{tabular}{c} 
Surface Tension $15^{\circ} \mathrm{C}(\mathrm{N} / \mathrm{m})$ \\
\hline
\end{tabular} & 0.00945 & 0.0074 \\
\hline
\end{tabular}


Table 3: Environmental Properties

\begin{tabular}{|c|c|c|}
\hline Property & HFC-134a & HFO-1234yf \\
\hline ODP & 0 & 0 \\
\hline GWP & 1300 & 4 \\
\hline
\end{tabular}

\subsection{Test Section}

In this test section, a copper piece of area $1-\mathrm{cm}^{2}$ which is oxygen free is used as a heater (which simulates the high heat flux generating power electronic device). The copper piece that was exposed to the spray was $10 \mathrm{~mm} \times 10 \mathrm{~mm}$. On the other side of the copper piece a matching size thick film resistor (which usually reads $10 \Omega$ ) is soldered. Two lead wires also will be soldered onto this resistor to generate heat when the voltage is applied across the heater (Figure 4).

\footnotetext{
Figure 4: Schematic diagram of the heater surface
} 
The heat flux is determined from the total power supplied into the thick film resistor per unit resistor base area as shown below.

$$
\mathrm{q}^{\prime \prime}=\frac{\mathrm{V} \cdot \mathbf{I}}{\mathrm{A}}
$$

The temperature of the heater will be monitored with the help of the two T-type thermocouple of gauge 36 are embedded halfway in the heater wall and spaced across the $1-\mathrm{cm}^{2}$ area as illustrated in the Figure above. The temperature spread from the two TCs did not exceed $\pm 0.3^{\circ} \mathrm{C}$ at $100 \mathrm{~W} / \mathrm{cm}^{2}$, and $\pm 0.5^{\circ} \mathrm{C}$ at $200 \mathrm{~W} / \mathrm{cm}^{2}$ indicating uniform cooling across the surface. Spray surface temperature was calculated by extrapolating average of two TC readings through the known distance to the surface (consistently taken as half of heater wall thickness $(1 \mathrm{~mm})$ ) and assuming steady 1-D conduction through the heater wall as

$$
T_{\text {surf }}=T C_{a v g}-\left(\frac{q^{\prime \prime} \cdot x}{K}\right)
$$

The heater tested for this research was plain smooth copper surface. The plain, smooth spray surfaces were prepared following a consistent procedure. First, 1200-grit sandpaper is used to remove scratches and oxide layer from the copper piece. Then aluminum oxide (Al2O3) solution with $5 \mu \mathrm{m}$ particle size is added on the polishing pad spinning at high speed. The copper piece is held at rotating pad with dripping water for $30 \mathrm{~s}$. This polishing process is repeated with $\mathrm{Al}_{2} \mathrm{O}_{3}$ solution having 1 and $0.05 \mu \mathrm{m}$ particle size while rotating the sample position $90^{\circ}$ at each step. Then the heater surface is rinsed thoroughly with water and dried. This heater surface is considered as reference spray surface for the performance evaluation. 


\subsection{Test conditions and procedures}

Initially, the heater was installed onto the spray chamber with 2-56 size screws. Using a vacuum pump, a vacuum level of as low as $720 \mu \mathrm{m}$ was attained to ensure the system was sealed well, and air was evacuated. Then the refrigerant was charged into the closed loop system at an appropriate level. For the change of the heater, the nozzle chamber was isolated with ball valves, and after the heater change a similar evacuation process was done for the isolated section and refrigerant was added if necessary.

All the tests were conducted at $\sim 22^{\circ} \mathrm{C}$ (room temperature) and 72 psig (for HFC-134a) or 75 psig (for HFO-1234yf) saturation conditions. Cooling curves, in the form of surface superheat $\left(T_{\text {sat }}=T_{\text {surf }}-T_{\text {sat }}\right) v$ s. heat flux $\left(q^{\prime \prime}\right)$, were generated for each test by increasing the heat flux gradually in steps of 2-10 W/cm ${ }^{2}$ up to CHF. The resulting heater temperatures were recorded every 1.0 s over 5 min durations at each heat flux level. The heater temperatures usually reached steady state in about $90 \mathrm{~s}$. If $\mathrm{CHF}$ is observed with a sudden temperature rise, the heat flux immediately lowered to the safe level $\left(100 \mathrm{~W} / \mathrm{cm}^{2}\right)$ and then gradually decreased back to 0 $\mathrm{W} / \mathrm{cm}^{2}$. A LabVIEW program in connection with the DAQ unit displays and records all the temperature, pressure and heat flux data. The following Figure 5,6 shows the front panel (user interface) and the block diagram of the fully developed LabVIEW program. 


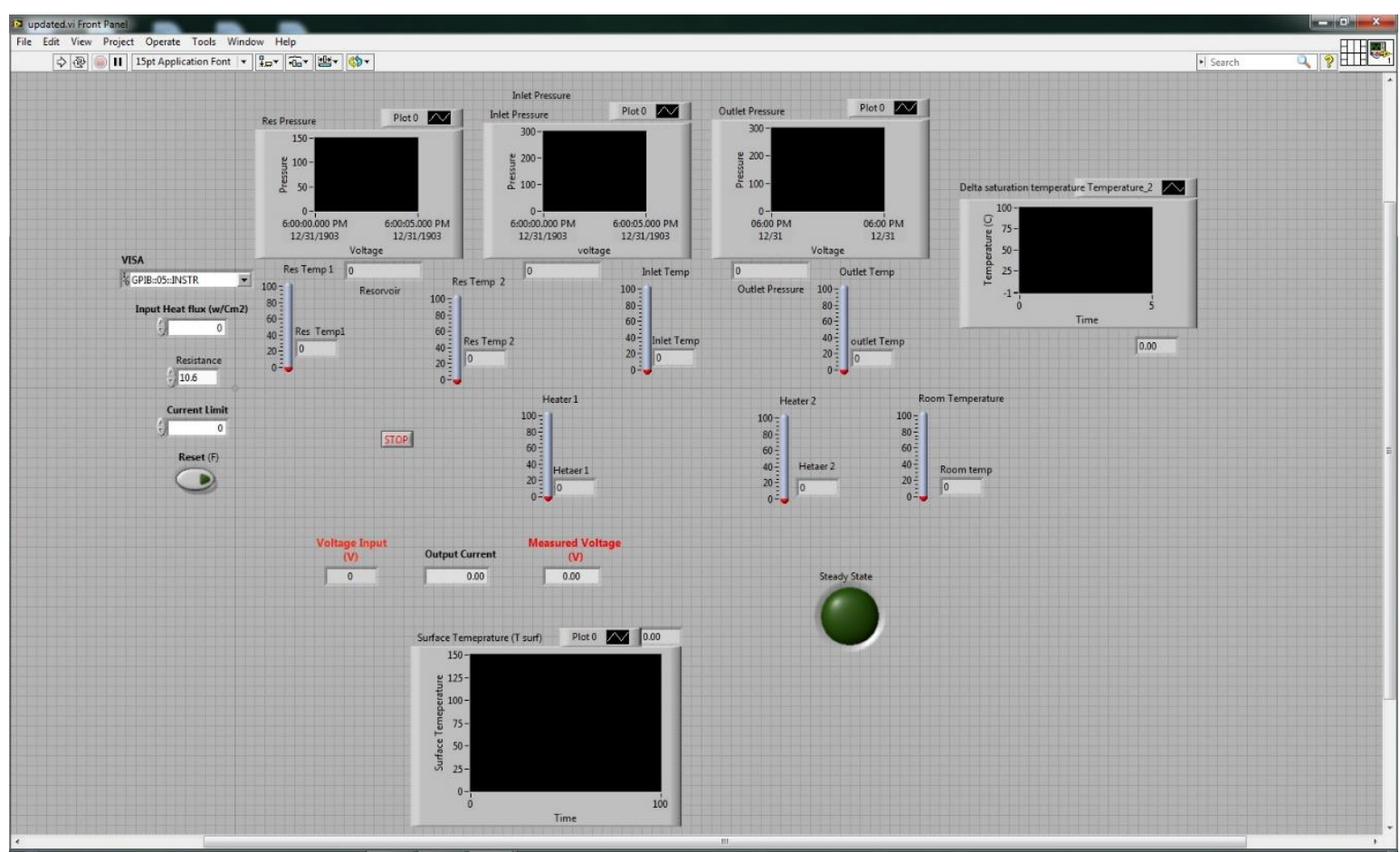

(2) $O C E$ e

Figure 5: Front panel of LabVIEW program

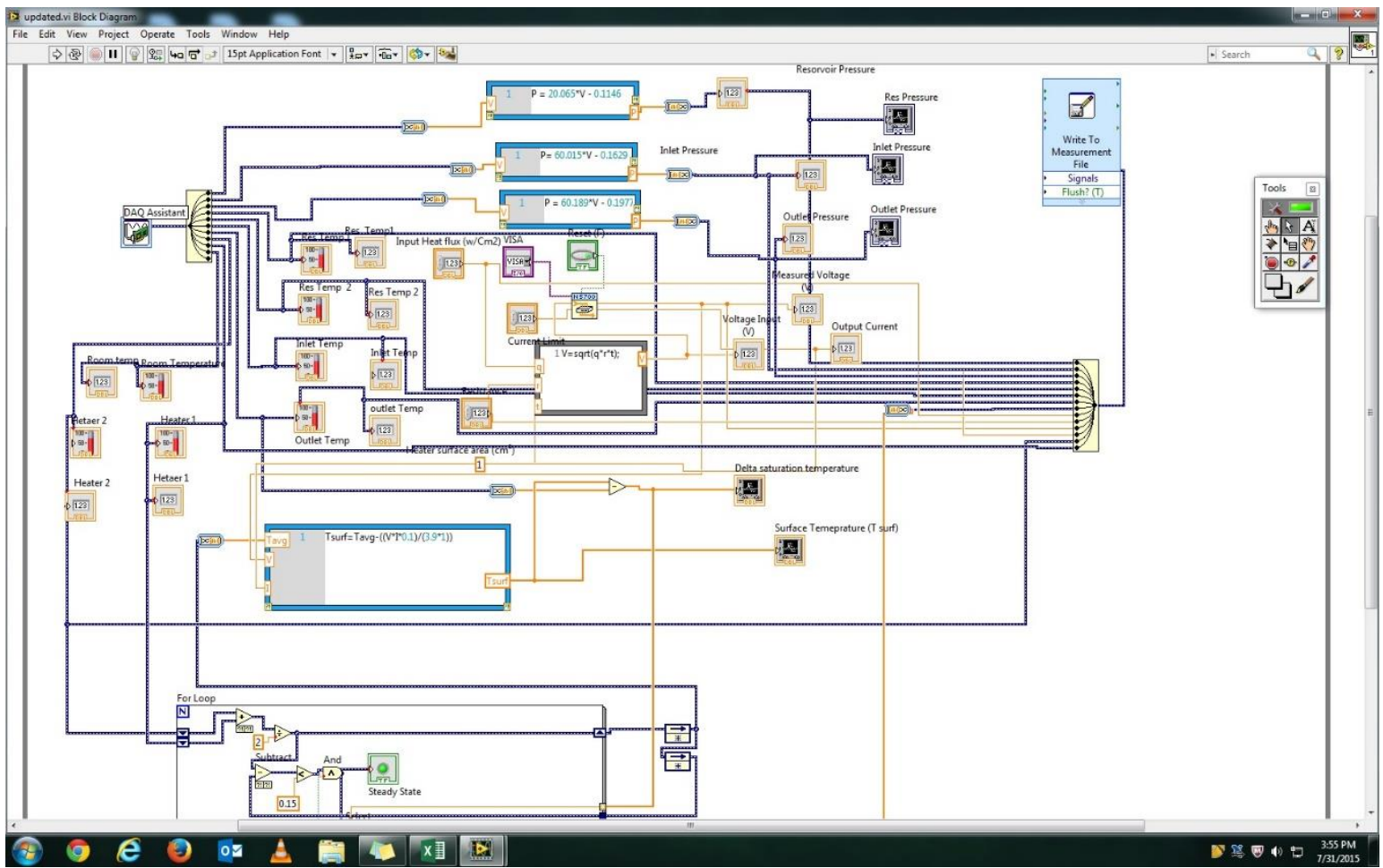

Figure 6: Block diagram of LabVIEW program 


\subsection{EXPERIMENTAL UNCERTAINITIES}

Experimental uncertainties were estimated mainly for heat flux and temperature measurements that are critical in performance evaluation. Uncertainties were estimated mainly for heat flux and temperature measurements that are critical in performance evaluation. Error involved in heat flux measurement (considering variations in voltage, current, and area) was $\pm 2.0 \%$ at $150 \mathrm{~W} / \mathrm{cm}^{2}$. Error in temperature measurements from the embedded TCs in the heater wall was calibrated to be $\pm 0.2^{\circ} \mathrm{C}$. Spray surface temperature had an uncertainty of approximately $\pm 0.3^{\circ} \mathrm{C}$ involving uncertainty in temperature extrapolation from the TC hole to the heater surface at $150 \mathrm{~W} / \mathrm{cm}^{2}$. Heat transfer coefficients included up to $\pm 3.1 \%$ uncertainty at $150 \mathrm{~W} / \mathrm{cm}^{2}$ considering all nozzle types and flow rates used. 


\section{CHAPTER IV RESULTS AND DISCUSSIONS}

This chapter provides the experimental results, and discusses the spray cooling performance based on the Heat Transfer Coefficient (HTC) and Critical Heat Flux (CHF). The spray characteristics and liquid flow rates on the cooling performance are investigated with selected coolants (HFC-134a and HFO-1234yf). The experimental results obtained from this study provide a frame work for spray cooling performance with the present and next generation refrigerants aimed for advanced thermal management of automotive power electronics.

\subsection{RESULTS FOR HFC-134a}

Smooth plain copper was tested with HFC-134a refrigerant using the all three commercial nozzle with different flow rates were tested. Initially the tests were performed using a TG0.3 nozzle as shown in Figure 7, With maintaining $2 \mathrm{ml} / \mathrm{s}$ flowrate the CHF value attained was $210 \mathrm{~W} / \mathrm{cm}^{2}$ at about $29.55^{\circ} \mathrm{C}$ surface superheat. The $\mathrm{CHF}$ value attained with $3 \mathrm{ml} / \mathrm{s}$ for the same nozzle type was $238 \mathrm{~W} / \mathrm{cm}^{2}$ which is a higher CHF than previous flow rate and maintaining the temperature of surface at $37.84^{\circ} \mathrm{C}$ surface superheat. Due to the high pumping power consumed by the nozzle to attain $4 \mathrm{ml} / \mathrm{s}$, the test for $4 \mathrm{ml} / \mathrm{s}$ with TG0.3 nozzle was eliminated. The heat transfer and the CHF monotonically increase with the spray flow rate for a given nozzle. From the Figure 7, there was drastically an increase of $13.3 \%$ critical heat flux. 
To make sure that our results are more repeatable, we conducted a repeatability for the nozzle TG0.3 at $2 \mathrm{ml} / \mathrm{s}$. From Figure 8 , the CHF obtained for both the tests was $210 \mathrm{~W} / \mathrm{cm}^{2}$ maintaining the surface temperature at $29.55^{\circ} \mathrm{C}$ and for second test $30.41^{\circ} \mathrm{C}$.

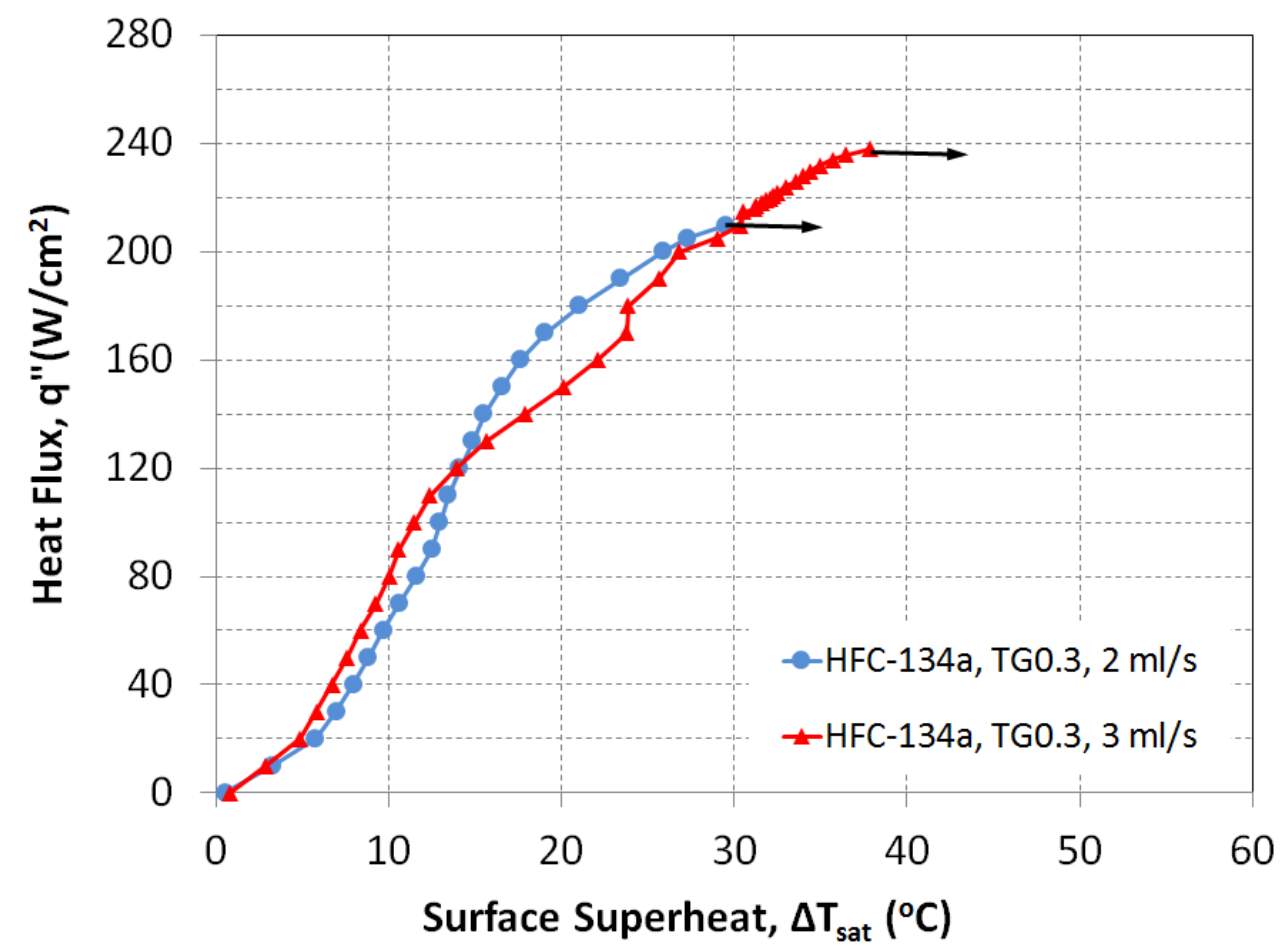

Figure 7: Heat transfer performance of HFC-134a with TG0.3 nozzle at flow rates of 2, $3 \mathrm{ml} / \mathrm{s}$ 


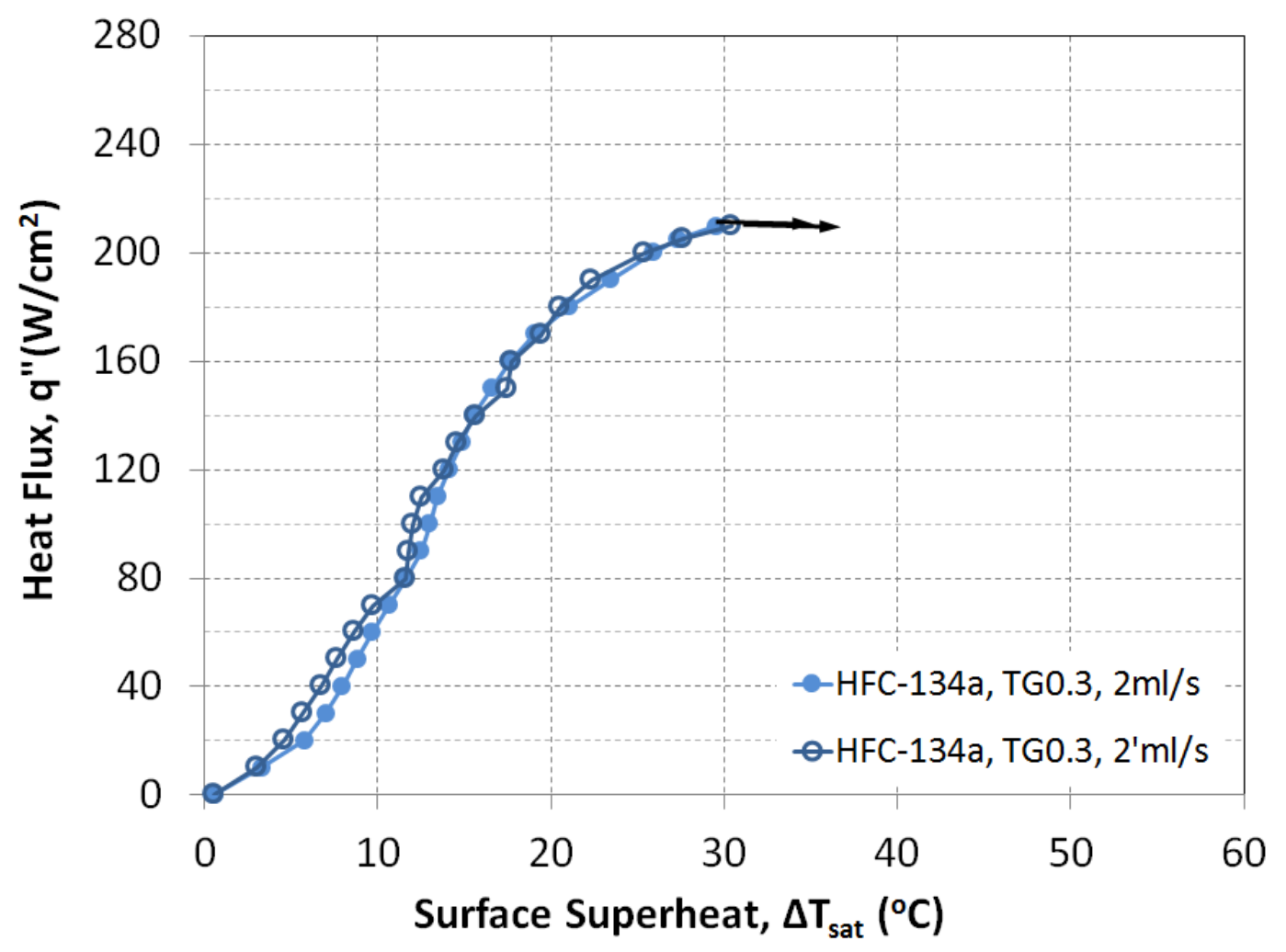

Figure 8: Repeatability of HFC-134a with TG0.3 nozzle at flow rate of $2 \mathrm{ml} / \mathrm{s}$

After evaluating the performance of HFC-134a with the TG0.3 nozzle at flow rates of $2,3 \mathrm{ml} / \mathrm{s}$, another nozzle that offers the full cone spray was installed to evaluate the performance of HFC134a. By performing the tests with newly installed nozzle type TG0.5 the results were plotted as shown in the Figure 9. A test conducted with TG0.5 nozzle at the flow rate of $2 \mathrm{ml} / \mathrm{s}$ resulted in attaining the $\mathrm{CHF}$ of $217 \mathrm{~W} / \mathrm{cm}^{2}$ while maintaining the surface temperature at $27.66^{\circ} \mathrm{C}$. With the increases flow rate, a test was conducted at $3 \mathrm{ml} / \mathrm{s}$ for the same nozzle type and the heater used the same and the CHF attained for this flow rate and nozzle type was $244 \mathrm{~W} / \mathrm{cm}^{2}$ and the surface temperature observed was 36.01 . This indicates that there was development $12.4 \%$ increase of CHF with increased flow rate. The same heater was used to determine the evaluation of TG0.5 
nozzle with flow rate of $4 \mathrm{ml} / \mathrm{s} \mathrm{HFC}-134 \mathrm{a}$ and it the $\mathrm{CHF}$ observed was $258 \mathrm{~W} / \mathrm{cm}^{2}$ and maintaining the surface superheat at $35.69^{\circ} \mathrm{C}$.

A test with TG0.5 for the flow rate $2 \mathrm{ml} / \mathrm{s}$ was repeated (Figure 10) to gain the repeatability of the results. The first test showed the $\mathrm{CHF}$ attained was at $217 \mathrm{~W} / \mathrm{cm}^{2}$ with the surface temperature of $27.66^{\circ} \mathrm{C}$ and the second test with the same heater showed the promising results following the same pattern as the first cooling curve by attaining the CHF at $215 \mathrm{~W} / \mathrm{cm}^{2}$ and maintaining the surface temperature at $24.85^{\circ} \mathrm{C}$. The difference in the $\mathrm{CHF}$ for the two repeatable tests was observed as decrease of $0.99 \%$.

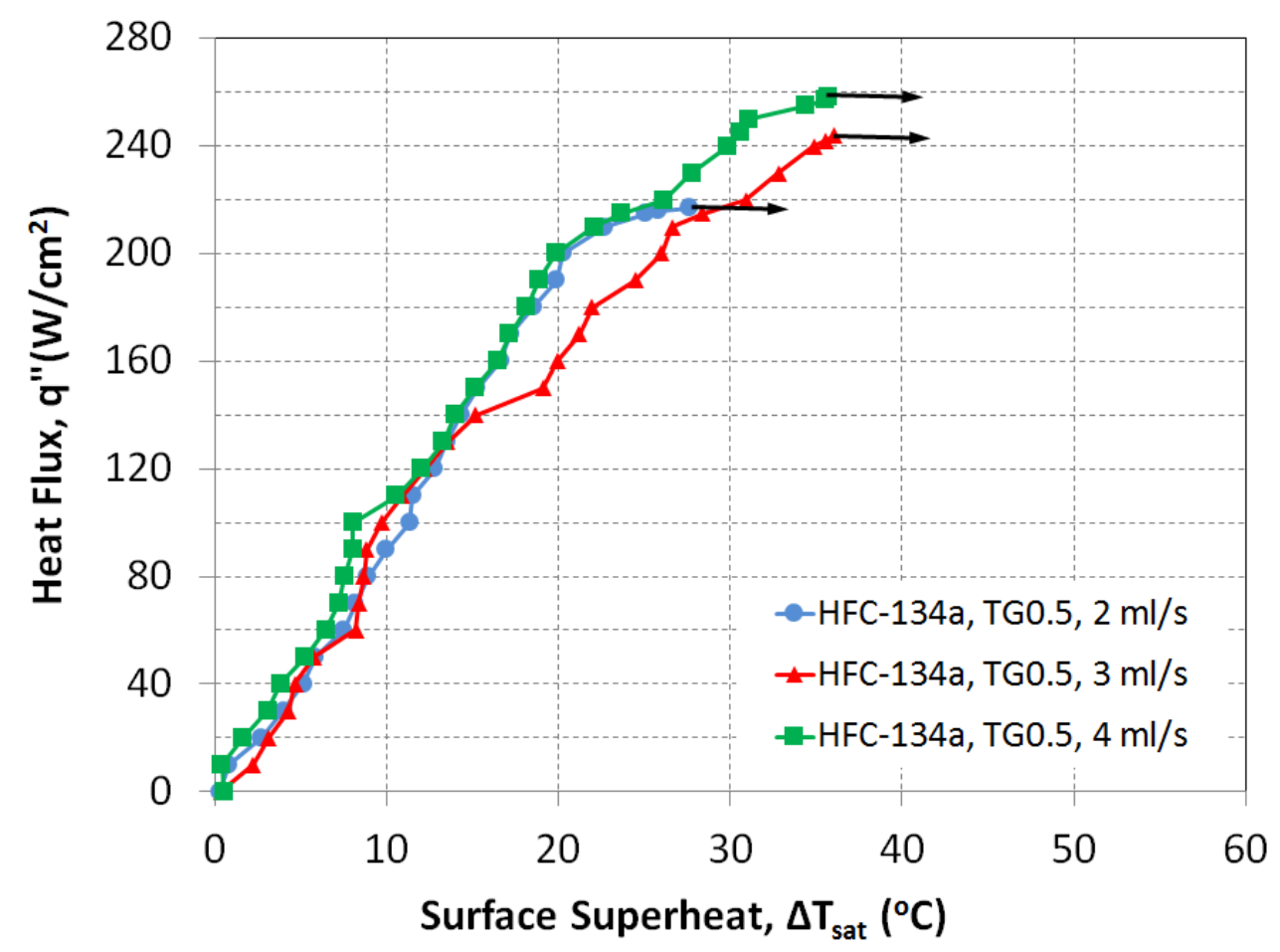

Figure 9: Heat transfer performance of HFC-134a with TG0.5 nozzle at flow rates 2, 3, $4 \mathrm{ml} / \mathrm{s}$ 


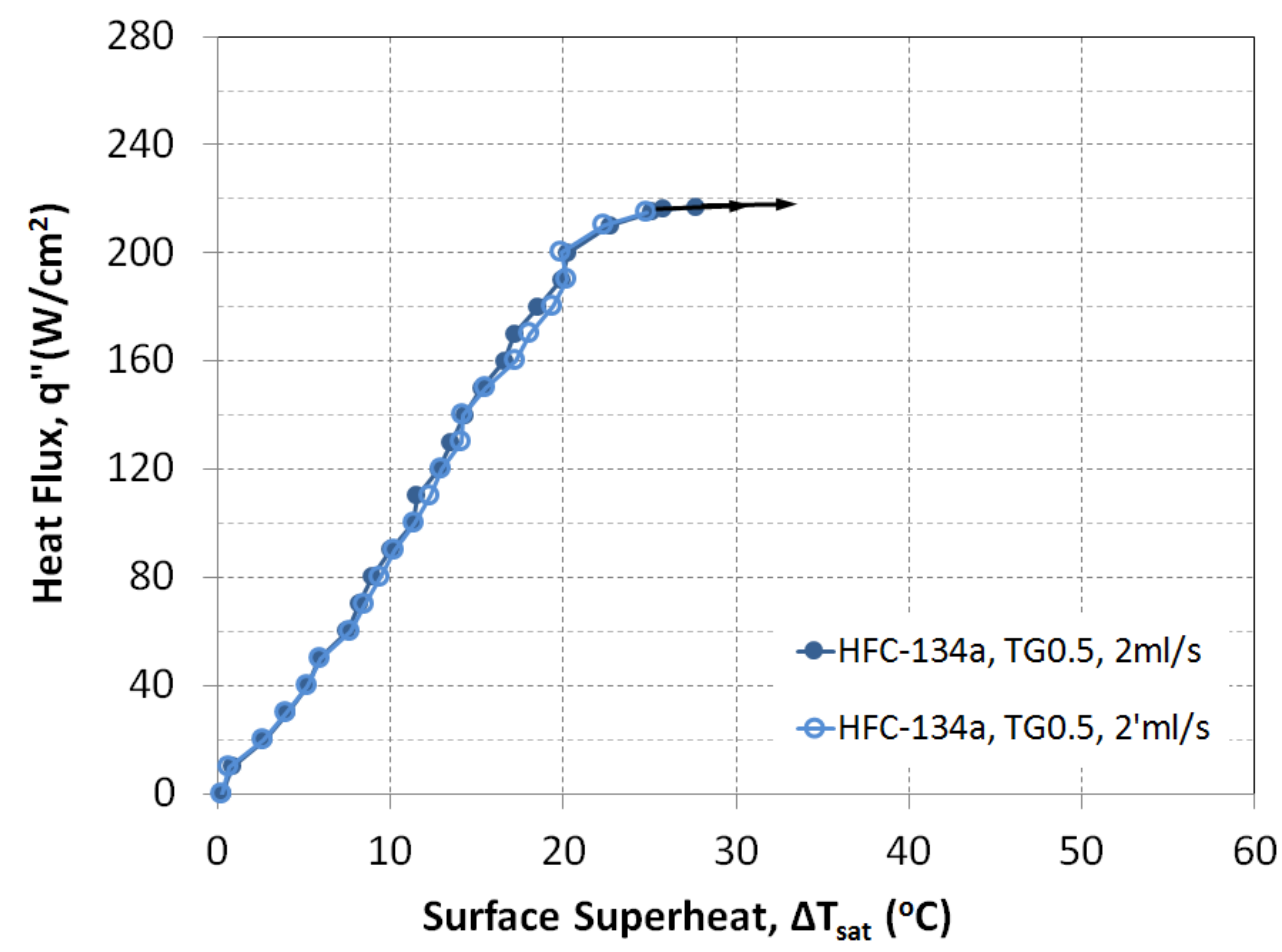

Figure 10: Repeatability of HFC-134a with TG0.5 nozzle at flow rate $2 \mathrm{ml} / \mathrm{s}$

The heater was now prepared to test the full cone nozzle TG0.7 with the refrigerant HFC1234 yf. The initial test was conducted with nozzle TG0.7 with the flow rate of $2 \mathrm{ml} / \mathrm{s}$ and the observations are that the CHF was attained at $200 \mathrm{~W} / \mathrm{cm}^{2}$ with surface temperature maintaining at $22.89^{\circ} \mathrm{C}$. For the flow rate $3 \mathrm{ml} / \mathrm{s}$ and the nozzle TG0.7, the $\mathrm{CHF}$ attained was $210 \mathrm{~W} / \mathrm{cm}^{2}$ and the surface temperature observed was $35.42^{\circ} \mathrm{C}$. For the similar conditions at $4 \mathrm{ml} / \mathrm{s}$ and for the same nozzle, the CHF observed was $230 \mathrm{~W} / \mathrm{cm}^{2}$, maintain the surface temperature at $34.05^{\circ} \mathrm{C}$. The results for the TG0.7 nozzle with different flow rates are presented in the form of spray performance curves in the Figure 11. From switching from $2 \mathrm{ml} / \mathrm{s}$ flowrate to $3 \mathrm{ml} / \mathrm{s}$ flowrate there was an increase in the $\mathrm{CHF}$ was $10 \%$ and from $2 \mathrm{ml} / \mathrm{s}$ to $4 \mathrm{ml} / \mathrm{s}$ there was increase in the $\mathrm{CHF}$ of $30 \%$ while the decrease in the surface temperature was $1.37^{\circ} \mathrm{C}$. A repeatability test was also conducted to gain the reproducibility and the results were plotted as shown in the Figure 12. 


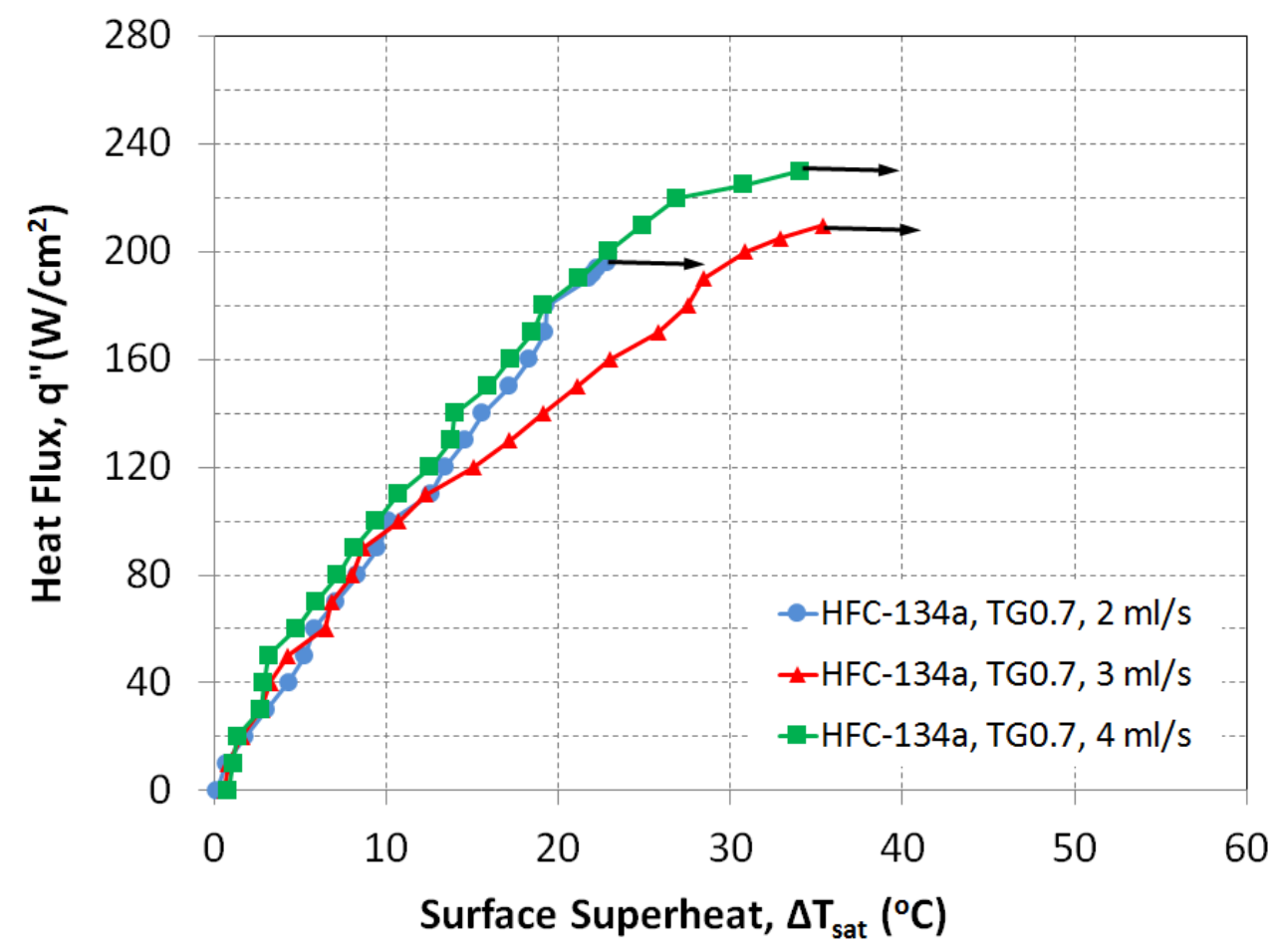

Figure 11: Heat Transfer performance of HFC-134a with TG0.7 nozzle at flow rates 2, 3, $4 \mathrm{ml} / \mathrm{s}$

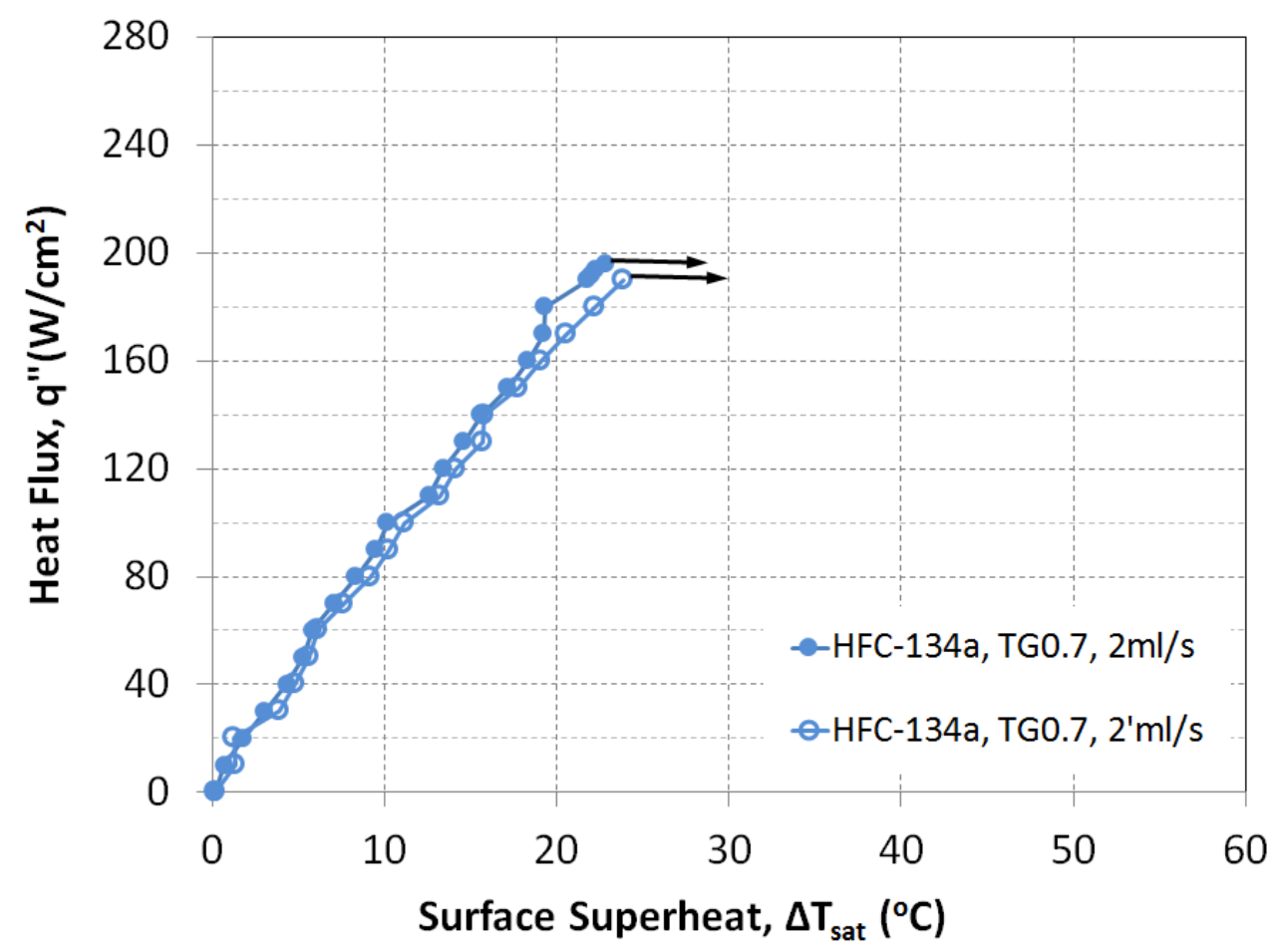

Figure 12: Repeatability of HFC-134a with TG0.7 nozzle at flow rate of $2 \mathrm{ml} / \mathrm{s}$ 
The comparison between the performance of different nozzles such as TG0.3, 0.5 and 0.7 for the flow rate $2 \mathrm{ml} / \mathrm{s}$ are plotted as shown in the Figure 13. For the TG0.3 nozzle the CHF was obtained at $210 \mathrm{~W} / \mathrm{cm}^{2}$ with surface superheat of $29.55^{\circ} \mathrm{C}$, for the TG0.5 for the same test conditions the observed $\mathrm{CHF}$ was $217 \mathrm{~W} / \mathrm{cm}^{2}$ maintaining the surface temperature of $27.66^{\circ} \mathrm{C}$. For, the same flow rate the TG0.7 gave an output $\mathrm{CHF}$ of $196 \mathrm{~W} / \mathrm{cm}^{2}$ while maintaining the surface temperature at $22.84^{\circ} \mathrm{C}$. For the same flow rate the with increase of the nozzle parameter (when the nozzle increases the spray droplet velocity and respective parameters changes) we can see there was an increase of the CHF for TG0.5 nozzle was 3.33\% and decrease in the surface temperature was $1.89^{\circ} \mathrm{C}$. Similarly, for the TG0.7 nozzle there was reduction of $7.14 \%$ and there was decrease in the surface temperature by $6.71^{\circ} \mathrm{C}$.

The comparison for the flowrate of $3 \mathrm{ml} / \mathrm{s}$ for different nozzle types were plotted as the cooling curves in the Figure 14 . For the $3 \mathrm{ml} / \mathrm{s}$ the TG0.3 nozzle showed the CHF at $238 \mathrm{~W} / \mathrm{cm}^{2}$ having the surface temperature of $37.84^{\circ} \mathrm{C}$. When used the same heater the TG0.5 nozzle at the same flow rate showed an improvement in the $\mathrm{CHF}$ at $244 \mathrm{~W} / \mathrm{cm}^{2}$ while maintaining the surface temperature at $36.01^{\circ} \mathrm{C}$. TG0.7 nozzle showed the $\mathrm{CHF}$ at $210 \mathrm{~W} / \mathrm{cm}^{2}$ having the surface temperature of $35.42^{\circ} \mathrm{C}$ for the same flow rate throughout the experiment. For the flow rate of $3 \mathrm{ml} / \mathrm{s}$ for the TG0.5 nozzle there was increase in the CHF by $2.52 \%$ and decrease in the surface temperature by $1.83^{\circ} \mathrm{C}$ when compare to TG0.3. Similarly, for the TG0.7 nozzle there was a decrease in the $\mathrm{CHF}$ value by $13.3 \%$ and decrease in the surface temperature by $2.42^{\circ} \mathrm{C}$. 


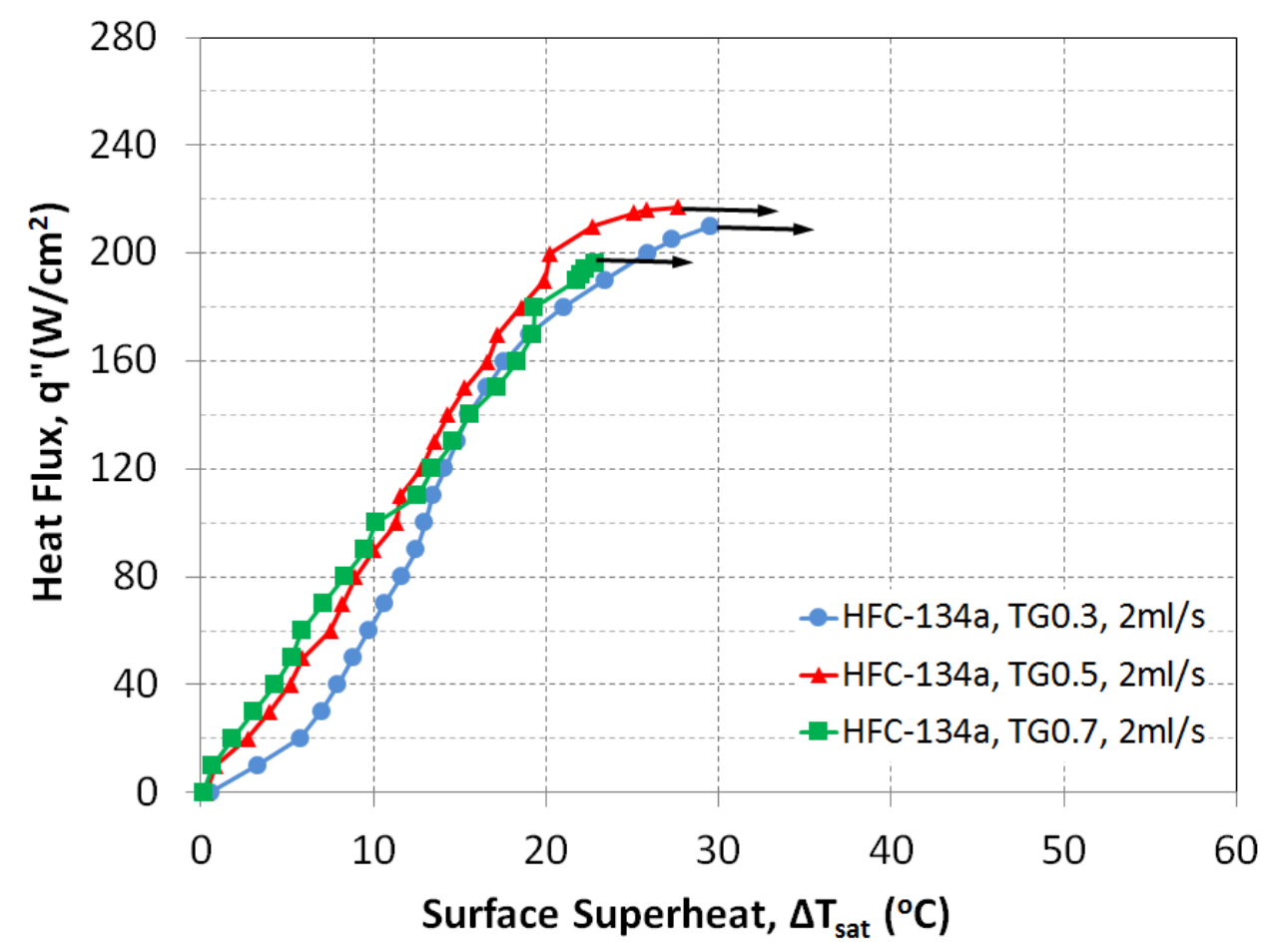

Figure 13: Heat Transfer performance of HFC-134a with nozzles TG0.3, 0.5, and 0.7 at flow rate of $2 \mathrm{ml} / \mathrm{s}$

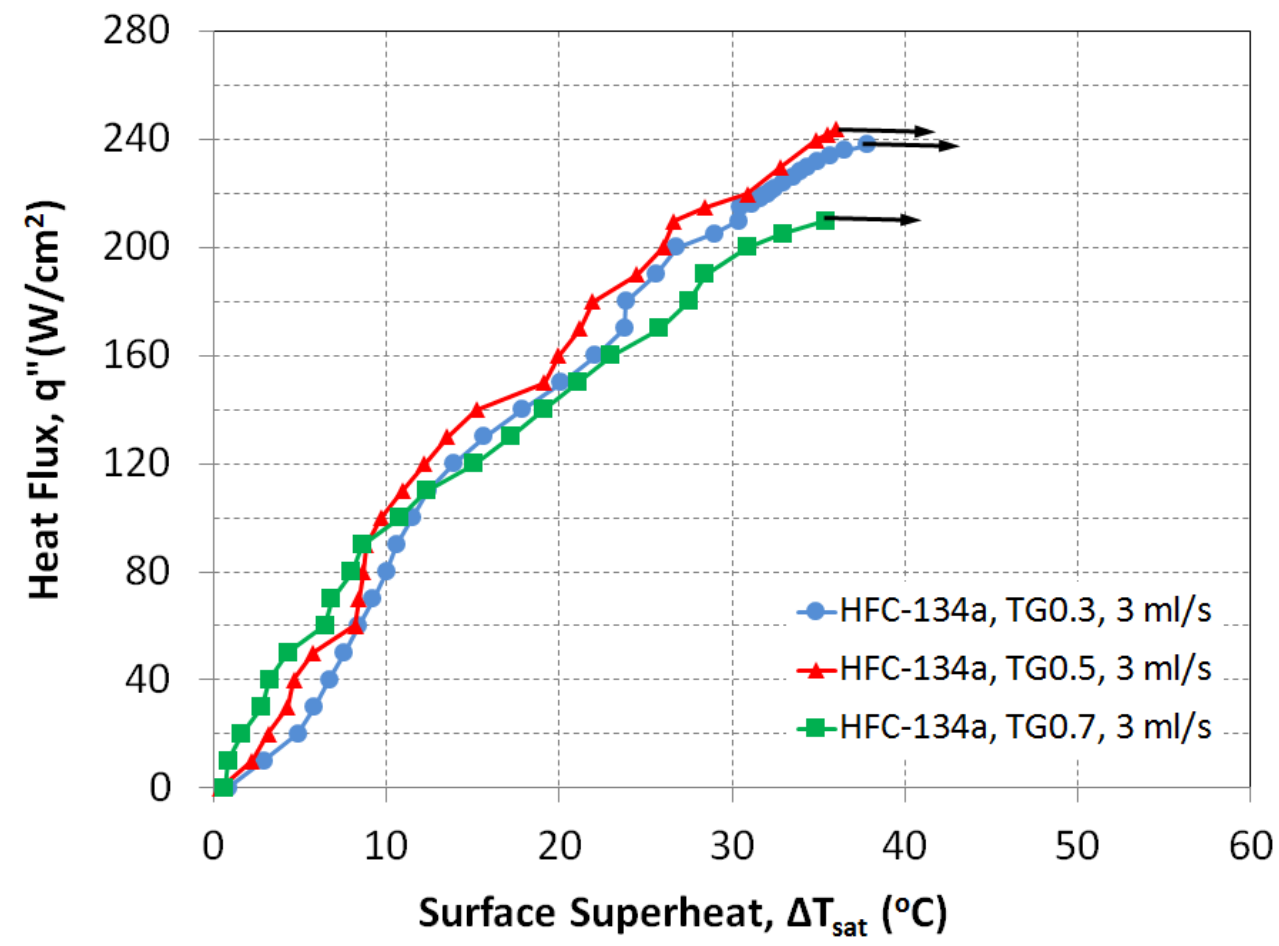

Figure 14: Heat transfer performance of HFC-134a with nozzles TG0.3, 0.5 and 0.7 at flow rate of $3 \mathrm{ml} / \mathrm{s}$ 
The comparison of the Nozzles TG0.5 and TG0.7 are compared for the flow rate of $4 \mathrm{ml} / \mathrm{s}$ and the results are plotted as shown in the Figure 15 . For the nozzle TG0.5 for the $4 \mathrm{ml} / \mathrm{s}$, the CHF observed was $257 \mathrm{~W} / \mathrm{cm}^{2}$ maintaining the surface super heat of $35.51^{\circ} \mathrm{C}$. When looking at the TG0.7 nozzle for the flow rate of $4 \mathrm{ml} / \mathrm{s}$ the CHF obtained was at $230 \mathrm{~W} / \mathrm{cm}^{2}$, where the surface temperature observed as $34.05^{\circ} \mathrm{C}$. The Nozzle TG0.7 for the same flow rate showed an increase in the $\mathrm{CHF}$ by $11.7 \%$ whereas there was decrease in the surface temperature by $1.46^{\circ} \mathrm{C}$. The flow rate $4 \mathrm{ml} / \mathrm{s}$ for the nozzle TG0.3 was eliminated because of the power consumed by the pump was too high and cannot be assumed as good condition for the spray cooling setup developed for the given conditions.

Figure 16, represents the Heat transfer coefficient data for refrigerant type of HFC-134a for the Nozzle type TG0.3 with the flow rates of 2, 3, 4ml/s. For the TG0.3 nozzle, the highest HTC values were observed at mid heat flux ranges because of the two phase heat transfer is more dominant at those ranges. For, the TG0.3 at $2 \mathrm{~m} / \mathrm{s}$ the high heat flux that was obtained was 90.5 $\mathrm{Kw} / \mathrm{m}^{20} \mathrm{C}$ at heat flux range of $150 \mathrm{~W} / \mathrm{cm}^{2}$. For the TG0.5 nozzle the highest HTC obtained was $95.6 \mathrm{Kw} / \mathrm{m}^{20} \mathrm{c}$ for the heat flux of $100 \mathrm{~W} / \mathrm{cm}^{2}$. The HTC obtained with the TG0.7 nozzle was highest at $122.5 \mathrm{Kw} / \mathrm{m}^{20} \mathrm{C}$ at the heat flux range of $110 \mathrm{~W} / \mathrm{cm}^{2}$. When compared for the TG0.5 nozzle there was an increase of $5.63 \%$ with respect to TG0. 3 nozzle and there was increase of $28.1 \%$ for the nozzle TG0.7. 


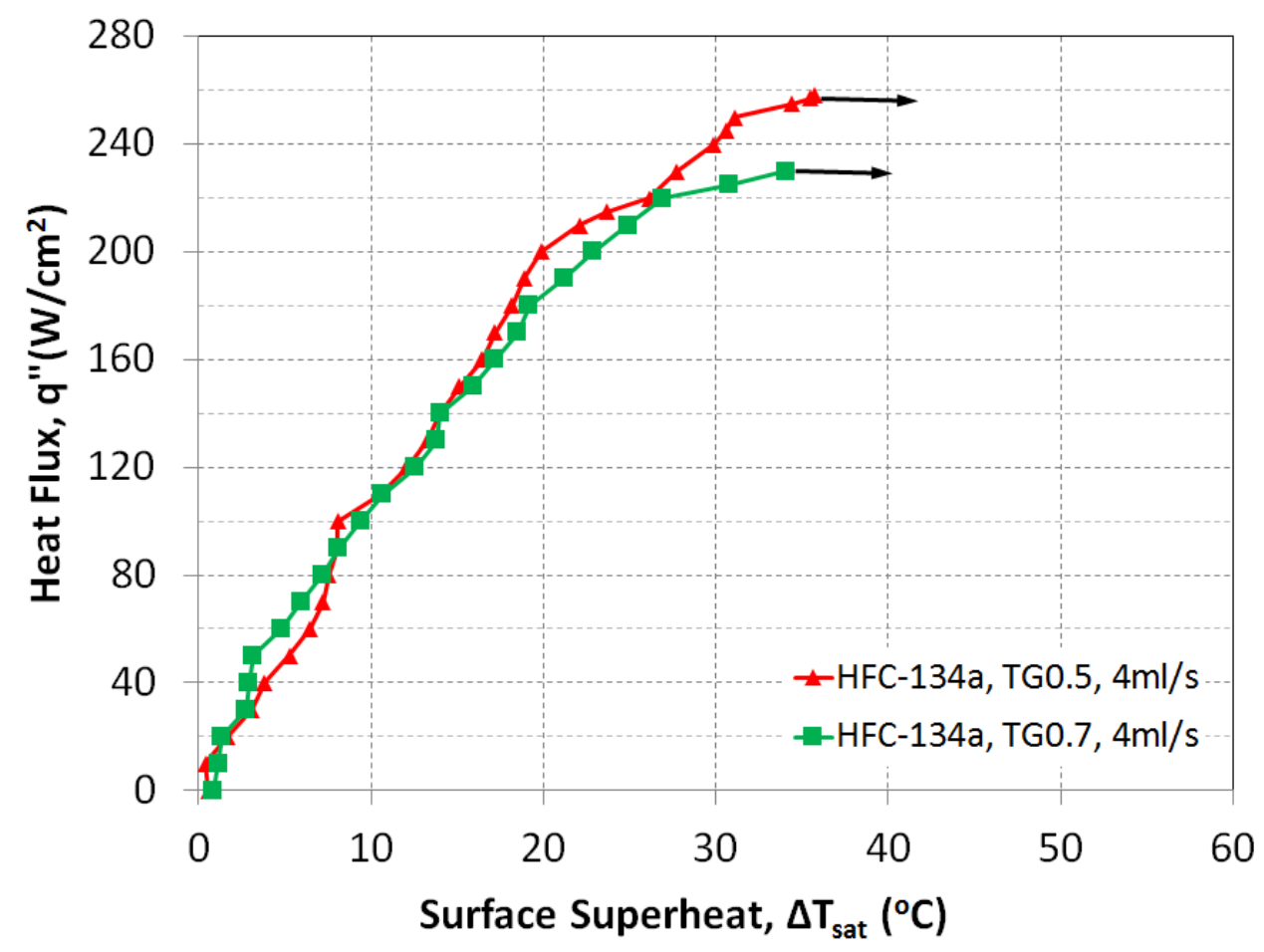

Figure 15: Heat transfer performance of HFC-134a with nozzles TG0.5 and 0.7 at flow rate $4 \mathrm{ml} / \mathrm{s}$

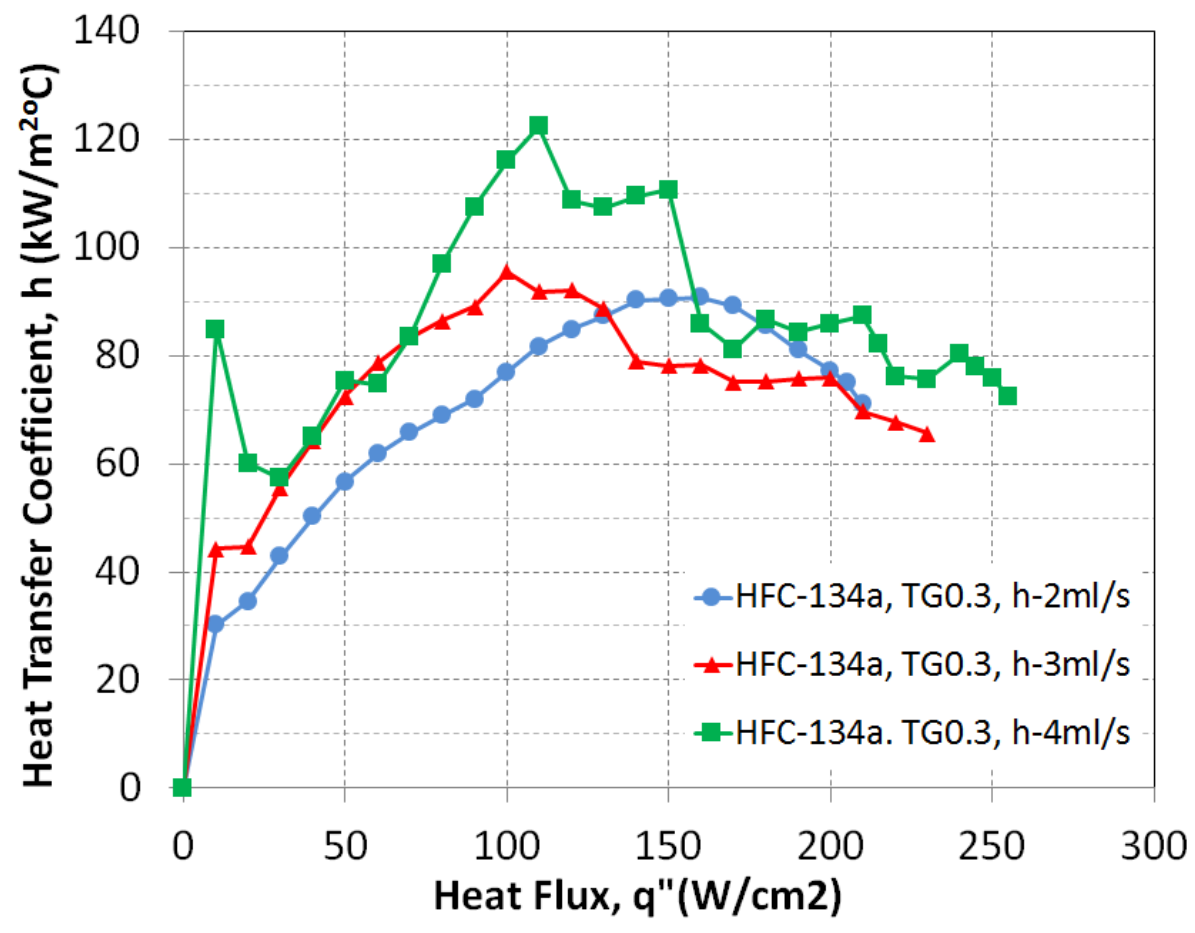

Figure 16: HTC of HFC-134a with nozzle TG0.3 at flow rates 2, 3, 4ml/s. 
Figure 17, is the HTC data for the refrigerant HFC-134a for the nozzle TG0.5 at the flow rates of $2,3,4 \mathrm{ml} / \mathrm{s}$. For the nozzle TG0.5 at flow rate of $2 \mathrm{mls}$ the $\mathrm{HTC}$ is obtained at the maximum heat flux of $217 \mathrm{~W} / \mathrm{cm}^{2}$ and was $84.1 \mathrm{Kw} / \mathrm{m}^{2 \circ} \mathrm{C}$. For the same nozzle and for the flow rate of 3 $\mathrm{ml} / \mathrm{s}$ the HTC obtained at the maximum heat flux of $244 \mathrm{~W} / \mathrm{cm}^{2}$, with the heat transfer coefficient value as $67.8 \mathrm{Kw} / \mathrm{m}^{2 \circ} \mathrm{C}$. With the flow rate of $4 \mathrm{ml} / \mathrm{s}$, the heat $\mathrm{HTC}$ value was $72.3 \mathrm{Kw} / \mathrm{m}^{2{ }^{\circ}} \mathrm{C}$ at the maximum heat flux of $258 \mathrm{~W} / \mathrm{cm}^{2}$. With the nozzle type TG0.5 for the given $3 \mathrm{ml} / \mathrm{s}$ flow rate there was a decrease of heat transfer coefficient value by $24.04 \%$ when compared with the flow rate of $2 \mathrm{ml} / \mathrm{s}$ and for the same nozzle with flow rate of $4 \mathrm{ml} / \mathrm{s}$ there was decrease by $16.3 \%$.

HTC for the nozzle type TG0.7 for the flow rate $2,3,4 \mathrm{ml} / \mathrm{s}$ are plotted as a function of the heat flux in the Figure 18. For the nozzle TG0.7 at the flow rate of $2 \mathrm{ml} / \mathrm{s}$ the heat transfer coefficient at the maximum heat $200 \mathrm{~W} / \mathrm{cm}^{2}$ was obtained as $87.4 \mathrm{Kw} / \mathrm{m}^{2 \circ} \mathrm{C}$. For the flow rate 3 $\mathrm{ml} / \mathrm{s}$ the HTC for the maximum heat flux of $210 \mathrm{~W} / \mathrm{cm}^{2}$ was obtained as $59.3 \mathrm{Kw} / \mathrm{m}^{2 \circ} \mathrm{C}$ and for the flow rate $4 \mathrm{ml} / \mathrm{s}$ at the heat flux of $230 \mathrm{~W} / \mathrm{cm}^{2}$, the $\mathrm{HTC}$ value was $67.6 \mathrm{Kw} / \mathrm{m}^{2 \circ} \mathrm{C}$. For the TG0.5 nozzle at the flow rate of $3 \mathrm{ml} / \mathrm{s}$ there was decrease in the HTC by $47.3 \%$ at their respective maximum heat fluxes. For the flow rate of $4 \mathrm{ml} / \mathrm{s}$ when compared to flow rate of $2 \mathrm{ml} / \mathrm{s}$ there was decrease in the HTC value by $29.2 \%$. 


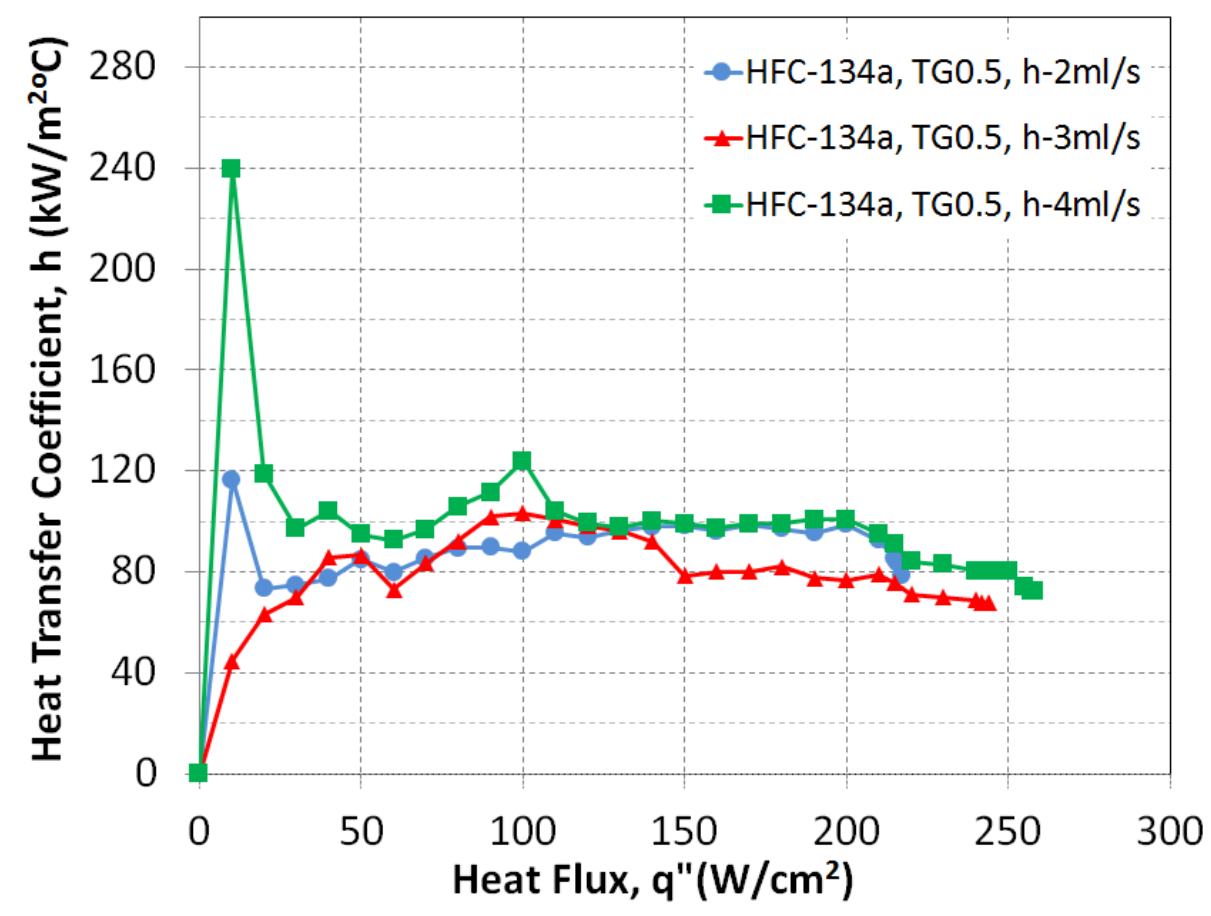

Figure 17: HTC of HFC-134a with nozzle TG0.5at flow rates 2, 3, 4ml/s

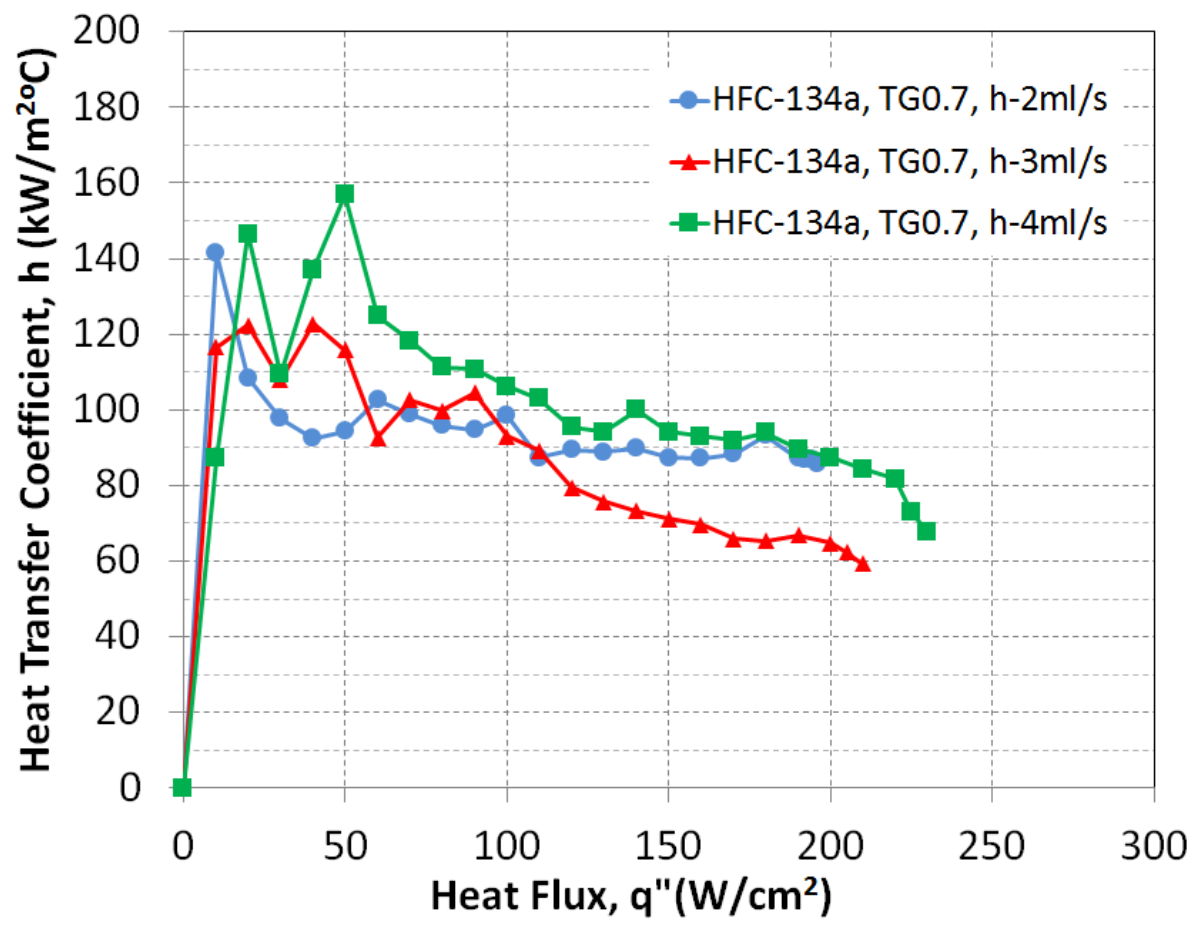

Figure 18: HTC of HFC-134a with nozzle TG0.7 at flow rates 2, 3, 4ml/s 
With the refrigerant HFC-134a, three nozzles were tested with different flow rates. The resulted CHF values were plotted in the Figure 19 as function of the flow rate $(\mathrm{ml} / \mathrm{s})$.

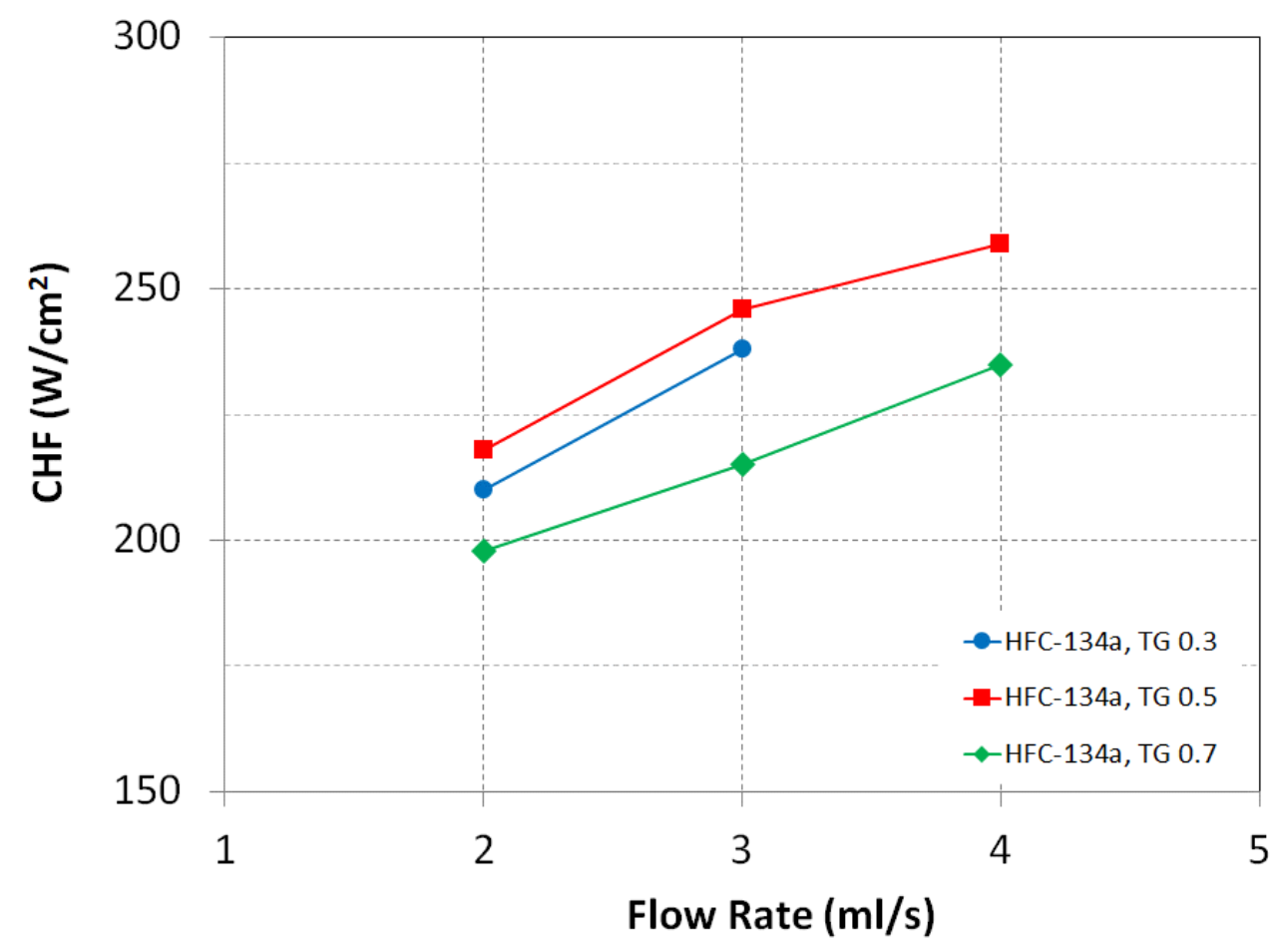

Figure 19: CHF values as a function of liquid flow rate of HFC-134a for nozzles TG0.3, 0.5 and 0.7 . 


\subsection{Results for HFO-1234yf refrigerant}

Heat transfer performance of the refrigerant HFO-1234yf for the nozzle TG0.3 at the flow rates of $3,4 \mathrm{ml} / \mathrm{s}$ are plotted as shown in the Figure 20 . With the nozzle TG0.3, the CHF value that was attained for the $2 \mathrm{ml} / \mathrm{s}$ was $150 \mathrm{~W} / \mathrm{cm}^{2}$ by having the surface temperature at $73.07{ }^{\circ} \mathrm{C}$. For the same nozzle with the flow rate of $4 \mathrm{ml} / \mathrm{s}$ the $\mathrm{CHF}$ value observed was 160 $\mathrm{W} / \mathrm{cm}^{2}$ with the surface temperature at $76.12{ }^{\circ} \mathrm{C}$. In comparison, the $\mathrm{CHF}$ value for the nozzle TG0.3 at flow rate $3 \mathrm{ml} / \mathrm{s}$ has a CHF value increased by $6.66 \%$ and the surface temperature was also increased by $4.17 \%$. To ensure the repeatability of the results, the same heater was tested and the results were plotted as shown in the Figure 21.

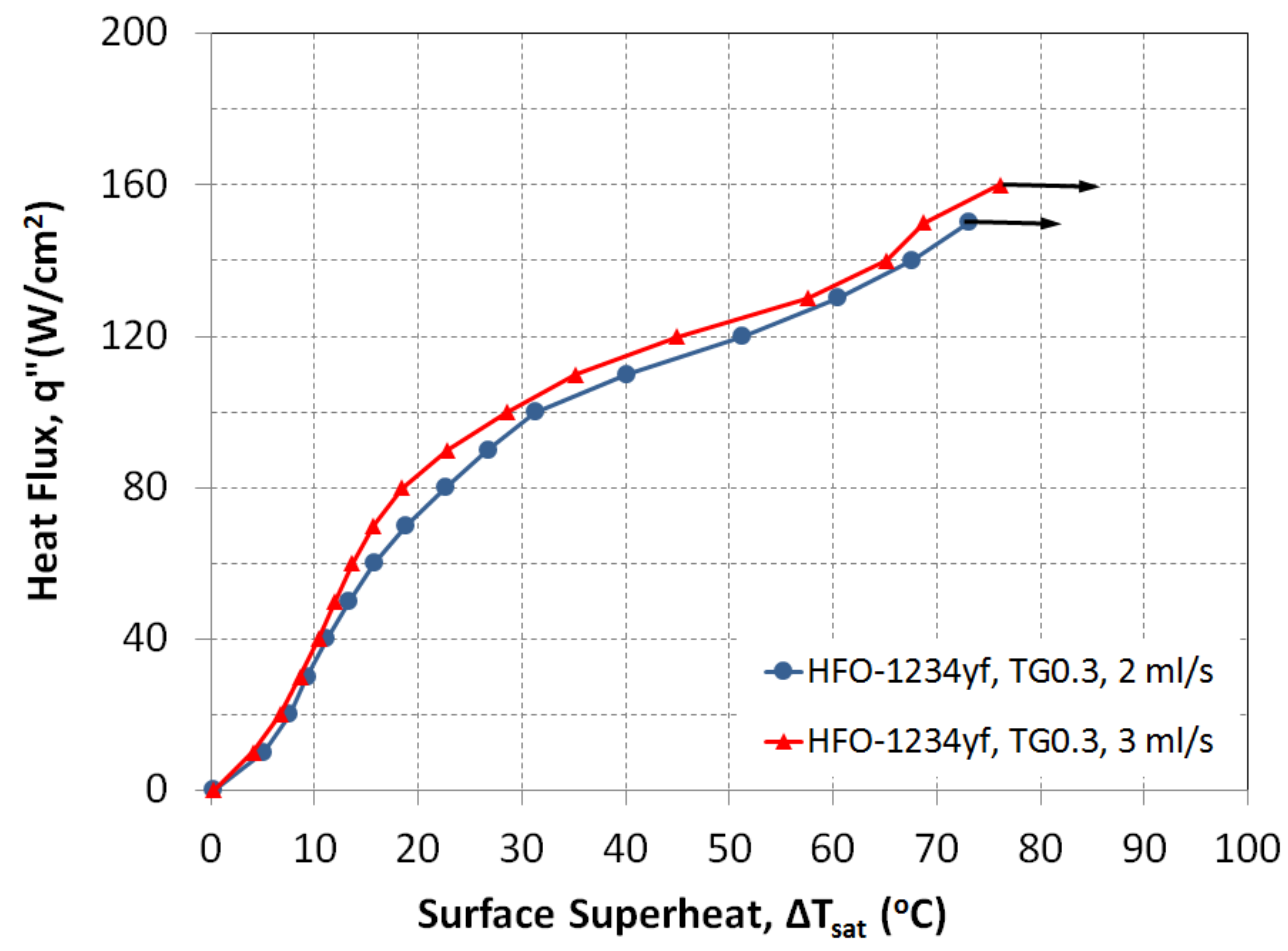

Figure 20: Heat transfer performance of HFO-1234yf with TG0.3 nozzle at flow rates of 2, 3ml/s 


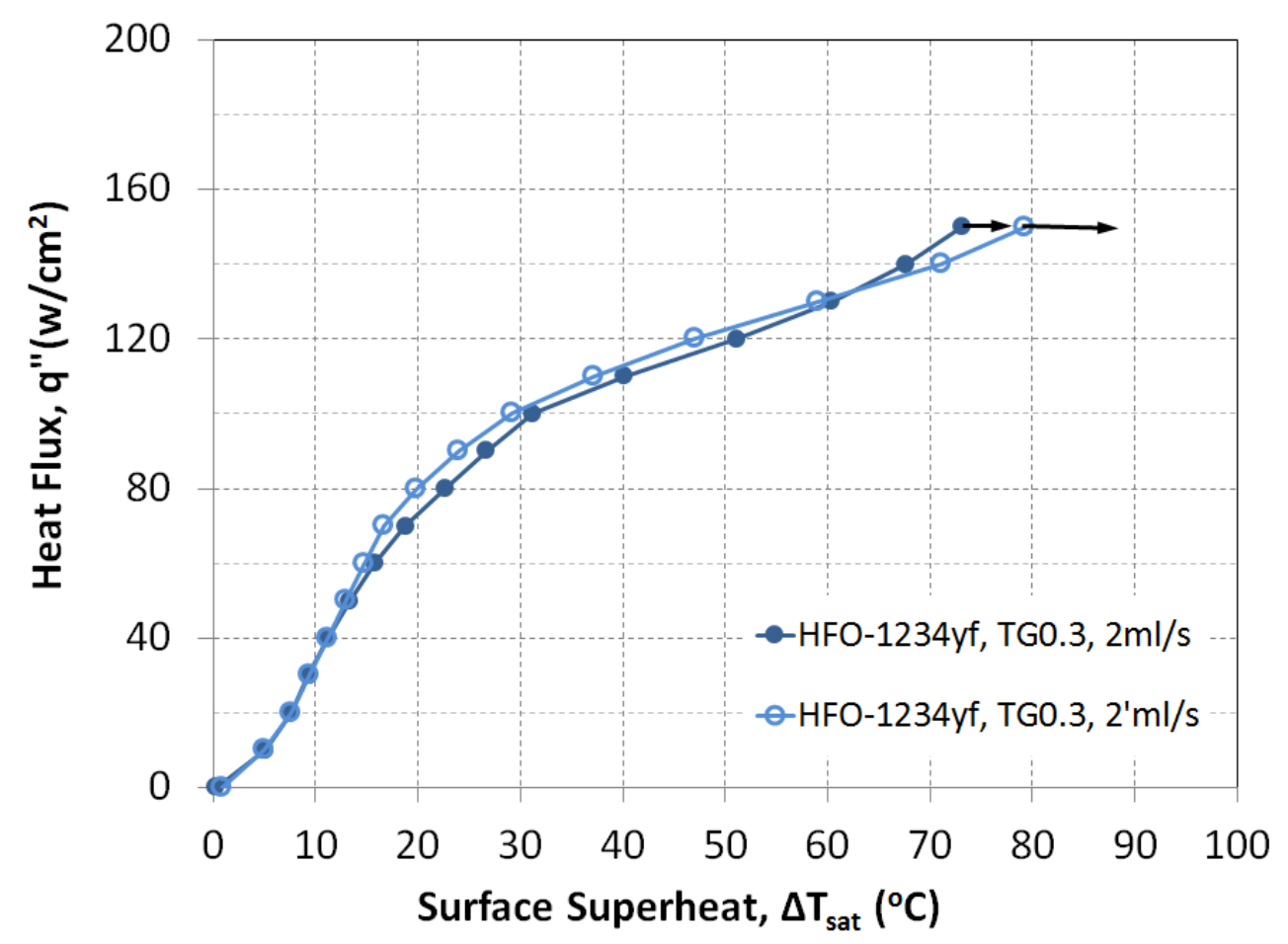

Figure 21: Repeatability of HFO-1234yf for nozzle TG0.3 at flow rate $2 \mathrm{ml} / \mathrm{s}$

Another experiment conducted with the nozzle TG0.5 for the flow rates of $2,3,4,5 \mathrm{ml} / \mathrm{s}$ are plotted with respect to the heat flux vs surface superheat in the Figure 22 . For the flow rate of $2 \mathrm{ml} / \mathrm{s}$, the CHF value obtained was $140 \mathrm{~W} / \mathrm{cm}^{2}$ with surface super heat of $76.38{ }^{\circ} \mathrm{C}$. For the same nozzle with the flow rate of $3 \mathrm{ml} / \mathrm{s}$ the $\mathrm{CHF}$ value obtained was $160 \mathrm{~W} / \mathrm{cm}^{2}$ with surface temperature of $69.34^{\circ} \mathrm{C}$. By the increasing the flow rate to $4 \mathrm{ml} / \mathrm{s}$ the $\mathrm{CHF}$ value observed was $170 \mathrm{~W} / \mathrm{cm}^{2}$ with the surface temperature observed at $60.62^{\circ} \mathrm{C}$. As we observed the maximum the flow rate the maximum was the $\mathrm{CHF}$ observed, we increased the flow rate to $5 \mathrm{ml} / \mathrm{s}$ and the $\mathrm{CHF}$ observed was $180 \mathrm{~W} / \mathrm{cm}^{2}$ with the surface superheat of $53.63^{\circ} \mathrm{C}$. From the respective Figure it was clearly indicated that greater the flow rate, the higher the value of CHF. Again to verify the reproducibility of the system two tests with nozzle TG0.5 were performed with the flow rates 2 , $3 \mathrm{ml} / \mathrm{s}$ and their results were plotted in the Figure 23 and Figure 24. 


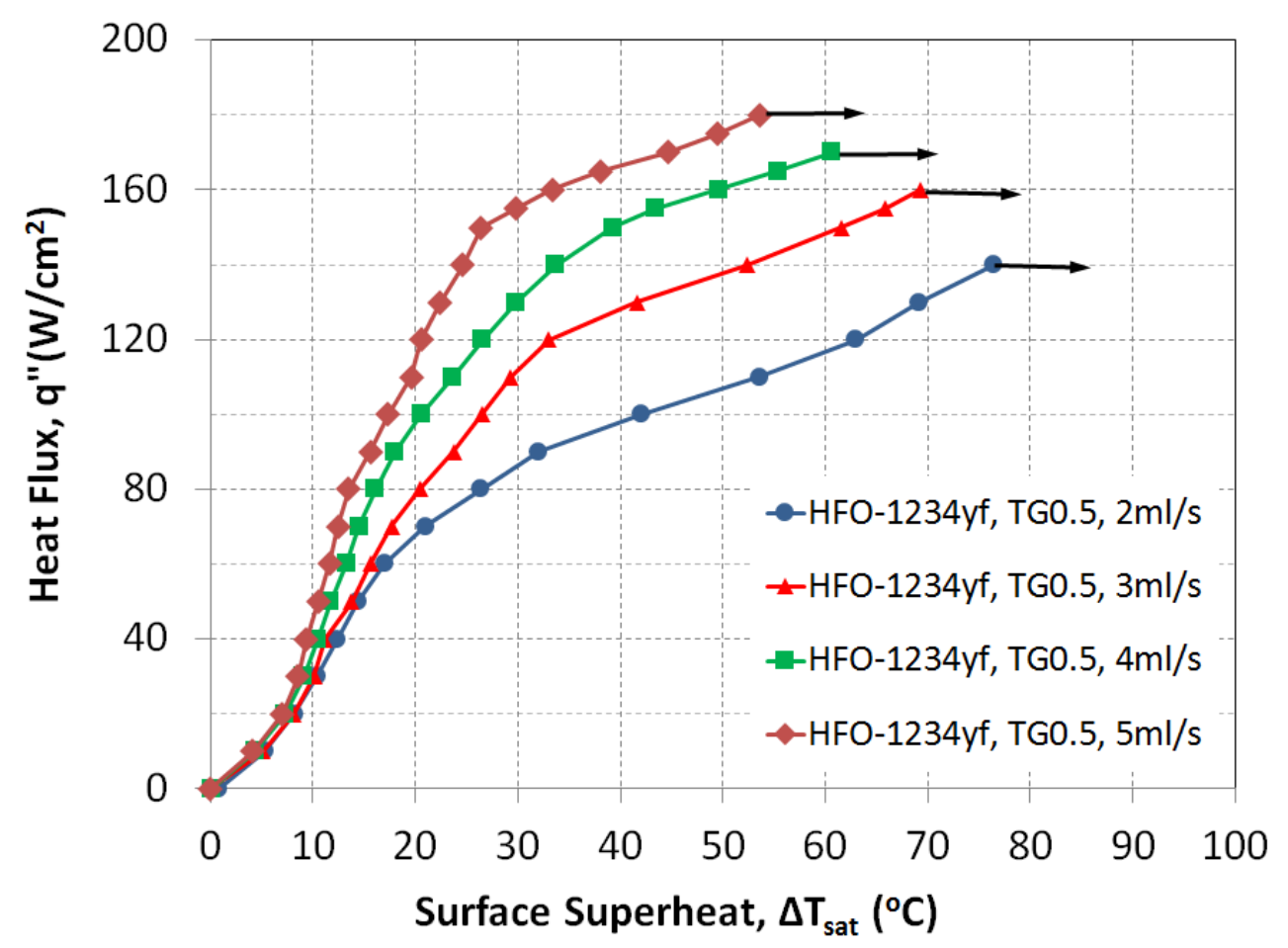

Figure 22: Heat Transfer performance of HFO-1234yf with TG0.5 nozzle at flow rates 2, 3, 4ml/s

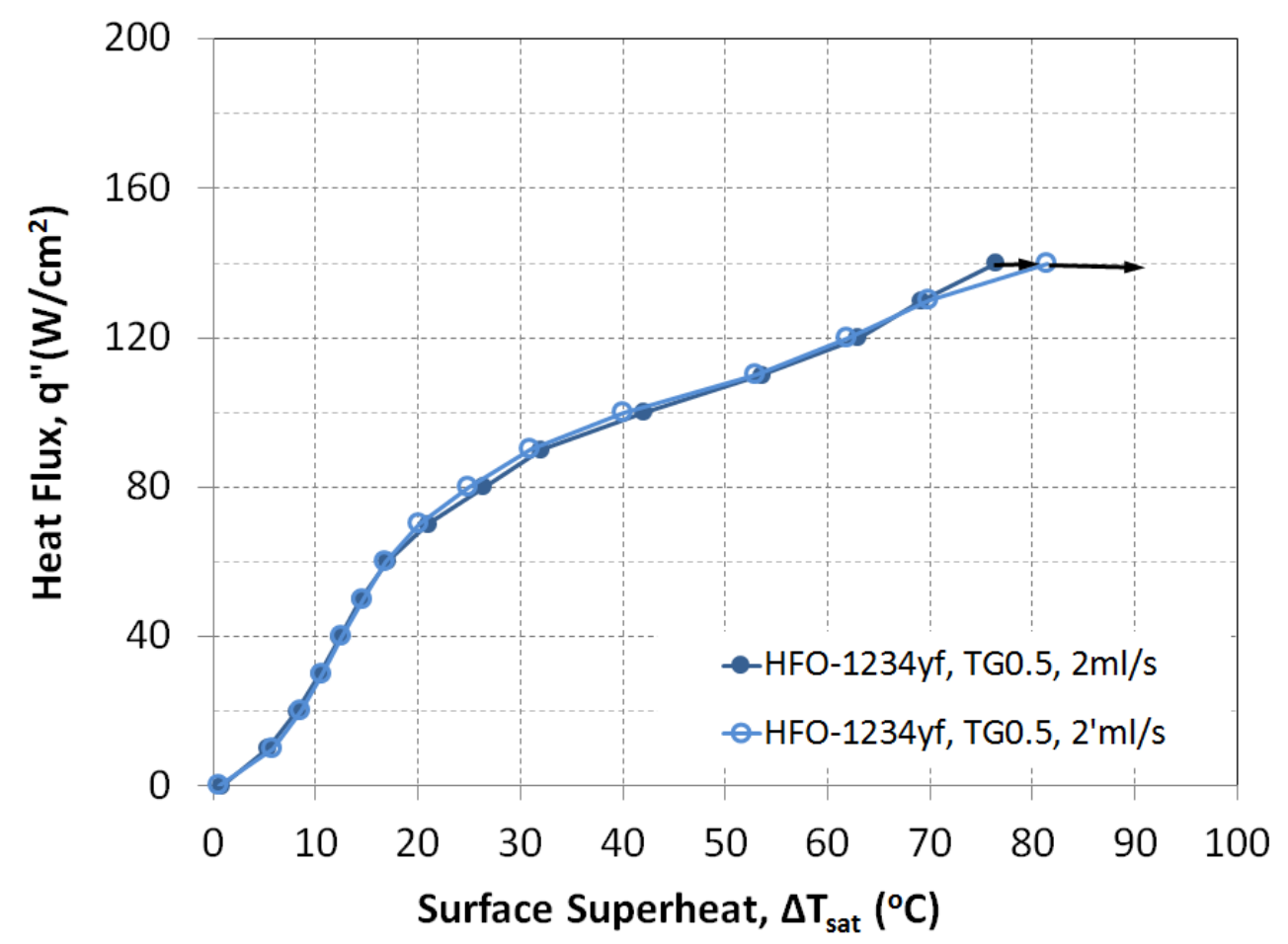

Figure 23: Repeatability of HFO-1234yf for TG0.5 nozzle at flow rate of $2 \mathrm{ml} / \mathrm{s}$. 


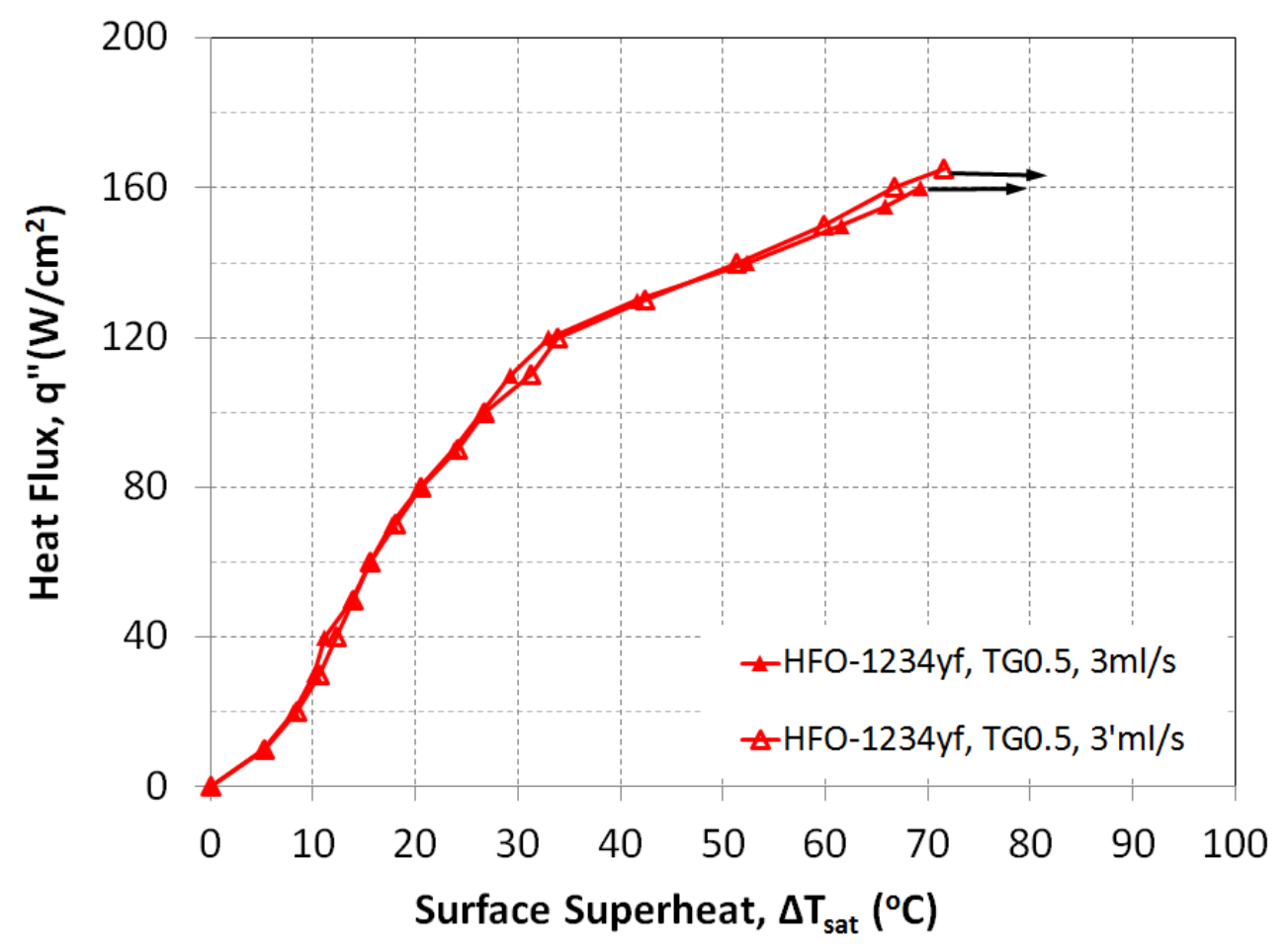

Figure 24: Repeatability of HFO-1234yf for nozzle TG0.5 at flow rate of 3ml/s.

Figure 25, represents the spray cooling performance of the refrigerant HFO-1234yf for the nozzle TG0.7 at the flow rate of $2,3,4 \mathrm{ml} / \mathrm{s}$. For the flow rate at $2 \mathrm{ml} / \mathrm{s}$ the CHF value observed was $145 \mathrm{~W} / \mathrm{cm}^{2}$ with the surface superheat of $85.16^{\circ} \mathrm{C}$. For the same nozzle with the flow rate of $3 \mathrm{mml} / \mathrm{s}$ the $\mathrm{CHF}$ values are $150 \mathrm{~W} / \mathrm{cm}^{2}$ by having the surface temperatures at $63.92^{\circ} \mathrm{C}$. We again tested the same heater for the greater flow rate of $4 \mathrm{ml} / \mathrm{s}$ and the maximum CHF value attained was $160 \mathrm{~W} / \mathrm{cm}^{2}$ with the surface superheat of $61.32^{\circ} \mathrm{C}$. since, we observed that the as increase in the flow rate resulted in the higher heat flux, we tested the setup with the same nozzle by increasing the flow rate to $5 \mathrm{ml} / \mathrm{s}$ and the $\mathrm{CHF}$ values that were attained was $175 \mathrm{~W} / \mathrm{cm}^{2}$ by having the surface temperatures at $58.16^{\circ} \mathrm{C}$. Clearly at this point the nozzle TG0.7 performs better with 
greater flow rate of $5 \mathrm{ml} / \mathrm{s}$. But when compared the same with the HFC-134a, the surface temperatures are much higher and the CHF values are low at the given flow rate.

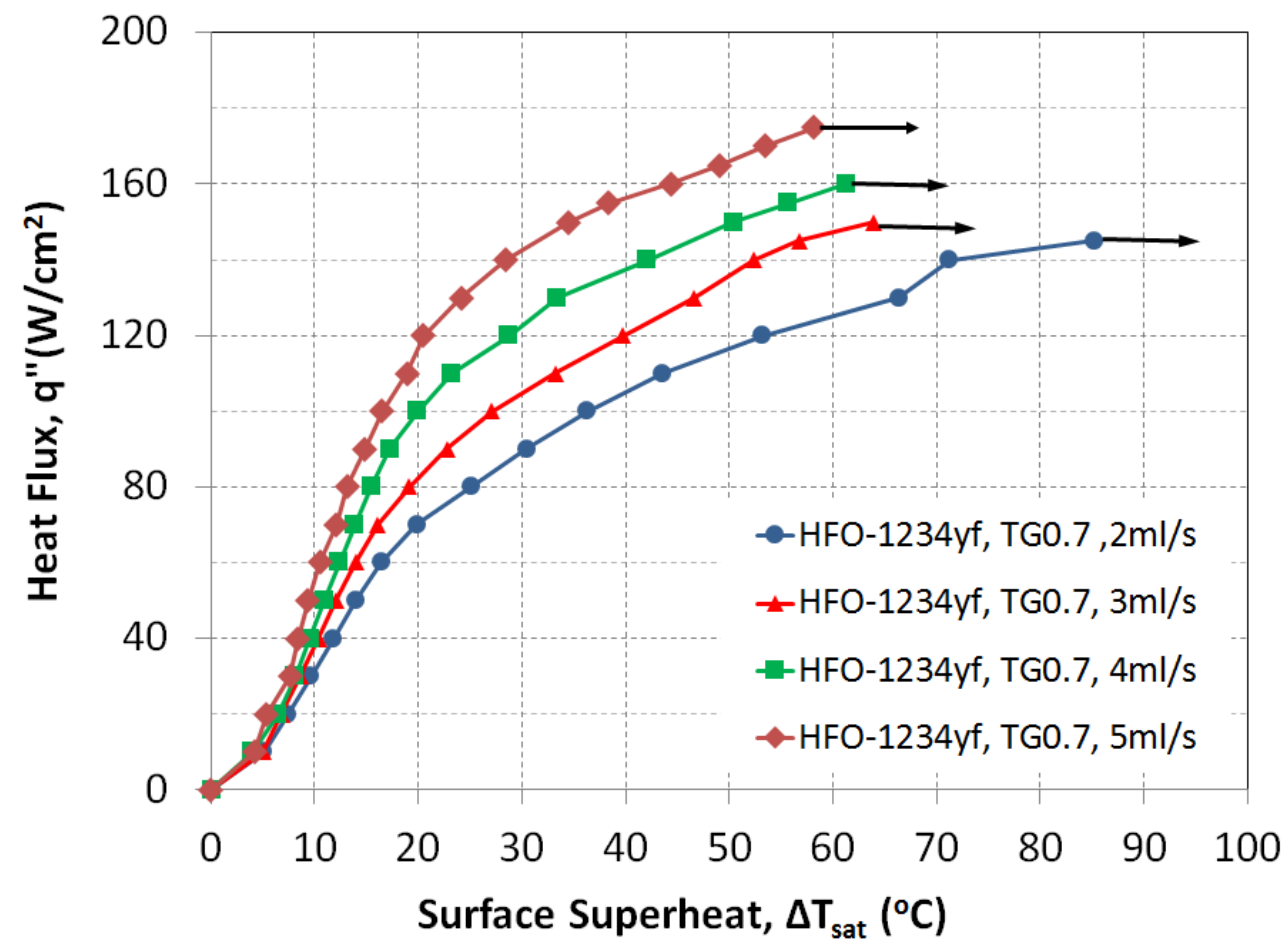

Figure 25: Heat Transfer performance of HFO-1234yf with TG00.7 nozzle at flow rates of 2, 3, and $4 \mathrm{ml} / \mathrm{s}$

HFO-1234yf refrigerant values for different nozzles for the flow rate of $2 \mathrm{ml} / \mathrm{s}$ was plotted in the Figure 26 . For the flow rate $2 \mathrm{ml} / \mathrm{s}$, the nozzle TG0.3 showed the CHF value at $152 \mathrm{~W} / \mathrm{cm}^{2}$ at the surface temperature of $72.87^{\circ} \mathrm{C}$. The CHF values that were observed for the TG0.5 nozzle for the given flow rate was $140 \mathrm{~W} / \mathrm{cm}^{2}$ by maintaining the surface temperature at $76.38^{\circ} \mathrm{C}$. The same flow rate was used for the TG0.7 nozzle and the CHF values observed was $145 \mathrm{~W} / \mathrm{cm}^{2}$ at the 
surface temperature of $85.16^{\circ} \mathrm{C}$. When compared the three nozzles at the flow rate of $2 \mathrm{ml} / \mathrm{s}$, the nozzle TG0.3 provided the better CHF and also with the low surface superheat values.

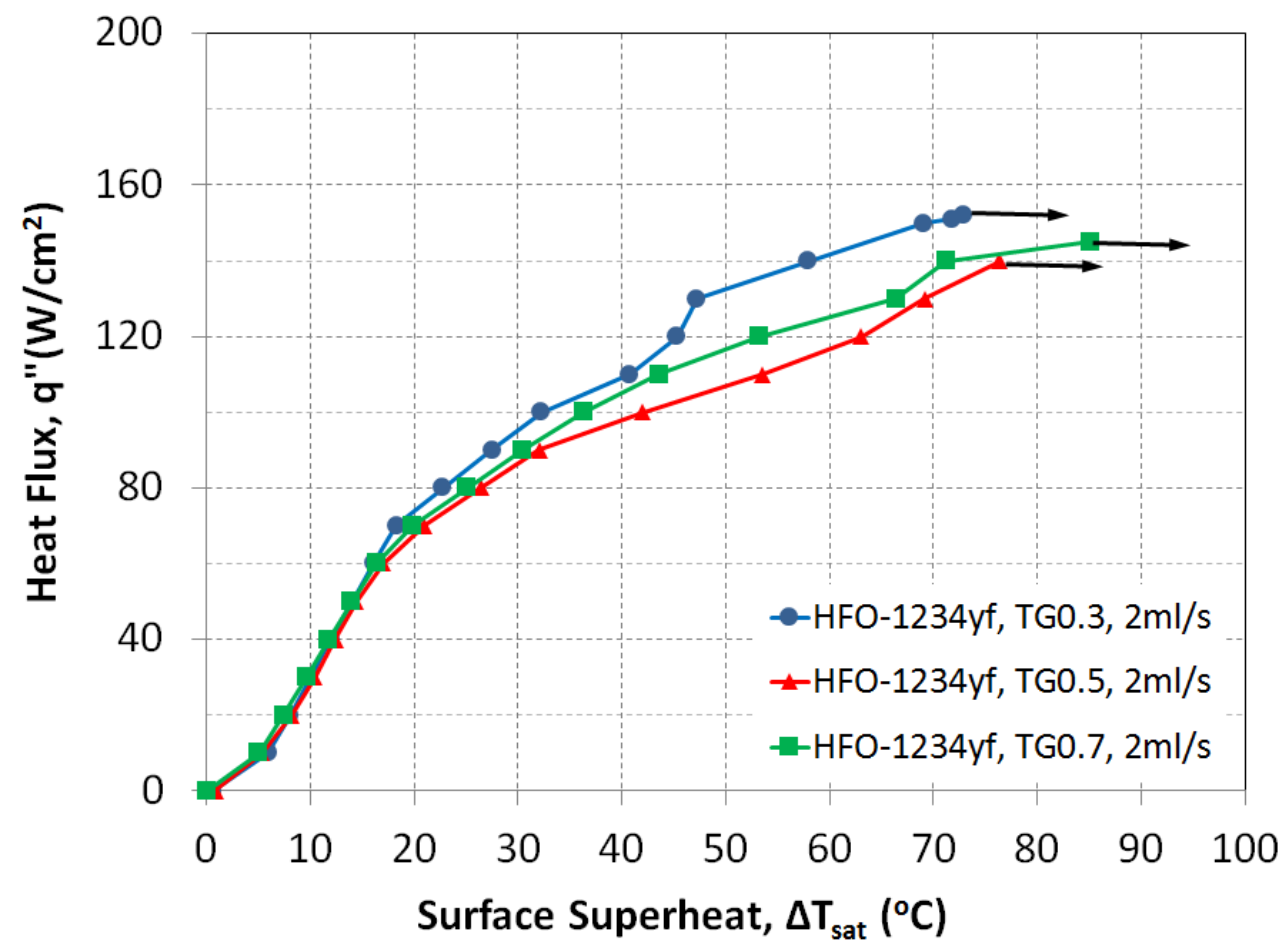

Figure 26: Heat transfer performance of HFO-1234yf for nozzle TG0.3, 0.5, and 0.7 at flow rate of $2 \mathrm{ml} / \mathrm{s}$.

A set experiments were conducted to evaluate the spray cooling performance of the three different nozzle at the flow rate of $3 \mathrm{ml} / \mathrm{s}$ was plotted with the related data in the Figure 27 . The CHF values that were obtained for the nozzle TG0.3 for the flow rate $3 \mathrm{ml} / \mathrm{s}$ was $160 \mathrm{~W} / \mathrm{cm}^{2}$ and with the surface temperature of $76.12^{\circ} \mathrm{C}$. The $\mathrm{CHF}$ values observed for the nozzle TG0.5 at the same flow rate was $160 \mathrm{~W} / \mathrm{cm}^{2}$ by maintaining the surface temperatures at $69.34^{\circ} \mathrm{C}$. The nozzle TG0.7 was also tested with the flow rate of $3 \mathrm{ml} / \mathrm{s}$ and the resulted CHF was $150 \mathrm{~W} / \mathrm{cm}^{2}$ and the 
surface temperatures observed was $63.92^{\circ} \mathrm{C}$. For the $3 \mathrm{ml} / \mathrm{s}$, the nozzle TG0.5 provided better results in the area of $\mathrm{CHF}$ and the low surface temperatures.

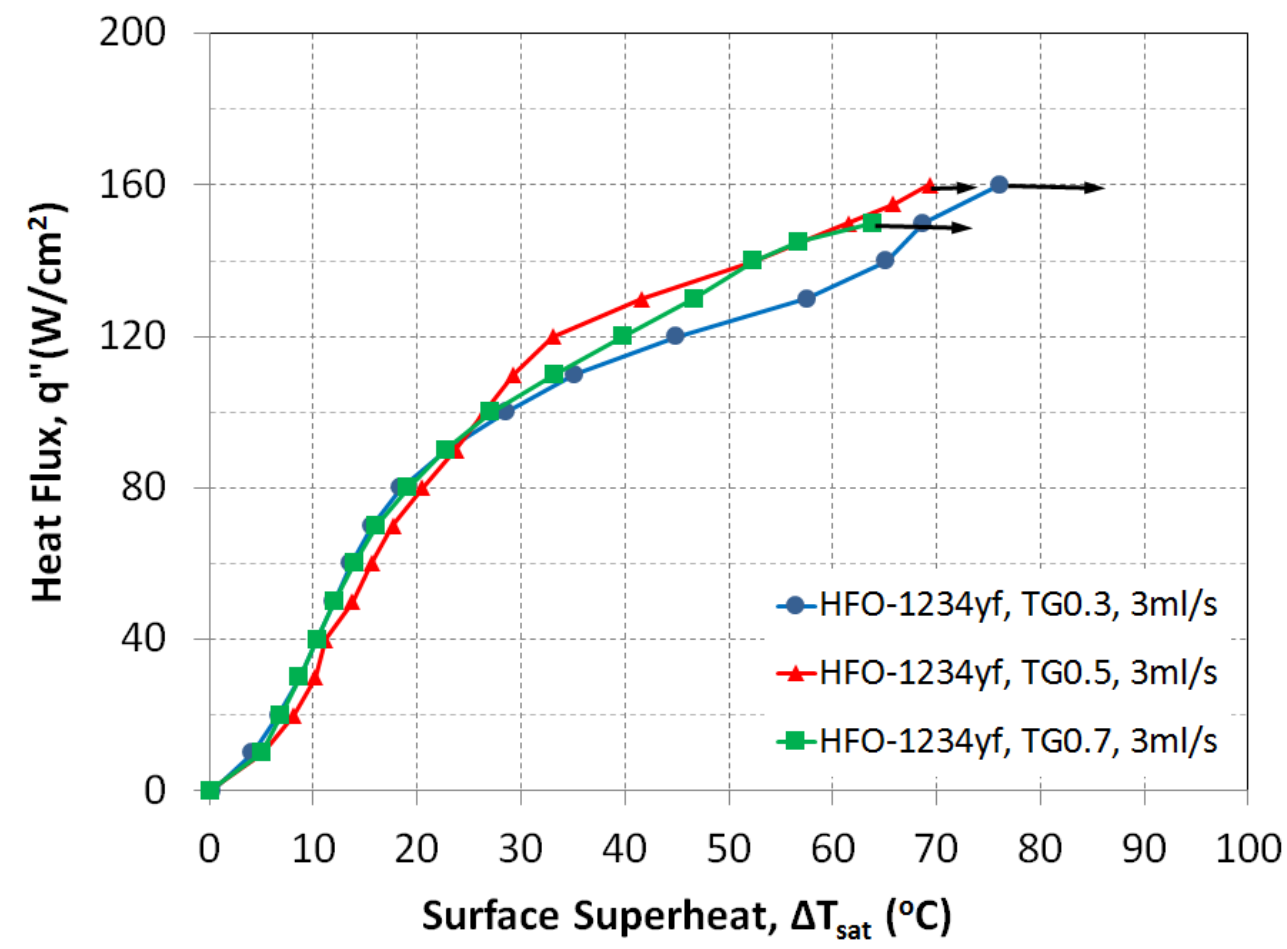

Figure 27: Heat transfer performance of HFO-1234yf for nozzle TG0.3, 0.5, and 0.7 at flow rate of $3 \mathrm{ml} / \mathrm{s}$.

The comparison for the flowrate of $4 \mathrm{ml} / \mathrm{s}$ between the nozzle TG0.5 and TG0.7 are plotted in the form of cooling curves in the Figure 28. The flow rate of $4 \mathrm{ml} / \mathrm{s}$ for the TG0.3 was eliminated because of the high pumping power and the smaller orifice of the nozzle cannot accommodate that much of the pressure difference. The nozzle TG0.5 for the flow rate of $4 \mathrm{ml} / \mathrm{s}$ produced the $\mathrm{CHF}$ value at $170 \mathrm{~W} / \mathrm{cm}^{2}$ with the surface temperature observed was $60.62^{\circ} \mathrm{C}$. For the same flow rate of $4 \mathrm{ml} / \mathrm{s}$, the nozzle TG0.7 with the bigger orifice showed the CHF value at $160 \mathrm{~W} / \mathrm{cm}^{2}$ with the resulting surface temperature at $61.32^{\circ} \mathrm{C}$. Though the $\mathrm{TG} 0.7$ has the bigger orifice it provided 
less CHF and surface temperature values than the TG0.5 nozzle and also provided better performance throughout the tests.

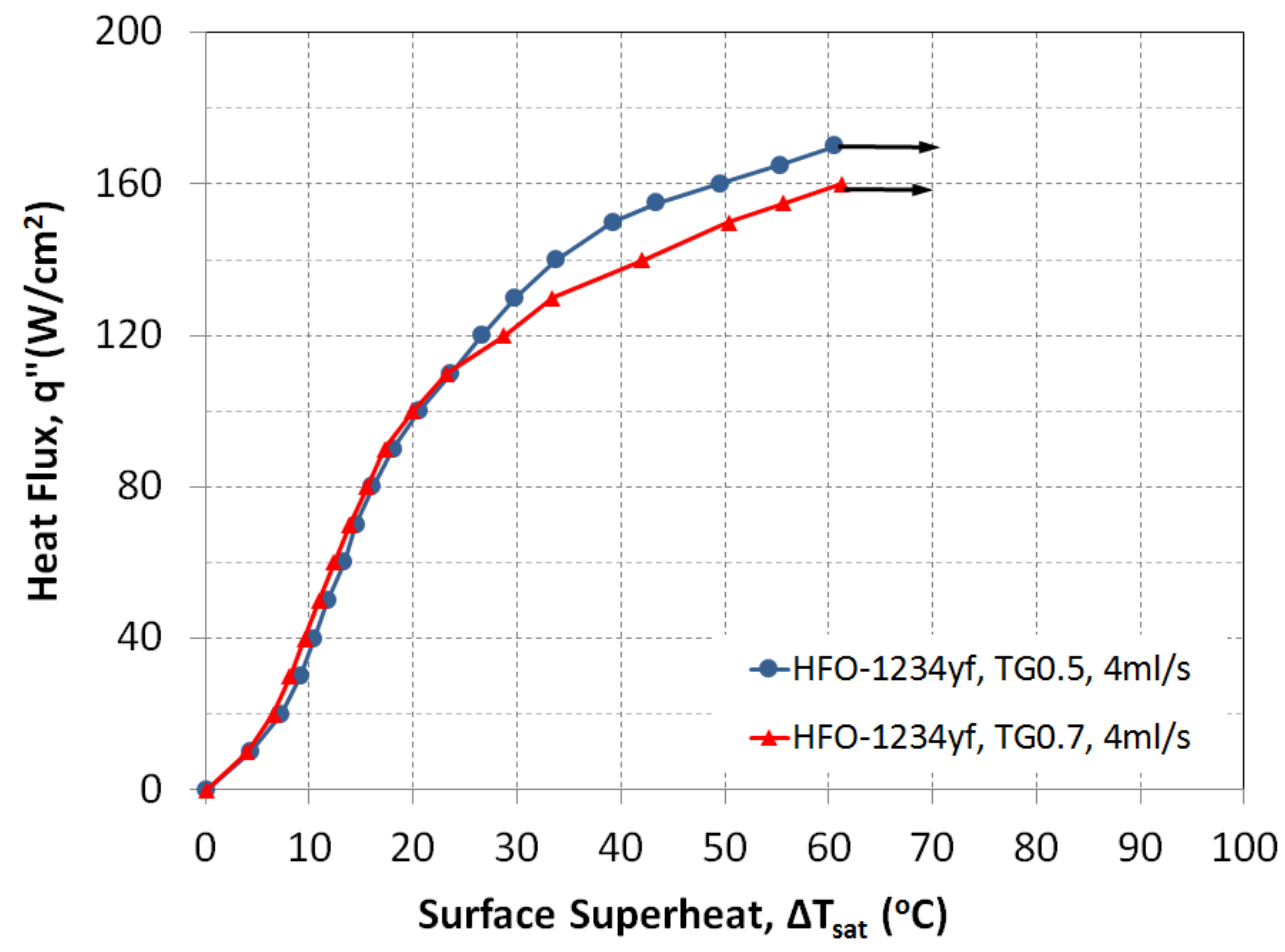

Figure 28: Heat transfer performance of HFO-1234yf for nozzle TG0.5 and 0.7 for flow rate of $4 \mathrm{ml} / \mathrm{s}$.

The heat transfer coefficient values for the HFO-1234yf for the flow rate $2,3 \mathrm{ml} / \mathrm{s}$ for the nozzle TG0.3 are plotted in the Figure 29. The maximum HTC value for the nozzle TG0.3 with flow rate of $2 \mathrm{ml} / \mathrm{s}$ was $38.2 \mathrm{Kw} / \mathrm{m}^{2}{ }^{\circ} \mathrm{C}$ at the heat flux value of $70 \mathrm{~W} / \mathrm{cm}^{2}$. The $\mathrm{HTC}$ values for the flow rate $3 \mathrm{ml} / \mathrm{s}$ for the same nozzle provided the maximum value of $44.6 \mathrm{Kw} / \mathrm{m}^{2}{ }^{0} \mathrm{C}$ at the heat flux value of $70 \mathrm{~W} / \mathrm{cm}^{2}$. From the comparison we can say that the nozzle TG0.3 with the flow rate of $3 \mathrm{ml} / \mathrm{s}$ provided the better HTC values for the refrigerant HFO-1234yf. At the CHF, the HTC value observed for the TG0.3 nozzle for the flow rate of $2 \mathrm{ml} / \mathrm{s}$ was $20.9 \mathrm{Kw} / \mathrm{m}^{2}{ }^{\circ} \mathrm{C}$ and for the flow rate of $3 \mathrm{ml} / \mathrm{s}$ for the same nozzle at CHF the HTC observed was $21 \mathrm{Kw} / \mathrm{m}^{20} \mathrm{C}$. 


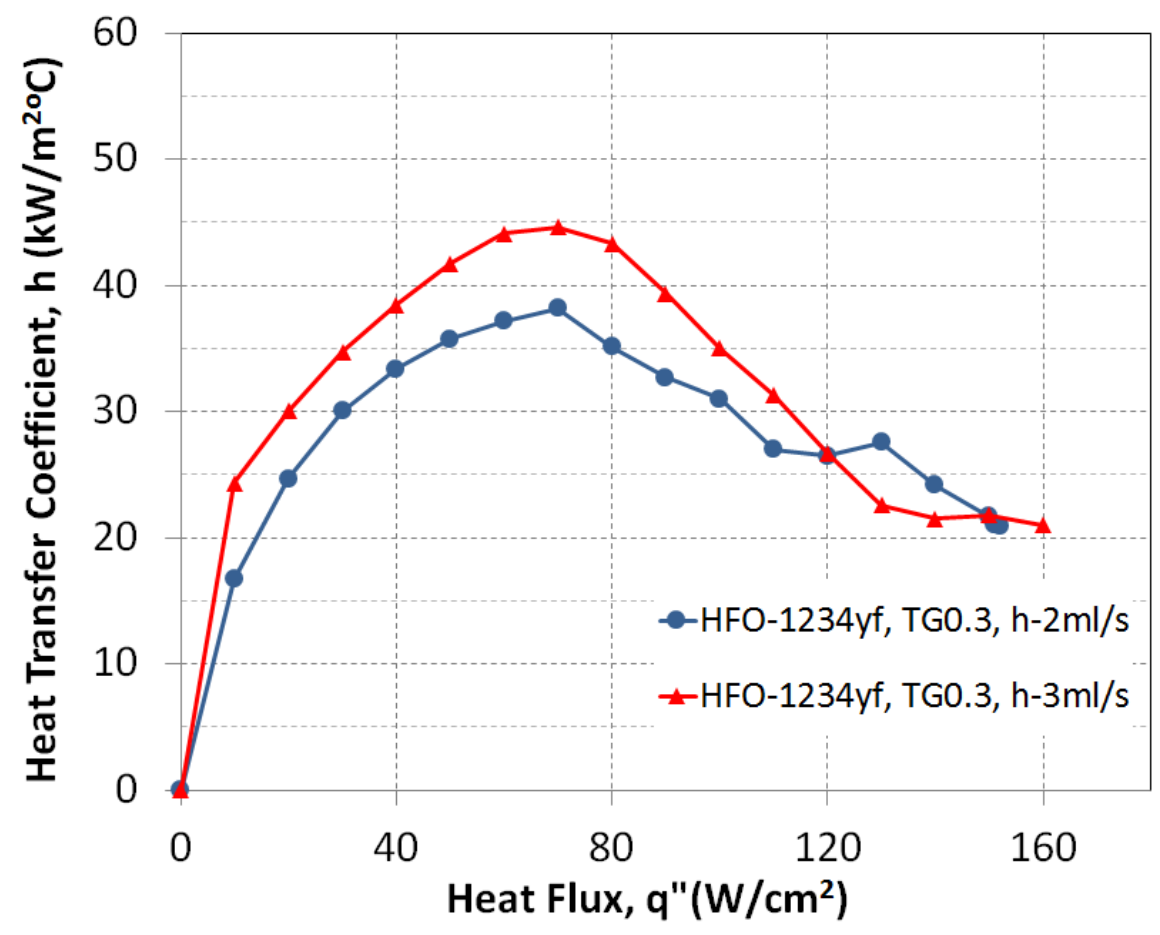

Figure 29: HTC of HFO-1234yf with nozzle TG0.3 at flow rates of 2, 3ml/s.

The nozzle TG0.5 was tested with four different flow rates such as $2,3,4,5 \mathrm{ml} / \mathrm{s}$ and the resulted data was plotted in the Figure 30. The maximum HTC value attained for the flow rate $2 \mathrm{ml} / \mathrm{s}$ for the nozzle TG0.5 was $35.2 \mathrm{Kw} / \mathrm{m}^{20} \mathrm{C}$ at the $\mathrm{CHF}$ of $60 \mathrm{~W} / \mathrm{cm}^{2}$. For the flow rate of $3 \mathrm{ml} / \mathrm{s}$ the same TG0.5 nozzle produced the maximum HTC of $39.6 \mathrm{Kw} / \mathrm{m}^{2}{ }^{\circ} \mathrm{C}$ at the $\mathrm{CHF}$ value of 70 $\mathrm{W} / \mathrm{cm}^{2}$. The maxim HTC observed for the flow rate of $4 \mathrm{ml} / \mathrm{s}$ was $49.8 \mathrm{Kw} / \mathrm{m}^{2}{ }^{\circ} \mathrm{C}$ at the $\mathrm{CHF}$ value of $90 \mathrm{~W} / \mathrm{cm}^{2}$. Again, an experiment with the higher flow rate of $5 \mathrm{ml} / \mathrm{s}$ for the TG0.5 nozzle attained the maximum $\mathrm{HTC}$ value of $59.23 \mathrm{Kw} / \mathrm{m}^{2}{ }^{\circ} \mathrm{C}$ at $80 \mathrm{~W} / \mathrm{cm}^{2}$. From the overall comparison, the nozzle TG0.5 performed well and the flow rate of $5 \mathrm{ml} / \mathrm{s}$ attained the highest value of HTC. 


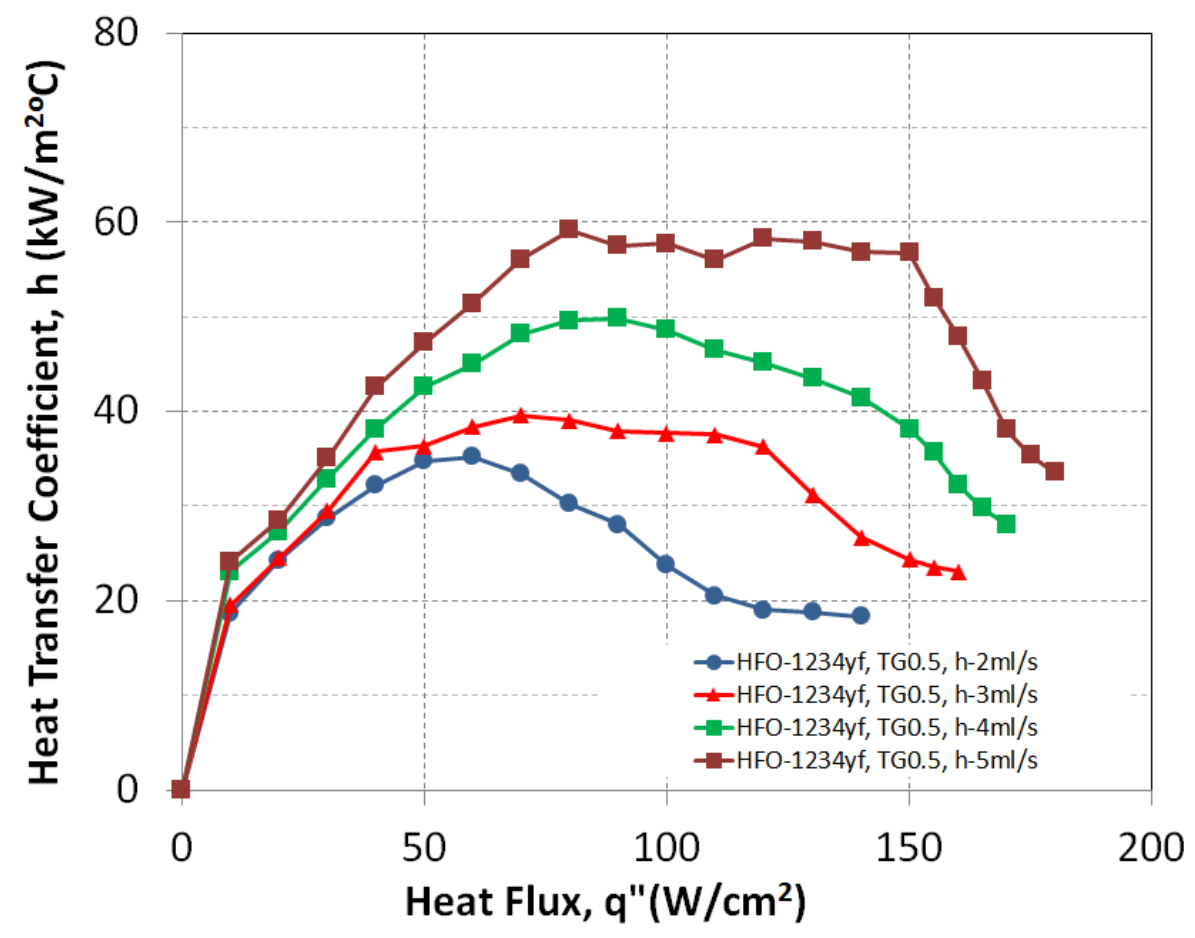

Figure 30: HTC of HFO-1234yf with nozzle TG0.5 at flow rates of 2, 3, and 4ml/s.

The nozzle TG0.7 also produces better HTC results when tested with different flow rates such as $2,3,4,5 \mathrm{ml} / \mathrm{s}$. The results were showed in the Figure 31 . The maximum HTC for the nozzle TG0.7 with flow rate $2 \mathrm{ml} / \mathrm{s}$ was observed at $60 \mathrm{~W} / \mathrm{cm}^{2}$ having $36.5 \mathrm{Kw} / \mathrm{m}^{2}{ }^{0} \mathrm{C}$. For the different flow rate of $3 \mathrm{ml} / \mathrm{s}$, the maximum value observed was $43.5 \mathrm{Kw} / \mathrm{m}^{2}{ }^{\circ} \mathrm{C}$ at the $\mathrm{CHF}$ value of 70 $\mathrm{W} / \mathrm{cm}^{2}$. By increasing the flow rate to $4 \mathrm{ml} / \mathrm{s}$ the resultant maximum value of HTC observed was $52.1 \mathrm{Kw} / \mathrm{m}^{2}{ }^{\circ} \mathrm{C}$ at $90 \mathrm{~W} / \mathrm{cm}^{2}$. When the nozzle was tested with the better flow rate of $5 \mathrm{ml} / \mathrm{s}$ the value of $\mathrm{HTC}$ maximum observed was $60.88 \mathrm{Kw} / \mathrm{m}^{2}{ }^{\circ} \mathrm{C}$ at the heat flux of $80 \mathrm{~W} / \mathrm{cm}^{2}$. From the detailed plot shown in the below Figure we can say that the greater the flow rate, the maximum was the HTC value can attained. For the nozzle TG0.7, the flow rate of $5 \mathrm{ml} / \mathrm{s}$ helped in attaining the greater HTC values and also increase in the CHF value. 


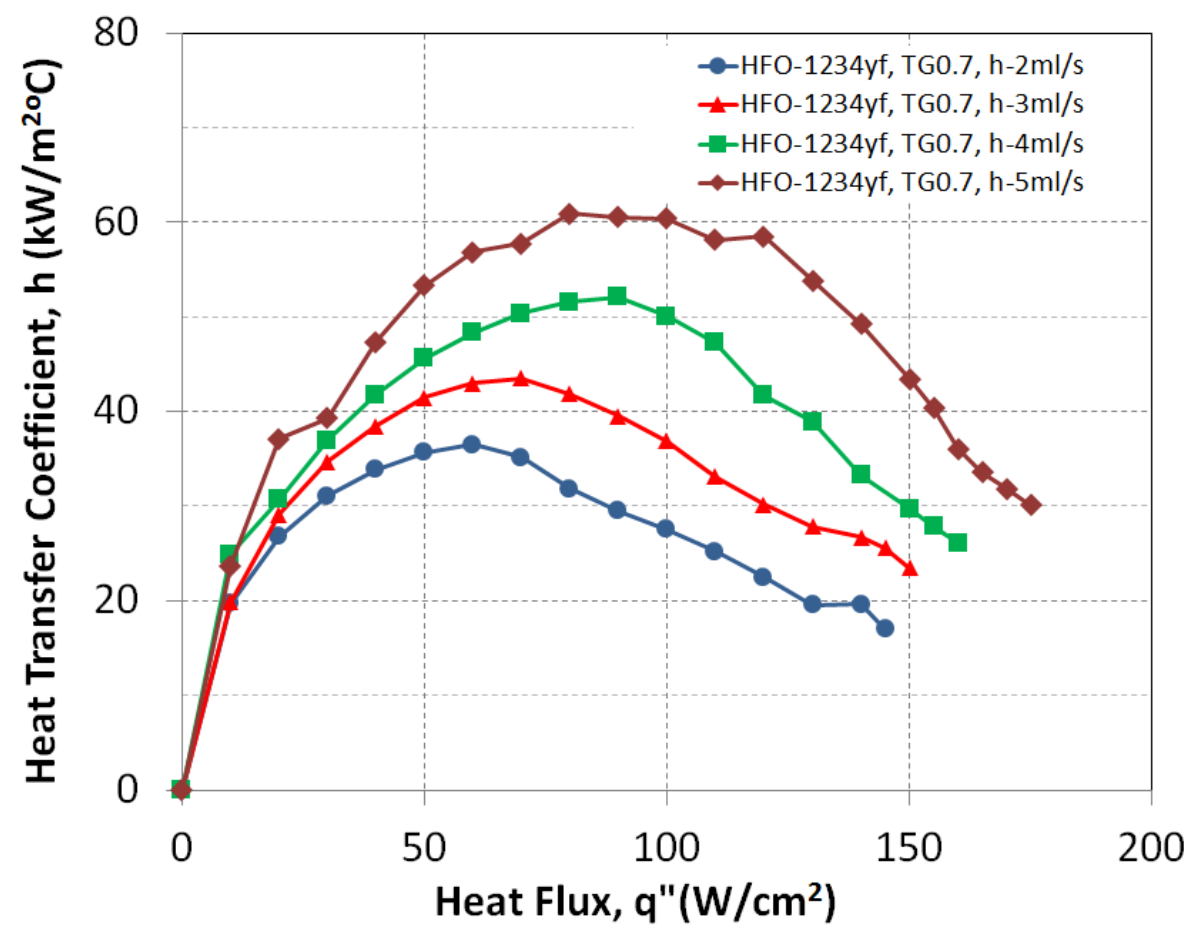

Figure 31: HTC of HFO-1234yf with nozzle TG0.7 at flow rates of 2, 3, and 4ml/s.

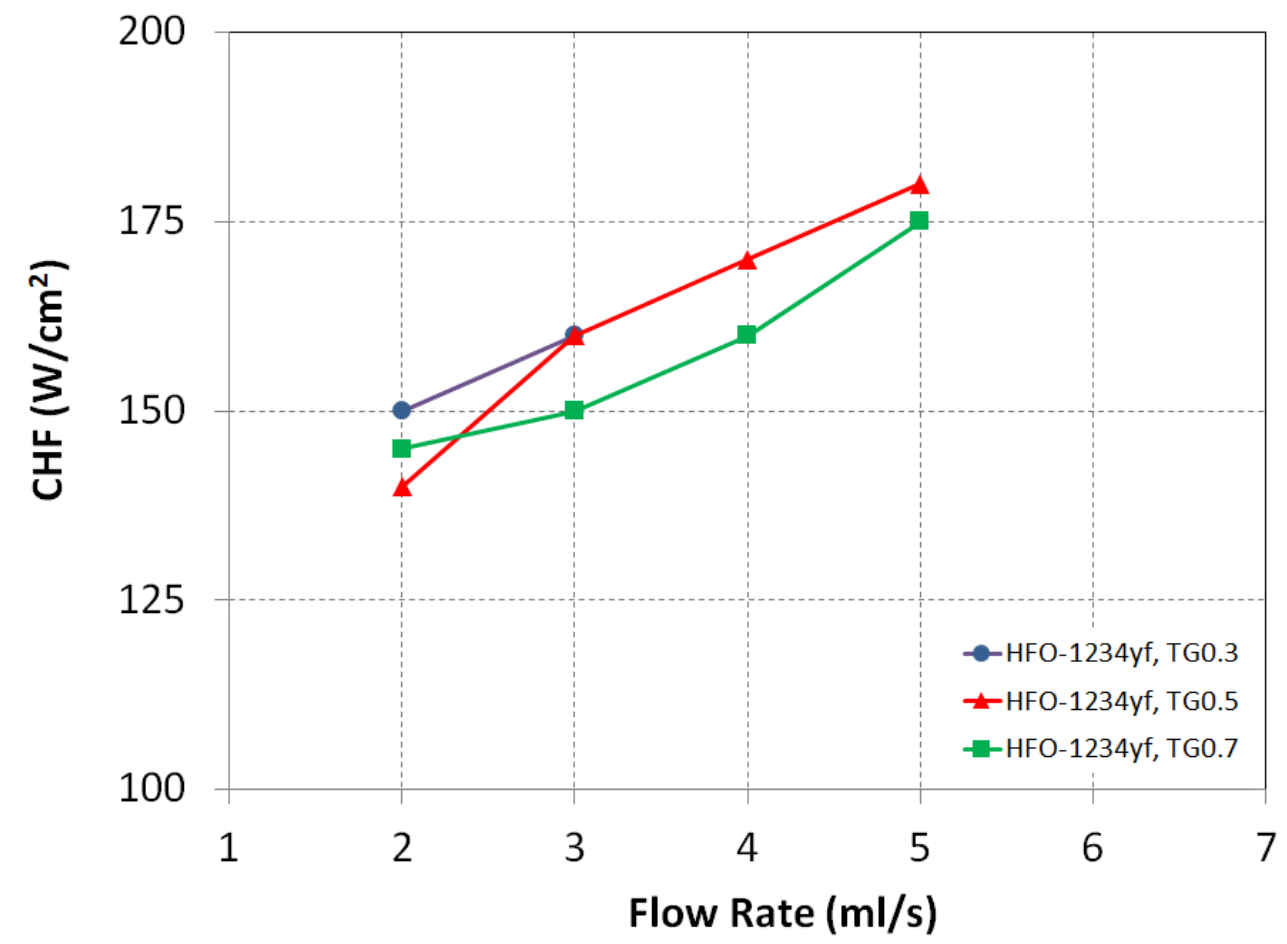

Figure 32: CHF values as a function of liquid flow rate of HFO-1234yf for nozzle type TG0.3, 0.5 and 0.7. 
HFO-1234yf refrigerant was tested with three different type of nozzles such as TG0.3, 05 and 0.7 with respect to the different flow rates such as $2,3,4,5 \mathrm{ml} / \mathrm{s}$ and the resulted CHF values are plotted as shown in the Figure 32. The values were plotted with the resultant CHF values as a function of flow rate.

\subsection{Comparison between the HFC-134 and HFO-1234yf}

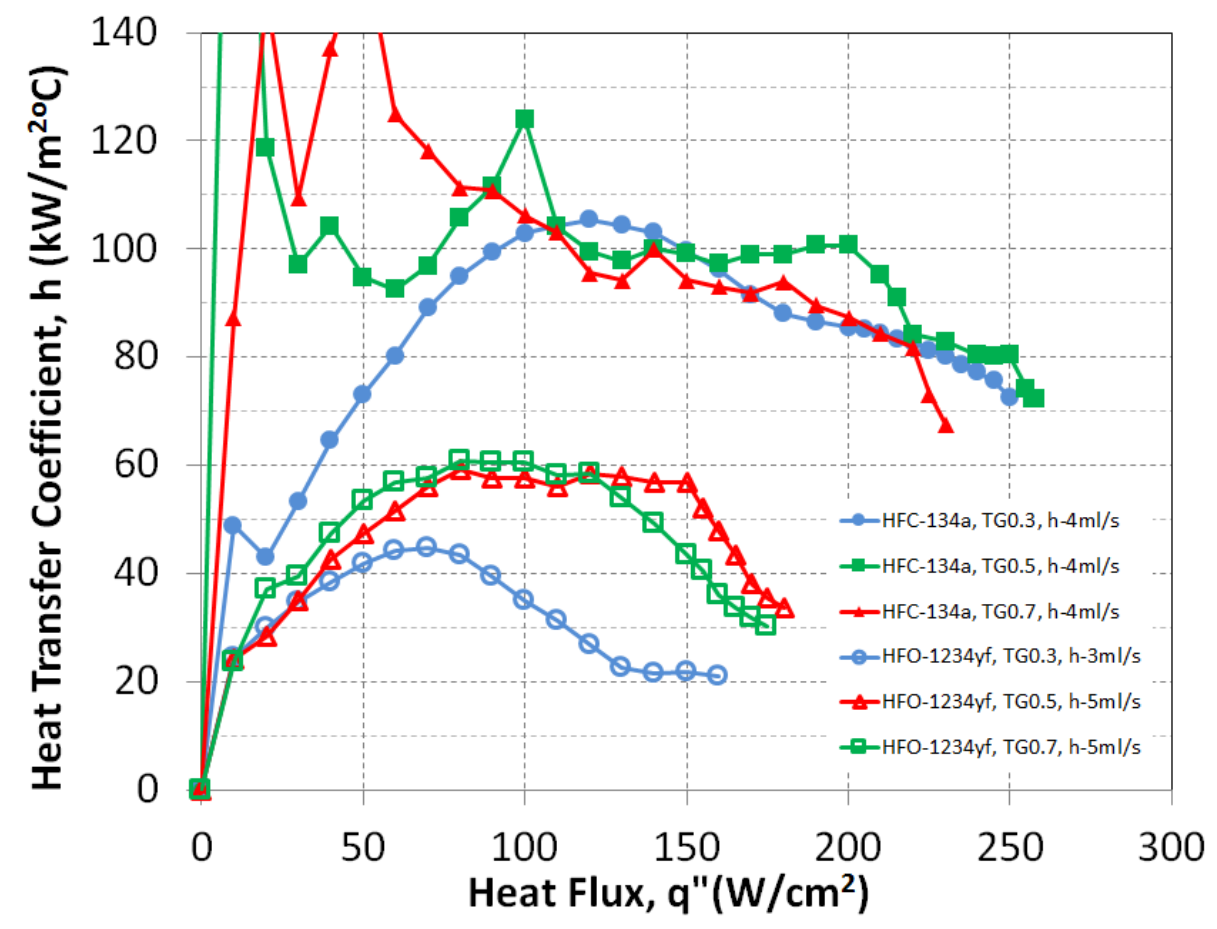

Figure 33: HTC of HFC-134a and HFO-1234yf with nozzles TG0.3, 0.5 , and 0.7 at flow rates of $3 \mathrm{ml} / \mathrm{s}$.

Figure 33, presents HTC values as a function of heat flux from both refrigerants considering the best performed test conditions for each nozzle type such as TG0.3, TG0.5, and 
TG0.7 at various flow rates such as $2,3,4,5 \mathrm{ml} / \mathrm{s}$. As a common trend, HTC values peak at midheat-flux range as two-phase heat transfer mechanisms become more pronounced, and then deteriorate at high-heat-flux range towards CHF. For R134a, $\mathrm{HTC}$ reaches $\sim 140 \mathrm{Kw} / \mathrm{m}^{2{ }^{\circ} \mathrm{C}}$ at 100 $\mathrm{W} / \mathrm{cm}^{2}$ heat flux. For HFO-1234yf, HTC values are much lower, with a maximum of $\sim 60,000$ $\mathrm{W} / \mathrm{m}^{2 \circ} \mathrm{C}$ at $80 \mathrm{~W} / \mathrm{cm}^{2}$ heat-flux.

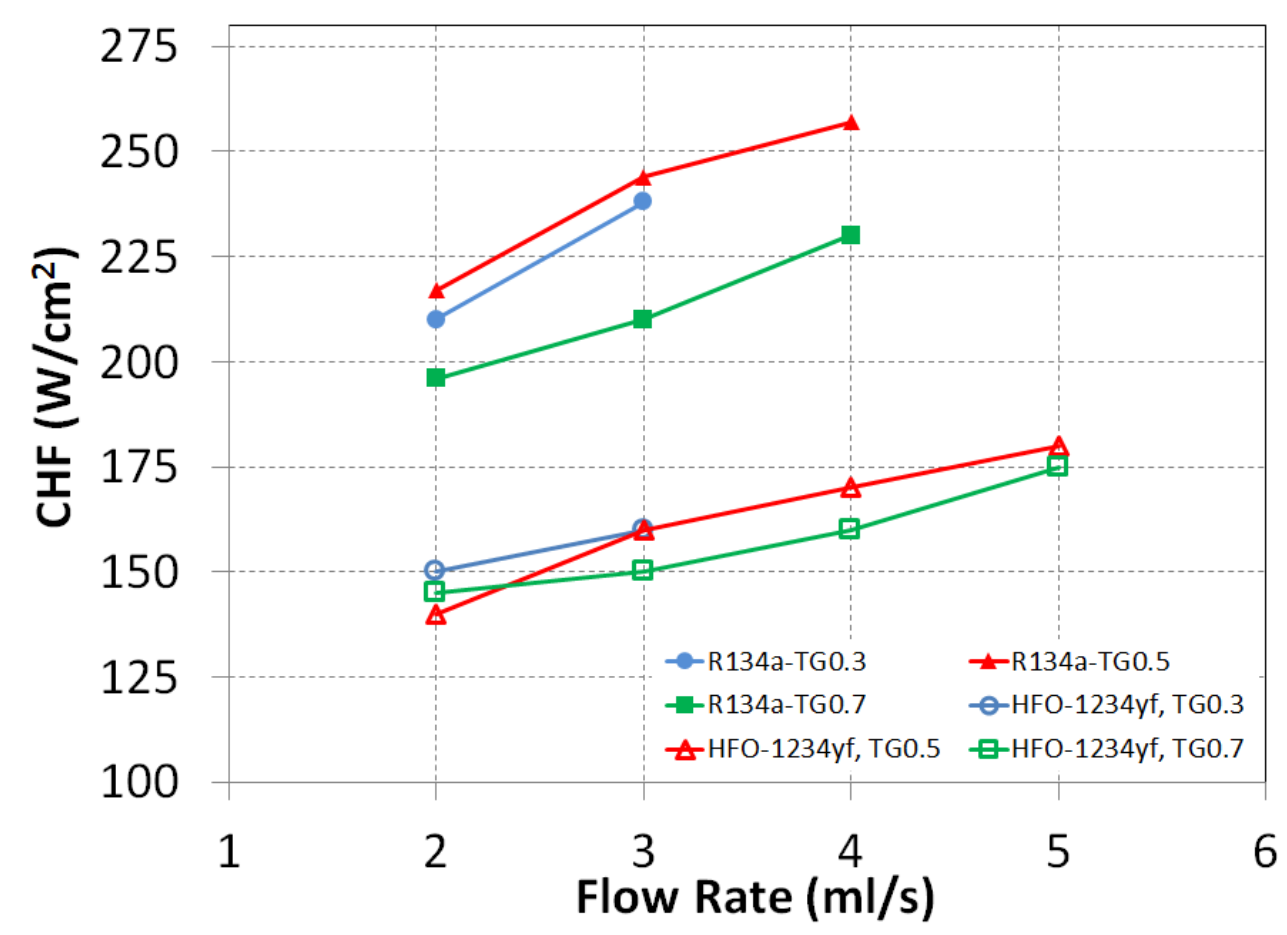

Figure 34: CHF value as a function of liquid flow rate for nozzle types of TG0.3, 0.5 , and 0.7 for HFC-134a and HFO-1234yf.

Effect of flow rate on CHF levels, for all three nozzle types, is summarized in Figure 34. The data clearly indicate that higher flow rate helps obtaining a higher CHF value, and TG0.3 and TG0.5 nozzles perform comparably throughout. Such CHF improvement (up to $18 \%$ for TG0.5) comes at the expense of higher pumping power. 
We also look into the efficiency of the spray cooling process by considering different parameters. The efficiency of the spray heat transfer is defined as the ratio of the heat transferred by the spray from the surface to the total heat that could be potentially carried by the liquid at the given flow rate and the subcooling level if the liquid fully evaporates. The experimental spray heat transfer efficiency $(\eta)$ is calculated using the following equation [43].

$$
\eta=\frac{\mathrm{q}_{\mathrm{CHF}}^{\prime \prime} A}{Q \rho_{\mathrm{f}}\left(\mathrm{C}_{\mathrm{p}} \Delta \mathrm{T}_{\text {sub }}+\mathrm{h}_{\mathrm{fg}}\right)}
$$

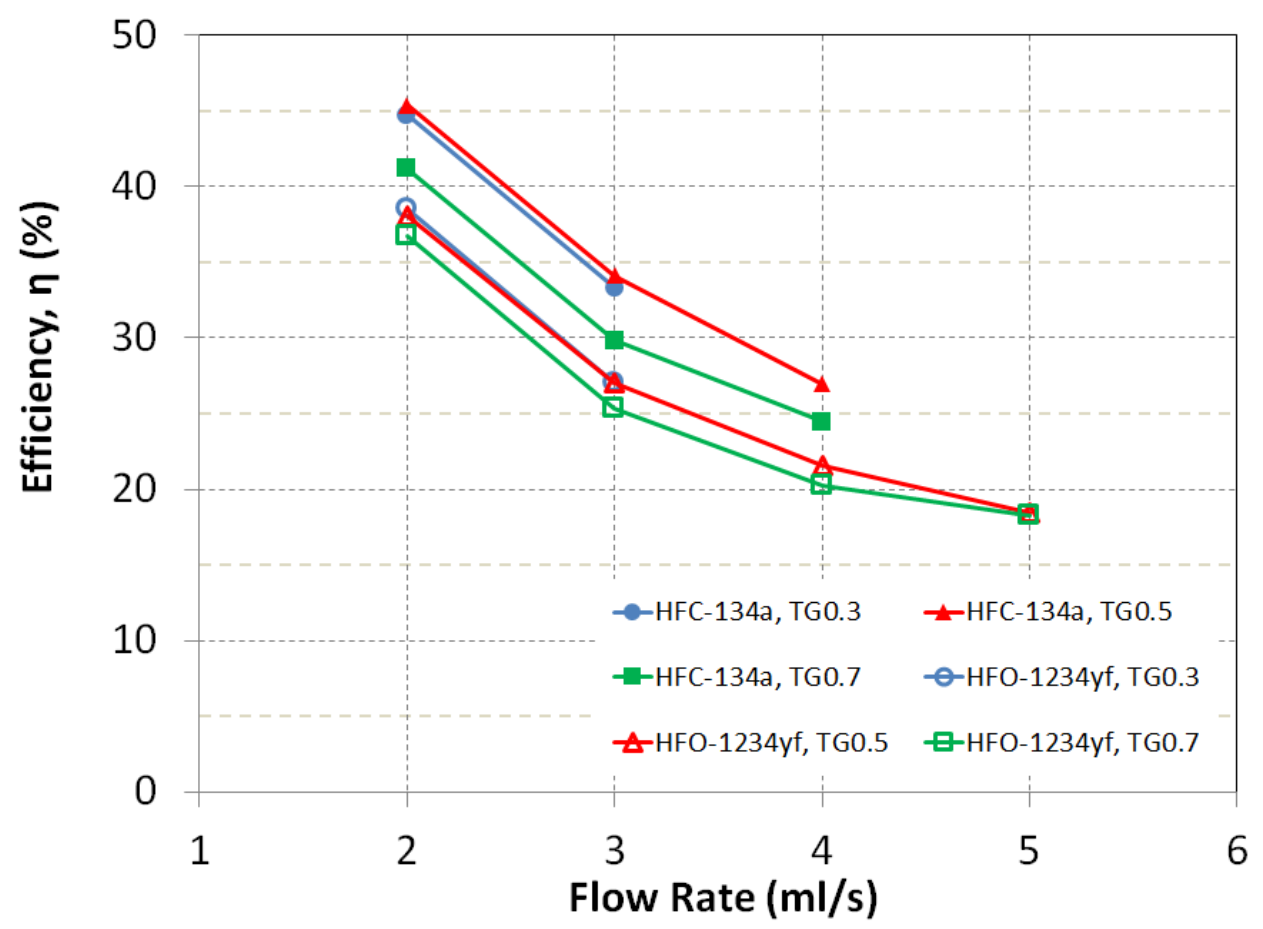

Figure 35: Efficiency of spray heat transfer for HFC-134a and HFO-1234yf.

For HFC-134a, the efficiency ranges from $44.74 \%$ to $24.45 \%$ for different nozzle types and at different flow rates. Whereas HFO-1234yf efficiency ranges from $38.53 \%$ to $18.25 \%$. Figure 35 , 
provides the data of efficiencies for both HFC-134a and HFO-1234yf for the given flow rate and nozzle type. It is evident that the efficiency of the HFO-1234yf is comparatively low when compared to HFC-134a and this is mainly because of the less heat removal capacity. 


\section{CHAPTER V \\ Conclusion and Recommendations}

\subsection{Concluding Remarks}

This study investigated the spray cooling characteristics of R-134a and HFO-1234yf refrigerants and provided experimental data on their initial performance comparison. Three types of pressure-atomized spray nozzles (TG0.3, TG0.5, TG0.7) were used at varying liquid flow rates $(2,3,4 \mathrm{cc} / \mathrm{s})$, and a plain, smooth spray surface represented as a reference case. Based on the results, the following main conclusions can be drawn:

- Within the considered flow rate range, higher flow rates resulted in higher HTC and $\mathrm{CHF}$ values.

- TG0.5 nozzle, with a medium orifice size $(0.61 \mathrm{~mm})$ performed the best.

- HFC-134a consistently provided better spray cooling performance compared to HFO-1234yf. HTC values were as high as $\sim 100,000$ and $\sim 68,000 \mathrm{~W} / \mathrm{m}^{2 \circ} \mathrm{C}$ for HFC134a and HFO-1234yf, respectively. CHF values were up to 255 and $175 \mathrm{~W} / \mathrm{cm}^{2}$ for HFC-134a and HFO-1234yf, respectively. This significant difference in heat transfer performance is believed to be mainly driven by the thermophysical properties that affect both the spray characteristics and heat acquisition ability. 


\subsection{Recommendations for Future Research}

The following topics can be recommended as future research directions that will compliment and expand the current study:

- Evaluation of the spray cooling performance of HFC-134a and HFO-1234yf at elevated saturation temperatures that would simulate realistic hot environment conditions.

- Utilizing available correlations to determine the critical spray parameters and CHF levels, and developing modified correlations to better predict performance of spray cooling with HFC and HFO type refrigerants.

- Investigation of spray cooling performance of HFC-134a and HFO-1234yf with the enhanced micro-scale heat transfer surfaces to improve HTC and CHF. 


\section{REFERENCES}

[1] Desikan. B., Hassani. V.; "Spray cooling: An assessment for use with automotive power electronics applications", National Renewable Energy laboratory, prepared for power electronic task FY05-7000.

[2] Toda, S., "A study of mist cooling, 1st report: investigation of mist cooling", Heat Transfer, Japanese Research, Vol. 1, pp. 39-50, 1972.

[3] Monde, M., "Critical heat flux in saturated forced convection boiling with an impinging droplet", Trans. JSME, Vol. 46, pp. 1146-1155, 1980.

[4] Mudawar, I., Valentine, W.S., "Determination of the local quench curve for spray cooled metallic surfaces", J. Heat Treating, Vol. 7, pp. 107-121, 1989.

[5] Pautsch, A.G., "Heat transfer and film thickness characteristics of spray cooling with phase change", Master's Thesis, Dept. of Mechanical Engineering, University of Wisconsin-Madison, 2004.

[6] Mudawar, I. and Estes, K.A., "Optimizing and predicting CHF in spray Cooling of a square Surface", J. Heat Transfer, Vol. 118, no. 3, pp. 672-679, 1996.

[7] Chen, R-H., Chow, L.C., Navedo, J.E., "Effects of spray characteristics on critical heat flux in subcooled water spray cooling”, Int. J. Heat and Mass Transfer, Vol. 45, pp. 4033-4043, 2002.

[8] Toda, S., "A study of mist cooling, 1st report: investigation of mist cooling", Heat Transfer, Japanese Research, Vol. 1, pp. 39-50, 1972. 
[9] Pais, M.R., Chow, L.C., Mahefkey, E.T., "Surface roughness and its effect on the heat transfer mechanism in spray cooling", J. Heat Transfer, Vol. 114, pp. 211-219, 1992.

[10] Sehmbey, M. S., Chow, L. C., Hahn, O. J., M. R. Pais, "Spray cooling of power electronics at cryogenic temperatures", AIAA Journal of Thermophysics Heat Transfer, Vol. 9, pp. 123-128, 1995.

[11] Bostanci, H., "High heat flux spray cooling with ammonia on enhanced surfaces", PhD Thesis, Dept. of Mechanical Engineering, University of Central Florida, 2010.

[12] Peterson, C.O., "An experimental study of the dynamic behavior and heat transfer characteristic of water impinging upon a heated surface", Int. J. Heat Mass Transfer, Vol. 13, pp. 369-381, 1970.

[13] Bonacina, C., Del Giudice, S., Comini, G., "Dropwise evaporation”, ASME Journal of Heat Transfer, Vol. 101, pp. 441-446, 1979.

[14] Bonacina, C., Comini, G., Del Giudice, S., "Evaporation of atomized liquids on hot surfaces", Letters in Heat and Mass Transfer, Vol. 2(5), pp. 401-406, 1975.

[15] Kim, Y.C., Nishio, S., Ohkubo, H., "Heat transfer in a high temperature region of spray cooling interacting with liquid film flow", Heat Transfer, Japanese Research, Vol. 26 (4), 1997.

[16] Yang, J., Chow, L.C., Pais, M.R., "Nucleate boiling heat transfer in spray cooling”, J. Heat Transfer, Vol. 118 , pp. 668-671, 1996.

[17] Mudawar, I. and Estes, K.A., "Optimizing and predicting CHF in spray Cooling of a square Surface", J. Heat Transfer, Vol. 118, no. 3, pp. 672-679, 1996. 
[18] Pautsch, A.G., Shedd, T.A., "Adiabatic and diabatic measurements of the liquid film thickness during spray cooling with FC-72", Int. J. Heat Mass Transfer, Vol. 49, pp. 2610-2618, 2006.

[19] Pais, M.R., Chow, L.C., Mahefkey, E.T., "Surface roughness and its effect on the heat transfer mechanism in spray cooling", J. Heat Transfer, Vol. 114, pp. 211-219, 1992.

[20] Kim, J., "Spray cooling heat transfer: the state of the art", Int. J. Heat and Fluid Flow, Volume 28(4), pp. 753-767, 2007.

[21] Pautsch, A.G., Shedd, T.A., "Adiabatic and diabatic measurements of the liquid film thickness during spray cooling with FC-72", Int. J. Heat Mass Transfer, Vol. 49, pp. 2610-2618, 2006.

[22] Pautsch, A.G., Shedd, T.A., "Spray impingement cooling with single- and multiple nozzle arrays, Part I: Heat transfer data using FC-72", Int. J. Heat Mass Transfer, Vol. 48, 3167-3175, 2005.

[23] Kalantari, D., "Characterization of liquid spray impact onto walls and films", PhD Thesis, Technischen Universitat Darmstadt, Darmstadt, Germany, 2007.

[24] Yang, J., Chow, L.C., Pais, M.R., "Nucleate boiling heat transfer in spray cooling", J. Heat Transfer, Vol. 118 , pp. 668-671, 1996.

[25] Rini, D.P., Chen, R.H., Chow, L.C., "Bubble behavior and nucleate boiling heat transfer in saturated FC-72 spray cooling", J. Heat Transfer, Vol. 124, pp. 63-72, 2002.

[26] Oliphant, K., Webb, B.W., McQuay, M.Q., "An experimental comparison of liquid jet array and spray impingement cooling in the non-boiling regime", Experimental Thermal and Fluid Science, Vol. 18, pp. 1-10, 1998. 
[27] Rybicki, J. R., Mudawar, I., "Single-phase and two-phase cooling characteristics of upwardfacing and downward-facing sprays", Int. J. Heat Mass Transfer, Vol. 49, pp. 5-16, 2006.

[28] Karwa, N., Kale, S.R., Subbarao, P.M.V., "Experimental study of non-boiling heat transfer from a horizontal surface by water sprays", Experimental Thermal and Fluid Science, Vol. 32, pp. 571-579, 2007.

[29] Lin, L., Ponnappan, R., “Heat transfer characteristics of spray cooling in a closed loop”, Int. J. Heat Mass Transfer, Vol. 46, pp. 3737-3746, 2003.

[30] Cheng, W., Liu, Q., Zhao, R., Fan, H., “Experimental investigation of parameters effect on heat transfer of spray cooling", Journal of Heat Mass Transfer, Vol. 46, pp. 911-921, 2010.

[31] Hsieh, S-S., Fan, T-C., Tsai, H-H., "Spray cooling characteristics of water and R-134a., Part I, nucleate boiling", Int. J. Heat Mass Transfer, Vol. 47, pp. 5703-5712, 2004.

[32] Campbell, J.B., Tolbert, L.M., Ayers, C.W., Ozpineci, B., Lowe, K.T., "Two-phase Cooling Method using the R134a refrigerant to cool Power Electronic Devices," IEEE Transaction on Components and Packaging Technologies, vol.43 (3), pp. 648-656, 2007.

[33] Ayers, C. W, Hsu. J. S. "Fundamentals of Floating Loop Concept Based on R134a Refrigerant Cooling of High Heat Flux Electronics," Oakridge National Laboratory, 22nd IEEE Semi-Thermal Symposium, 2006.

[34] Mudawar. I., Desikan B., Kenneth K., and Sreekanth N., "Two Phase Spray Cooling of Hybrid Vehicle Electronics." IEEE Transactions and Packaging Technologies, vol 32, No 2, pp.501-511, 2009. 
[35] Mudawar, I. and Estes, K.A., "Optimizing and predicting CHF in spray Cooling of a square Surface", J. Heat Transfer, Vol. 118, no. 3, pp. 672-679, 1996.

[36] Bostanci H., David van Ee, Benjamin a. Saarloos, Daniel P. Rini, and Louis C. Chow. "Thermal Management of Power Inverter Modules at High Fluxes via Two Phase Spray Cooling," IEEE Transactions, Packaging and Manufacturing Technology, vol.2, no.9, pp.2156-3950, 2012.

[37] Augusto G. U., Jader R.B., "Experimental Evaluation of Spray Cooling of R134a on Plain and Enhanced Surfaces," International Journal of Refrigeration 36, pp.527-533, 2013.

[38] Ayers, C. W, Hsu. J. S. "Fundamentals of Floating Loop Concept Based on R134a Refrigerant Cooling of High Heat Flux Electronics," Oakridge National Laboratory, 22nd IEEE Semi-Thermal Symposium, 2006.

[39] Augusto G. U., Jader R.B., "Experimental Evaluation of Spray Cooling of R134a on Plain and Enhanced Surfaces," International Journal of Refrigeration, Vol. 36, pp. 527-533, 2013.

[40] R. H Chen. L.C. Chow and J. E. Navedo, " Effects of spray characteristics on Critical Heat Flux in subcooled water spray Cooling", Int. J. Heat Mass Transfer, Vol.38, PP. 1201 - 1216, 1995.

[41] Moreno G., Narumanchi S., and King C., "Pool Boiling Heat Transfer Characteristics of HFO1234yf on Plain and Microporous-Enhanced Surfaces," ASME Journal of Heat Transfer, vol. 135 (11), pp. 111014- 1 to $111014-10,2013$.

[42] Del Col D., Torresin D., and Cavallini A., "Heat transfer and pressure drop during condensation of the low GWP Refrigerant R1234yf," International Journal of Refrigeration, vol. 33, pp. 1307-1318, 2010. 
[43] Suraj J. T., Sreekant N., Yang R., "Effect of flow rate and subcooling on spray heat transfer on microporous copper surfaces", Int. J. Heat Mass Transfer, Vol 69, pp. 493 - 505, 2014. 